\title{
The Untold Story of Commodity Futures in China
}

\author{
John Hua FAN* and Tingxi ZHANG \\ Department of Accounting, Finance and Economics, Griffith Business School \\ Griffith University
}

December 2019

Journal of Futures Markets, forthcoming

DOI: $10.1002 /$ fut.22087

\begin{abstract}
We investigate the behavior of commodity futures risk premia in China. In the presence of retail-dominance and barriers-to-entry, the term structure and momentum premia remain persistent, whereas hedging pressure, skewness, volatility and liquidity premia are distorted by time-varying margins and strict position limits. Furthermore, open interest, currency and inflation premia are sensitive to institutional settings. The observed premia cannot be attributed to common risks, sentiment, transactions costs or data-snooping, but are related to liquidity, anchoring, and regulation-induced limits-to-arbitrage. We highlight the distinctive features of Chinese futures markets and assess the challenges posed to theories of commodity risk premia.
\end{abstract}

JEL Classification: G13, G14, G15, G41, N25, Q02

Keywords: China; Commodity futures; Position limits; Margins; Price discovery; Momentum; Term structure; Hedging pressure; Liquidity; Diversification

\footnotetext{
*Corresponding author. Address: Department of Accounting, Finance and Economics, Griffith Business School, Griffith University, Nathan Campus, 170 Kessels Road, Nathan, Queensland 4111, Australia. Tel: +61 (0)7 3735 3948; E-mail: j.fan@ griffith.edu.au.

A previous version of this paper was circulated under the title "Demystifying Commodity Futures in China". An Internet Appendix with supplementary results may be found in the online version of this article. We thank Robert Webb (editor), an anonymous referee, as well as Carol Alexander, Aysegul Ates, Dirk Bauer (ACMC discussant), Robert Bianchi, Hui Bu, Etienne Borocco, David Broadstock, Stephen Brown, Jaime Casassus (CEMA discussant), Michael Drew, Adrian Fernandez-Perez, Ana-Maria Fuertes, Ying Jiang, Andrew Kaleel, Matthew Kaleel, Tom Kelly, Bin Li, Jingyu Li (ICFOD discussant), Xiaoquan Liu, Joelle Miffre, Di Mo, Beyza Mina OrduAkkaya, Scott Pappas, Marcel Prokopczuk, Xiao Qiao (JPMCC discussant), Geert Rouwenhorst, Marta Szymanowska, Ke Tang, Hilary Till, Neda Todorova, Stefan Trueck, Ron Ripple, Eduardo Roca, Marcel Rothenberger (GAIC discussant), Adam Walk, Yaw-Huei Jeffrey Wang and Jian Yang for insightful comments and discussions which greatly improved the paper. We also wish to thank seminar and conference participants at Macquarie Bank, CFA Society of Sydney, Griffith University, Fudan University, Australasian Commodity Markets Conference (ACMC, Sydney), Commodity and Energy Markets Annual Conference (CEMA, Rome), International Conference on Futures and Other Derivatives (ICFOD, Shanghai), Griffith Alternative Investments Conference (GAIC, Brisbane), $3^{\text {rd }}$ JP Morgan Centre for Commodities International Symposium (JPMCC, Denver) for their helpful comments. Financial support from the Griffith Centre for Personal Finance and Superannuation (GCPFS) is gratefully acknowledged. All remaining errors are our own.
} 


\section{Introduction}

This paper investigates the behavior of passive long and systematic risk premia in China. Taking a deep dive into the institutional settings in comparison to the US, we document the impact of unique market characteristics on empirical design and results. Our findings contribute to the literature in several ways. First, we conduct a true out-of-sample test of existing theories in a unique environment. These findings inform the pricing of commodities in the presence of retail dominance, time-varying margin and strict position limits. Second, investors seeking new ways to improve their portfolios have embraced the idea of factor investing globally. ${ }^{1}$ In light of the ongoing internationalization process of commodity markets in China, our findings on systematic risk premia in an emerging futures market are of immediate interests to liquid alternatives, such as hedge funds and commodity trading advisors who seek for diversification opportunities. Last but not the least, we discuss policy implications for the efficient functioning of commodity markets.

Since the beginning of the millennium, commodity futures markets in China have undergone tremendous developments. The trading volume soared from a mere 3 trillion to 227 trillion RMB over the period 2001-2010 (China Futures Association, 2015). ${ }^{2}$ As of 2018, six of the world's top ten most active commodity contracts were traded in China. Furthermore, China accounted for $56 \%$ of global demand for nickel, $50 \%$ for coal, copper and steel, and $47 \%$ for aluminum and pork in 2017 (VisualCapitalist, 2018). To fulfill the economic transition, demand for commodities is expected to grow even further (FT, 2017). Along with the colossal demand, surging investor interests and the ongoing liberalization, the once extraneous market

\footnotetext{
${ }^{1}$ BlackRock (2018) notes the factor industry is \$1.9 trillion in Assets Under Management (AUM) and has grown organically at around $11 \%$ per year since 2011. In a survey of the world's 500 largest asset managers, $5.5 \%$ of the AUM of the firms surveyed was invested in factor-based strategies in 2016 (Willis Towers Watson, 2017). Similarly, Invesco (2017) estimated a 50\% growth in proportion of AUM allocated to factor investing by 2022. ${ }^{2}$ A similar trend is observed in the growth of open interests. However, while China dominates the trading volume comparison, the year-end open interests are consistently larger in the US. Based on our selected sample estimates, the dollar or RMB open interest is roughly 3.5 times larger in the US.
} 
in the global commodities trade has become a significant force in determining the international commodity prices (WSJ, 2016; Bloomberg, 2018b). However, the Chinese commodity futures market remains enigmatic to practitioners and academics alike due to the barriers-to-entry, state influences and unique trading rules.

One of the most striking characteristics the literature has become accustomed to, is the large presence of retail investors. By the end of 2016, more than $86 \%$ of the open interest was held by individual accounts (China Futures Association, 2016), compared to less than $15 \%$ in the US (Bhardwaj, Gorton, \& Rouwenhorst, 2016). Strikingly, the average holding period of a futures contract in China is less than four hours (Citi, 2016). Individuals are known to be less informed (Griffin, Harris, \& Topaloglu, 2003), and their trades are more correlated with volumes (Grinblatt \& Keloharju, 2000). Furthermore, retail-dominance also induces a higher degree of positive feedback trading (De Long, Shleifer, Summers, \& Waldmann, 1990) and herding (Li, Rhee, \& Wang, 2017). Therefore, combined with the lack of strong legal framework (Allen, Qian, \& Qian, 2006), a low level of investment risk perception and skills (Wang, Shi, \& Fan, 2006), and evidence of disposition, overconfidence and representativeness (Chen, Kim, Nofsinger, \& Rui, 2007), the Chinese commodity market is likely highly speculative. The predominant level of sophistication is crucial for the dynamics of risk premia (Campbell, Grossman, \& Wang, 1993).

Moreover, China's socialist market economy signifies the government's constant attempt at balancing productivity and stability. By limiting the market access and maintaining a tight control over its commodity markets, a unique institutional environment is created for the formation of prices. First, direct participation by foreign investors is currently restricted, 
although this is being loosened as part of the effort to internationalize these markets. ${ }^{3}$ However, historically being segregated from global investors likely caused market segmentation, limitsto-arbitrage and gradual information diffusion. For example, Yang, Yang, and Zhou (2012) find that barriers-to-entry reduces the information content of the futures prices in China. Second, directly managed by the government, the priority of the Chinese exchanges is market stability rather than the maximization of shareholders' wealth. Compared to developed markets such as the US, this fundamental difference inevitably leads to more frequent interventions and tighter regulatory controls, which are ultimately translated into unique implementations of price limits, margins and position limits. These unique settings convey significant implications for the futures price discovery and hence the dynamics of risk premia.

The paper presents four key findings. First, unlike the US markets where nearby contracts are most active, the nearest to maturity contracts in China account for less than $10 \%$ of total volume traded on the futures curve. Overlooked by the extant literature, this means inferences drawn from the nearest contracts are incomplete at best. Nonetheless, Ciner (2002) and Webb (1995) find Japanese speculators prefer deferred contracts as they believe there is more time for their futures position to become profitable. Chinese investors exhibit preferences toward longer-dated contracts with specific maturities. Exacerbated by the time-varying margins and strict position limits, speculators are involuntarily pushed away from the front end of the futures curve. ${ }^{4}$ As a result, a regulation-induced "limits-to-arbitrage" causes the liquidity

\footnotetext{
${ }^{3}$ As of October 2019, foreign investors can directly trade in crude oil (from March 2018), iron ore (from May 2018), PTA (from November 2018), STR rubber (from August 2019) and fuel oil (from December 2019) markets. Products under discussions include methanol, soybeans, palm olein, LLDPE, PP, copper, aluminum, nickel, zinc, lead and tin. These markets are expected to be opened shortly. Since then, qualified foreign brokerage firms are allowed to directly trade in the exchange, instead of conducting trades via a domestic intermediary.

${ }^{4}$ At the time when the paper was written, individual investors in common wheat are prohibited to hold any positions during the delivery month while non-individuals are limited to 200 contracts. In addition, a margin of $5 \%$ is applied from the first to the $15^{\text {th }}$ calendar day of the month prior to the delivery month. This margin is then increased to $10 \%$ for the remaining month and $20 \%$ in the delivery month. A forced liquidation process is triggered if positions exceed the defined limit. As speculators cannot trade sufficient volumes in the nearest contracts, moving to a more distant contract not only maintains continuous exposures but also avoids a higher margin cost.
} 
and volatility to be lower, and the expected returns to be higher in the nearest to delivery markets. In these markets, hedgers' ability to effectively transfer risks is impeded.

Second, passive long-only investing does not yield statistically significant profits, regardless of the time, sector or weighting schemes employed. This helps explain the relative absence of indexing instruments known to investors. ${ }^{5}$ In general, the performance of long-only commodities mirrors the rapid growth and recent slowdown of the Chinese economy. The absence of long-only premia suggests the theory of normal backwardation (Keynes, 1930; Hicks, 1939) does not hold well in China. Under this framework, net long speculators accrue a risk premium by assuming the price risk of net short hedgers. Even though some individual accounts may represent hedgers in disguise, the absence of long-only premia suggests that speculators overpower hedgers as a result of retail-dominance.

Third, unique institutional settings do not eliminate the risk premia. Among an exhaustive list of premia tested, term structure and momentum premia are inflated by, but are robust to, strict position limits and time-varying margins. As roll-yields and past returns are empirically linked to inventory (Gorton, Hayashi, \& Rouwenhorst, 2013), our findings suggest that unique trading rules do not disrupt the pricing fundamentals underpinned by the theory of storage (Working, 1949). However, hedging pressure, volatility, liquidity and skewness premia can be distorted. Thus, we argue that the hedging pressure hypothesis (Hirshleifer, 1989) and the selective hedging hypothesis (Fernandez-Perez, Frijns, Fuertes, \& Miffre, 2018) are potentially incomplete. On the other hand, we find the informational content of gross open interest, correlations with currency and inflation, are sensitive to excessive speculation,

\footnotetext{
${ }^{5}$ The Nanhua Commodity Index (www.nanhua.net) covers a board range of 20 commodities and follows a construction methodology similar to the Commodity Research Bureau. The CFMMC China Commodity Futures Index (CCFI) was introduced by the China Futures Market Monitoring Center in 2015. The CCFI covers 20 commodities as of January 2018 (www.cfmmc.com/main/views/index.html).
} 
government intervention and economic structures, respectively. ${ }^{6}$ Therefore, future research on commodity pricing ought to incorporate the effects of unique institutional settings.

Fourth, the term structure and momentum premia in China cannot be attributed to aggregate market risks, none-tradable macroeconomic risks or changes in market sentiments. However, illiquidity, anchoring bias and the regulation induced limits-to-arbitrage provide at least a partial explanation. Moreover, the hedging pressure premium can be adequately explained by the Bakshi, Gao, and Rossi (2019) model. While the broad commodity market in China is more intertwined with stocks than in the US, term structure, momentum and hedging pressure premia are found to offer promising diversification potential for Chinese equity exposures, though the benefit is immediate only to Chinese investors. Finally, our evidence suggests Chinese commodity prices are an important indicator of future economic growth in China. An extensive suite of robustness tests suggests our findings are consistent in the most liquid markets, randomly excluded commodity sectors, US dollar-denominated returns, a "matched" sample with the US, by altering futures return measurements, portfolio breakpoints, and cannot be subsumed by data-snooping or transactions costs.

\section{Institutional Settings}

\subsection{A brief walk down the great wall of commodity}

To better understand the dynamics of commodity futures in China, it is worthwhile to first understand its origin. The history began with a grain wholesale market established in October

\footnotetext{
${ }^{6}$ Hong and Yogo (2012) posit the gross open interest is a better predictor of future economic activity and asset prices than futures prices. In their model of limited arbitrage by speculators, futures prices adjust to long or short excess hedging demand. However, the substantial presence of speculators in China suggests that risk absorption capacity is unlikely to be an issue. On the other hand, the currency premium is significant when futures returns are denominated in US dollars. The inflation premium is positive in a sample predominately made up of foodstuffs-a major component of the CPI basket in China.
} 
1990 in Zhengzhou, the capital city of Henan Province, a major agricultural production region. Initially, the grain wholesale market only facilitated spot transactions, but quickly evolved to futures trading (Williams, Peck, Park, \& Rozelle, 1998). Due to the speculative nature of inexperienced participants and the ineffective regulatory oversight, the market experienced a chaotic period in its first decade of development. After several boom and bust cycles, a market overhaul took place in 2000 . The number of both the exchanges and products reduced from a peak of more than 50, to just three exchanges and nine products. A relatively steady period of development followed until the introduction of the index futures in 2010. The financial futures sparked enormous interests in futures trading, where the commodity futures markets also benefited from the soaring volume.

However, the regulators quickly introduced several policies to curb the excessive speculation in order to prevent a potential collapse. For example, starting from 2011, newly launched contracts were mainly big-scale. ${ }^{7}$ This fundamentally constrained speculation, and also made the Chinese market more compatible with international counterparts. Increased margins, price limits and transaction fees caused the trading lots to drop substantially (by 51\%) in 2011 (see Figure 1). However, the effectiveness of such actions on speculation remains unanswered, as recent studies find higher margins can lead to a reduction in open positions and increase in volatility (Hedegaard, 2014), whereas price limits may restrict price discovery but not stop speculation (Janardanan, Qiao, \& Rouwenhorst, 2019). After decades of consolidation, the Shanghai Futures Exchange (SHFE), Zhengzhou Commodity Exchange (ZCE), Dalian Commodity Exchange (DCE), along with the recently established China Financial Futures

\footnotetext{
${ }^{7}$ Those small-scale commodities traded during 1994-1998 experienced over-speculation by large speculators, which drove up the market risk (Xin, Chen, \& Firth, 2006). Soybean meal, one of the early contracts, was set as 10 tons per contract, while the recently launched thermal coal was designed as a big-scale contract- 100 tons per contract.
} 
Exchange (CFFEX) and the Shanghai International Energy Exchange (INE), constitute the contemporary Chinese futures markets.

Given the immaturity of the market, early studies have primarily focused on qualitative market developments (Williams et al., 1998). As the market became more mature, the research attention turned to the market efficiency and linkages with the US. Fung, Leung, and Xu (2003) compare the pricing impact and information transmission between China and the US and conclude that the less regulated products in China are affected more by the US market. Xin et al. (2006) find that copper and aluminum futures markets in China are efficient and they attribute the efficiency to improved regulations and skills of participants. Chan, Fung, and Leung (2004) find asymmetric responses in copper, mung beans, soybeans and wheat markets. They also show that volatility is positively (negatively) linked to trading volume (open interest).

Recent studies have examined the broad market performance (Fung, Tse, Yau, \& Zhao, 2013; Tu, Song, \& Zhang, 2013), trend-following strategies (Li, Zhang, \& Zhou, 2017), pricing implications (He, Jiang, \& Molyboga, 2019), volatility (Jiang, Ahmed, \& Liu, 2017; Tian, Yang, \& Chen, 2017), diversification potential (Hammoudeh, Nguyen, Reboredo, \& Wen, 2014; Liu, Tse, \& Zhang, 2018), the impact of speculation (Fan, Mo, \& Zhang, 2019; Wellenreuther \& Voelzke, 2019) and high frequency trading (Zhao \& Wan, 2018). For example, Tu et al. (2013) conclude that the correlation between the Chinese and the US markets has increased during the period 2000-2010. Li, Zhang, et al. (2017) find that trend-following strategies outperform buy and hold strategies. Moreover, Kang and Kwon (2017), He et al. (2019) and Ham, Cho, Kim, and Ryu (2019) document strong profitability of momentum strategies. Overall, the Chinese commodity markets have undergone remarkable developments in the past decades. While a vibrant literature exists on US and European commodities, studies on Chinese commodities are emerging rapidly. 


\subsection{Unique characteristics}

China's socialist market economy signifies the government's constant attempt at balancing productivity and stability. Restrictive measures such as limiting the market access and maintaining tight control over the exchanges are instituted to manage its commodity futures market. Consequently, this creates a unique institutional environment for the formation of prices. The following table presents a comparative summary of key institutional settings between China and the US. The table highlights noticeable distinctions in areas of market access, participants-mix, exchange ownership and regulations. Since these unique settings have significant implications on futures price discovery, we discuss their potential impacts on research design, empirical results and form testable hypotheses in the following sections.

\begin{tabular}{|c|c|c|}
\hline & China & U.S. \\
\hline Regulator & $\begin{array}{l}\text { China Securities Regulatory Commission } \\
\text { (CSRC) }\end{array}$ & $\begin{array}{l}\text { Commodity Futures Trading Commission } \\
\text { (CFTC) }\end{array}$ \\
\hline Self-regulation & China Futures Association & National Futures Association \\
\hline Barriers-to-entry & $\begin{array}{l}\text { Only qualified foreign institutions are allowed } \\
\text { to trade; strict approval process }\end{array}$ & Foreign investors are allowed to trade \\
\hline Traders & $>86 \%$ open interest held by individual accounts & Institutions dominate the market \\
\hline Exchanges & Public institutions & Private or listed firms \\
\hline Price limits & $\begin{array}{l}\text { Multi-level; unsystematic revision; } \\
\text { increases in delivery months (DCE only) }\end{array}$ & $\begin{array}{l}\text { Single or Dual-level; semi-annual revision; } \\
\text { no limit in delivery months }\end{array}$ \\
\hline Margins & $\begin{array}{l}\text { Increase significantly approaching maturity; } \\
\text { linked to price limits }\end{array}$ & $\begin{array}{l}\text { Small increases approaching maturity; } \\
\text { linked to volatility and liquidity }\end{array}$ \\
\hline Position limits & $\begin{array}{l}\text { Retail positions are restricted near delivery and } \\
\text { prohibited in delivery months }\end{array}$ & $\begin{array}{l}\text { Positions are restricted but not prohibited } \\
\text { in delivery months }\end{array}$ \\
\hline
\end{tabular}

\subsubsection{Retail-dominance}

The Chinese commodities market is dominated by individual investors. Broadly speaking, the trading accounts are classified into individuals and non-individuals, where non-individuals include corporations, asset management firms and risk management entities. By the end of 2016, there were a total of 1.18 million trading accounts, of which 1.15 million (97.5\%) were 
individual accounts (China Futures Association, 2016). Driven by the participation of private funds and asset management companies, the number of institutional trading accounts saw a growth of $49.5 \%$ in $2016(173.8 \%$ in 2015$)$, however, it was still a mere $16,500(11,500$ in 2015 ) accounts in total. ${ }^{8}$ Characterized by the size of accounts, $94.01 \%(87.58 \%)$ of investors held a margin account below 100 thousand RMB (equivalent to USD 15,000), 5.72\% (11.80\%) of investors had margin account balances ranging from 100 thousand to 10 million RMB, while the remaining $0.27 \%(0.6 \%)$ investors possess a margin account beyond 10 million RMB, by the end of 2015 (2016). Interestingly, the total capital under management by institutional investors accounted for $38 \%$, while the total trading volume contributed by institutions only accounted for $9.8 \%$.

According to the theory of normal backwardation, hedgers pledge an "insurance cost" in the form of risk premia to attract speculators to take on the price risk. Thus, we form the following testable hypotheses. First, retail-dominance in China implies that there may be an insufficient number of net-short hedgers, hence leading to zero long-only risk premia in these markets. However, retail-dominance does not prevent the long-short premia. Second, in the framework of selective hedging, hedgers not only want to minimize risk but also maximize skewness. Thus, skewness preferences can cause futures contracts to be mispriced (FernandezPerez et al., 2018). However, the key assumption is that commodity futures markets are dominated by large speculators and hedgers, with retail investors rarely participating. Therefore, we do not expect to find skewness premia in China. Third, retail-dominance is found to induce a higher degree of positive feedback trading (De Long et al., 1990) and herding (Li, Rhee, et

\footnotetext{
${ }^{8}$ Such retail-dominance is present for several reasons. First, due to an immature social security system, the household savings rate in China is among the highest in the world (Kang, Liu, \& Ni, 2002). In light of strict capital outflow restrictions, along with relative scarcity of fixed-income securities, investors have historically resorted to bank deposits, stocks and properties. However, the bank deposit rates in China are often kept below market rates, and property ownership is increasingly regulated. Hence, equity is the major wealth-building instrument favored by Chinese individual investors. The emergence of commodity futures market has provided a new vehicle to channel the wealth accumulated.
} 
al., 2017), which suggests that commodity price momentum is likely stronger compared to developed markets (Nofsinger \& Sias, 1999; Demirer, Lien, \& Zhang, 2015).

\subsubsection{Excessive speculation}

One of the unfavorable consequences of retail-dominance is excessive speculation. ${ }^{9}$ In fact, the speculative nature of Chinese individual investors is well documented. Allen et al. (2006) point out that the desire for quick gains combined with a lack of strong legal framework in China fostered a speculative attitude among investors. Wang et al. (2006) employ a 42-item questionnaire to investigate the psychological mechanisms of Chinese investors, with a sample of 1,547 individuals. They conclude that the Chinese investors are speculation-orientated, bear a low level of risk perception, investment knowledge and skills. Chen et al. (2007) find that Chinese investors suffer from behavioral biases such as disposition effect, overconfidence and representativeness more than the US investors do.

The primary function of a futures market is to enable the transfer of spot price risks. Although higher trading volume translates to market liquidity, a market can be over-speculative if the volume is not well justified by the size of the underlying spot market. This is evident in the Chinese market both presently and historically. For example, Williams et al. (1998) highlight that the open interest of mung bean futures in 1996 represents roughly three times national production. Citi (2016) shows the average holding period of a contract is less than four hours. More recently, Bloomberg (2018a) reports the trading volume of apple futures on $15^{\text {th }}$ May 2018 alone is equivalent to half of the annual production worldwide (or China's annual crop).

\footnotetext{
9 The CSRC implicitly refers to "drastic price turbulence" and "abnormal trading volume" as indicators of excessive speculation. Thus, one can interpret "excessive speculation" as excess volatility and/or trading volume, in line with our use of the term. See http://www.csrc.gov.cn/shanxi/xxfw/sxgzjx/201605/t20160505_296971.htm.
} 
Foreign investors, especially institutional investors, are presumed to possess a higher level of experience, rationality and information compared to Chinese investors. Thus, if allowed to participate they are expected to improve the market quality by reducing the price volatility (Li, Nguyen, Pham, \& Wei, 2011). However, access to Chinese commodity futures market has been difficult for foreign investors. Currently, institutional investors who are members of (R)QFII (RMB Qualified Foreign Institutional Investor) program are allowed to invest. The membership is subject to approval and quota of the government. Foreign individual investors are only allowed to trade crude oil, iron ore and PTA contracts as of early 2019. Although the market liberalization has accelerated in recent years, Yang et al. (2012) find that barriers-to-entry reduces the information content of the index futures prices and the market's price discovery performance. As a consequence, barriers-to-entry along with retail-dominance hinders the market's ability to neutralize excessive speculation.

\subsubsection{Exchange ownership and regulations}

In addition to retail dominance and excessive speculation, the exchanges are directly managed by the government in the form of public institutions, rather than private or publicly listed firms in the US or Europe. ${ }^{10}$ This means the top priority of the exchanges is not to maximize the shareholders' wealth. Bai, Lu, and Tao (2006) assert that state-owned entities in China are "grossly inefficient and ill-prepared for market competition". The exchanges are responsible for organizing trading-related matters, such as managing contracts and facilitating transactions. With the political risk embedded, bureaucracy will likely impede the operational (informational) efficiency of commodity exchanges (markets) in China. Since the priority of the exchanges is to maintain market stability, it inevitably leads to more frequent interventions and tighter regulatory controls compared to developed markets. These are ultimately translated into price

\footnotetext{
${ }^{10}$ Public institutions are fully or partly funded by the government, which historically included all public schools, universities, clinics, hospitals, libraries, performing groups, research institutes and media organizations in China.
} 
limits, margin requirements and position limits. ${ }^{11}$ As margins and price limits are found to have significant impacts on futures price discovery, it is paramount to understand these unique institutional settings before examining the performance of premia or investment strategies.

Price limits. First, the price limits in both China and the US share similarities in terms of the expansion mechanism, with three to five levels in China and only one to two levels in the US. If the initial price limit is reached, the expanded limit(s) will be applied on the following day(s), until the trading is halted. The expansion levels vary by commodities and exchanges. Second, the price limit may increase in the delivery month in China whereas no limit is applied in the US. According to the "DCE Administrative Measures for Risk Management", the initial daily price limit for all contracts during non-delivery months is $4 \%$ within the settlement price of the previous trading day, while it becomes $6 \%$ in the delivery month. ${ }^{12}$ This does not apply for commodities traded on the ZCE and the SHFE. Finally, price limits are systematically reset twice a year in the US to reflect the market information. However, Chinese exchanges can adjust the limits whenever they believe is necessary. While the multilevel price limits in China are designed to constrain excessive speculation and facilitate price discovery, Liu and An (2011) argue that they can adversely impact the market in terms of reflecting new information in futures prices.

Margins. First, unlike the US where margins are relatively stable, the margin requirements in China increase significantly as a contract approaches the delivery month. ${ }^{13}$ For the DCE, a margin of $5 \%$ is applied from the first trading day to the $15^{\text {th }}$ calendar day of the

\footnotetext{
${ }^{11}$ Investors could have opted for other exchanges in the Asia-Pacific region with a more transparent legal framework and a more advanced operational infrastructure (e.g SGX-Singapore Exchange). However, the existence of capital outflow restrictions means home-bias is not entirely discretional.

${ }^{12}$ An exchange-level ordinance, drafted in accordance with the "DCE Trading Rules", periodically reviewed to reflect the current market condition. The latest version took effect on $8^{\text {th }}$ April 2019. See http://www.dce.com.cn/dalianshangpin/fg/fz/6142914/6142922/6146604/index.html.

${ }^{13}$ All commodity futures traded in China require physical delivery for settlement. The delivery process is similar to the US. Internet Appendix II outlines a list of authorized delivery warehouses, for each commodity in our sample. As of October 2019, there are a total of 573 delivery locations across 25 provinces.
} 
month prior to delivery, then increases to $10 \%$ for the remainder of the month. The margin is elevated to $20 \%$ when the contract enters the delivery month. For the ZCE and SHFE, a similar structure applies but the margins vary by commodities. Second, the changes in margins are determined by the market volatility and liquidity in the US, margins in China are jointly determined by the price limits. This means that if the initial price limit is reached, the required margin will increase on top of the expanded price limit. For example, assuming a copper contract has a price limit of $5 \%$ and a margin of $4 \%$, if the closing price increases by $5 \%$, the price limit and the margin requirement will automatically rise to $8 \%$ and $10 \%$ respectively on the next trading day. Consequently, the time-varying margin creates the incentive for speculators to stay out of the maturing contracts.

Position limits. Position limits in the delivery month are common in global futures markets; however, Chinese retail investors are prohibited to hold positions in the delivery month. Additionally, their positions are restricted in the preceding month prior to contract delivery. A forced liquidation process is triggered for non-compliance. Taking the common wheat contract as an example, the maximum number of positions that non-futures company members and retail investors can hold before the $15^{\text {th }}$ calendar day of the month prior to the delivery is 2000 (600 for the remaining month). ${ }^{14}$ In the delivery month, only 200 positions are granted to non-futures company members, while a retail investor is prohibited to trade at all. Coupled with the time-varying margin requirements, the position limits imply that nearest contracts are unlikely to be the most liquid in China.

Accordingly, we form the following testable hypotheses. First, strict position limits prevent retail participation in the nearest to delivery contracts. Exacerbated by higher margin

\footnotetext{
${ }^{14}$ Futures companies serve as the intermediaries between the exchanges and investors. Non-futures companies, registered as membership holders of exchanges, also function as intermediaries. e.g. private futures funds, risk management, asset management and securities brokerage firms. See "Administrative Measures for Futures Companies Supervision" published on 29 October 2014 by the CSRC, available from http://www.shfe.com.cn/regulation/exchangelaw/911322933.html
} 
requirements approaching the delivery, most traders exit their positions before the contract enters the preceding month. Hence, the front contracts are expected to be less liquid compared to the distant contracts. Second, if the liquidity is lower on the front contracts, market volatility is also expected to be lower compared to distant contracts. Meanwhile, the absence of timevarying margin and strict position limits would suggest that spot market volatility (proxied by the nearest contracts) is higher in the US for the same commodity. Third, while the regulatory constraint creates a policy-induced limits-to-arbitrage on the front-end of the futures curve, higher margins lead to higher required returns as predicted by the margin-based asset pricing model of Gârleanu and Pedersen (2011). Therefore, we expect the risk premia to be higher on the front contracts. Finally, to accommodate the majority, most hedgers would employ contracts with higher liquidity to transfer risks. Consequently, the hedging pressure premia should only be observed on distant contracts.

In summary, the institutional environment of commodity markets presents significant implications for the formation of futures prices in China. Therefore, we aim to shed light on this gap by examining the impact of unique settings on the performance of long-only and an exhaustive list of long-short risk premia.

\section{Data and Methods}

\subsection{Sample selection}

We obtain the entire archive of Chinese commodity futures from Datastream International. From January 1992 to May 2017, we download the daily settlement price (in RMB), trading volume and open interest of 47 commodities of all maturities traded across DCE, ZCE and SHFE. This results in more than 4,000 contracts in total. We require each commodity to have at least four years of data and a minimum of 8 commodities in the cross-section to manage the 
volatility of portfolios. The cleaning process resulted in a final sample of 30 commodities, covering February 2004-May 2017. Following Szymanowska, de Roon, Nijman, and van den Goorbergh (2014), we categorize commodities into five sectors in accordance with the Commodity Research Bureau (CRB), which include industrials, grains, oilseeds, energies and metals. Table 1 outlines the commodity tickers, contract size, delivery months, initial price limit, margin requirements, first- and last- contracts and their maturity dates.

To compile continuous futures returns, we closely follow Miffre and Rallis (2007) and Fernandez-Perez et al. (2018). We hold contracts until the last trading day of the month prior to expiration. The positions are then rolled over to the next nearest contract. We also construct returns series based on distant contracts with $m^{\text {th }}$ maturity $(m=2,3$ and 4$)$. These contracts represent the majority of the volume and open interest on the futures curves in China (as can be seen in Figure 1). When compiling the $m^{\text {th }}$ nearest-contract returns, price changes of the $m^{\text {th }}$ maturity contract are held up to the last day of the month before the front contract matures, along with the corresponding open interest, volume and price series. Following Fuertes, Miffre, and Rallis (2010), our long-short portfolios can be viewed as 50\% collateralized. This implies a leverage factor of two, which is considerably conservative within the hedge fund industry. Our long-short portfolios would have been fully collateralized if a weighting of 0.5 was assigned to each of the long and short legs. By fully collateralizing long-short portfolio, the strategy returns and volatilities will be halved, while the risk-adjusted performance, significance of regression coefficients remain unaffected.

Table 2 reports the annualized returns (Panel A), standard deviations (Panel B), trading volume (Panel C) and the Amihud illiquidity measures (Panel D). Panel A shows that individual commodities do not perform well, as most of the commodities report large and negative returns. The returns range from $11.9 \%$ (soybean meal) to $-13.7 \%$ (coking coal) on the nearest contracts and $9.6 \%$ (rapeseed meal) to $-8.7 \%$ (silver) on the fourth nearest contracts. 
The difference-in-mean tests reveal that the first nearby contracts report higher returns than the third nearby contracts in only three markets. Furthermore, the standard deviation ranges from as low as $9.5 \%$ (common wheat fourth nearest) to $36.8 \%$ per annum (coking coke first nearest). In line with our hypothesis, the difference-in-mean tests reveal that the front contracts in 12 out of 30 commodities report lower volatility compared to the third nearby contracts. In contrast to Duong and Kalev (2008), these results suggest that the support for the Samuelson (1965) hypothesis is mixed in China. Turning to the trading volume, Panel $\mathrm{C}$ clearly shows that the number of contracts traded is concentrated in the more distant maturities. Correspondingly, the Amihud illiquidity measure in Panel D suggests that the majority of commodities present sufficient liquidity on the distant contracts for the implementation of systematic strategies. The $p$-values suggest that volume and liquidity are indeed higher on the third nearby compared to the first nearby contracts, consistent with our hypothesis.

We put forward two potential explanations on why the long-only premia is not higher on the first nearby contracts compared to the distant. First, higher margin and position limits on the front contracts can cause the distant contracts to be overpriced, leading to a compressed basis. Thus, lower basis and spot volatility can cause backwardated contracts to be less backwardated and contangoed contracts to be more contangoed, whereby increasing the selling pressure while reducing the buying pressure, thus reducing the risk premia. Second, as we do not consider prices during the delivery month (when margins are the highest), the changes in margins between the first and the third nearby contracts may not be large enough to make a difference in our sample.

\subsection{Macro variables and US data}

To facilitate the implementation of strategies and the construction of risk adjustment models, several macroeconomic and financial variables are obtained in local currency. The RMB 
effective exchange rate index is attained from the Bank for International Settlements (BIS). The Chinese unexpected inflation rate and unexpected industrial production are the difference between actual and forecasted figures. To track the movements of Chinese stocks, four indices are considered. Similar to the S\&P500, the CSI300 consists of the top 300 stocks traded on the Shanghai and Shenzhen stock exchanges. To capture the broader stock market, we also consider the Shanghai Composite Index and the Shenzhen Composite Index. Furthermore, to include large- and mid-cap Chinese stocks listed in Hong Kong, US and Singapore, we employ the MSCI All China Index. The Barclays China Aggregate Index is used as a proxy for the RMB-denominated fixed income market. The index covers fixed-rate treasury, government and corporate bonds. All macro and financial data are obtained from Bloomberg.

To rule out the possibility of a sample selection bias, we construct a "matched" sample consisting of "identical" US commodities. From the Commodity Research Bureau (CRB) InfoTech $\mathrm{CD}$, we obtain settlement price, open interest and volume on 14 commodities traded on US exchanges. We perform the same rolling procedures to compile futures returns at daily and monthly frequencies. Internet Appendix I provides a summary of the "matched" sample. Traders' positions data are retrieved from the CFTC commitments of traders (CoT) report. The US effective exchange rate is obtained from the BIS, and the inflation data are from Bloomberg.

\subsection{Long-short portfolios}

We consider an exhaustive list of risk premia from the literature. The first strand of premia is motivated by the Theory of Storage (Kaldor, 1939), the Hedging Pressure Hypothesis (Cootner, 1960) and the Selective Hedging Practice (Stulz, 1996; Gilbert, Jones, \& Morris, 2006). These

premia rely on the informational content of roll-yield (Gorton \& Rouwenhorst, 2006), past returns (Miffre \& Rallis, 2007), net positions of hedgers (Basu \& Miffre, 2013) and skewness (Fernandez-Perez et al., 2018). The second group of premia is inspired by economic and 
empirical intuitions, which exploits information such as value (Asness, Moskowitz, \& Pedersen, 2013), open interest (Hong \& Yogo, 2012), currency and inflation (Erb \& Harvey, 2006), volatility and liquidity (Szymanowska et al., 2014). To capture these risk premia, we construct systematic long-short portfolios through characteristic sorts. At month end, each strategy buys (sells) the commodity quartile predicted by the commodity characteristic or signal to appreciate (depreciate). Appendix A lists the definitions of sorting variables.

Term Structure (TS): The TS strategy is motivated by the theory of storage (Working, 1949; Brennan, 1958) which links the slope of the term structure with inventory levels and the benefits of owning spot commodities. Studies have shown a premium can be generated by taking long (short) positions in commodities with high (low) roll-yields (Erb \& Harvey, 2006; Gorton et al., 2013).

Hedging Pressure (HP): The HP strategy is motivated by the hedging pressure hypothesis (Cootner, 1960; Hirshleifer, 1990) which posits that net long (short) speculators demand compensation for taking on the price risk of net short (long) hedgers. Evidence of a hedging pressure premium can be found in De Roon, Nijman, and Veld (2000) and Basu and Miffre (2013). Due to the absence of trader positions data in China, we employ the hedging ratio proposed by Lucia and Pardo (2010) as a proxy for HP. ${ }^{15}$

Momentum (MOM): The MOM strategy buys (sells) past winners (losers) based on the cumulative performance over the most recent 12 months. The existence of the momentum

\footnotetext{
${ }^{15}$ Due to the absence of positions data, the hedging ratio is the only tool available to measure the hedging pressure. Although we are unable to formally establish the link in the Chinese market, evidence from the US market suggests that hedging ratio produces similar results compared to hedging pressure constructed using the CFTC CoT reports (Robles, Torero, \& Von Braun, 2009). Our use of the hedging ratio is based on the assumption that hedgers hold positions longer than speculators. This is generally supported by the exchange statistics. In theory, a higher hedging ratio suggests more trades are triggered by hedgers. Thus, in a cross-sectional setting, we interpret a higher hedging ratio as a signal for a higher hedging pressure relative to other commodities. We acknowledge that hedging ratio is an imperfect measure of HP. Nevertheless, HP constructed using the CoT data are also heavily criticized for its ambiguity in trader group classifications (Briese, 2012; Cheng \& Xiong, 2014; Fan et al., 2020). Thus, we employ the hedging ratio to conduct a "bottom-line" test and draw inferences on the hedging pressure hypothesis in China.
} 
premium is documented extensively in the literature (Miffre \& Rallis, 2007; Bianchi, Drew, \& Fan, 2015; Bakshi et al., 2019).

Volatility (VOLA): The VOLA strategy is motivated by the theory proposed by Dhume (2011), where commodities with high spot volatility correlate positively with durable consumption growth. Since these commodities cannot act as a hedge against intertemporal risk, investors demand compensation for holding these assets. Studies have shown a volatility premium can be generated by buying (selling) commodities with high (low) volatility (Gorton et al., 2013; Szymanowska et al., 2014).

Open Interest (OI): The OI strategy is motivated by the findings of Hong and Yogo (2012), in which unexpected changes in OI predict commodity futures returns. An open interest premium can be generated by buying (selling) commodities with high (low) changes in OI (Szymanowska et al., 2014).

Liquidity (LIQ): The LIQ strategy is empirically motivated as investors demand compensations for holding commodities with relatively low liquidity. Szymanowska et al. (2014) employ the Amivest measure (Marshall, Nguyen, \& Visaltanachoti, 2012) and show that a liquidity premium can be generated in US commodity futures.

Currency and Inflation (FX/INF): The FX and INF strategies are motivated by the empirical fact that commodities prices are negatively correlated with the US\$ effective exchange rate and positively correlated with inflation shocks (Gorton \& Rouwenhorst, 2006; Bhardwaj et al., 2016). Using regression beta as signals, Szymanowska et al. (2014) demonstrate that an FX premium can be generated by buying (selling) commodities with low (high) FX beta, and an INF premium can be generated by buying (selling) commodities with high (low) sensitivity to inflation shocks. 
Skewness (SKEW): The SKEW strategy is motivated by investors' preferences for skewness under cumulative prospect theory and selective hedging practices. Fernandez-Perez et al. (2018) demonstrate that a skewness premium can be generated by buying (selling) commodities with the most negative (positive) skewness.

Value (VAL): The VAL strategy is inspired by Asness et al. (2013). Using a long-term mean reversion measure, high-value, cheap or long-term loser commodities are found to outperform the long-term winner commodities.

\section{Results}

\subsection{Passive long-only}

Table 3 reports the performance of long-only investments in the broad market and sectors. The market is represented by an equally weighted portfolio of 30 commodities in the sample and rebalanced monthly. Since the majority of the trading volumes are on the third and fourth nearest contracts, we construct portfolios based on the first to fourth nearest contracts (also see Figure 1). Panel A reports the results over the sample period 2004-2017, whereas Panel B extends the sample to market inception. The findings in Table 3 suggest that regardless of time, sector and maturity specifications, long-only portfolios in China do not generate significant economic profits. Most notably, grains saw statistically significant losses on the first and second nearest contracts. These results can be better visualized in Figure 2.

Figure 2 illustrates the cumulative performance of the broad market and sectors based on the third nearest contracts. In addition to equal weights, we also employ alternative weighting schemes taking into account the impacts of trading volume and open interest. Regardless of schemes, passive long-only investments in the broad market or sectors deliver poor economic returns. Specifically, industrials are the worst performers followed by energy 
commodities, which lost more than half of their values since 2004. Notably, grains have outperformed the rest of the market under all weighting schemes. In the meantime, metals, oilseeds and energies exhibit non-synchronized growth with the broad market from 2004 leading to the global financial crisis (GFC). Over the last 5 years, all sectors have declined by varying degrees, although the decline is less pronounced in grains. This decline can be attributed to the excess supply and the slowed demand experienced by the Chinese economy.

Our findings clearly suggest the rejection of the null hypothesis of non-zero risk premium. The theory of normal backwardation suggests that speculators receive a risk premium as compensation for taking on the price risk of hedgers. However, since more than $97 \%$ of the trading accounts are individual-based, the absence of long-only premia in China may be viewed as evidence of speculators overpowering hedgers. ${ }^{16}$ It seems plausible that speculators demand liquidity from each other, because the long-only risk premia are largely negative across commodities. Nevertheless, one may still raise the question why are there so few hedgers in these markets? The answer traces back to the origin of the Chinese futures market.

The former vice chairman of the CSRC highlights the fundamental difference between the US and Chinese commodity futures markets. The former was established in the 1870 s as a result of the market demand, while the latter was directly propelled by the government as one of the measures to liberalize the economy in the early 1990s, during which the private sector was emerging. Put alternatively, the US commodity futures markets were founded to meet the producers' demands, whereas the Chinese markets were set up because the government believed it was necessary. Consequently, the number of corporates engaged in futures trading is relatively small, and futures trading is still recognized as a speculative game and complex to

\footnotetext{
${ }^{16}$ We acknowledge the limitation of this conjecture, as a classification independent of the business purpose could present a mixture of hedgers and speculators. One is unable to definitively distinguish the trading purpose of individual and non-individual traders. Besides, it is also probable that traders (companies) transact for hedging purpose with an account registered under an individual name.
} 
understand by majority of the producers (China Futures, 2019). However, instead of focusing solely on "excessive speculation", we stress the fact that hedgers in China have not had the time to complete the "learning process". Overall, the findings on long-only premia suggest that the theory of normal backwardation does not hold well in China. We now move on to the performance of long-short strategies.

\subsection{Long-short strategies}

Table 4 reports the performance of 10 long-short strategies on first (Panel A), second (Panel B), third (Panel C) and fourth (Panel D) nearest contracts. Following the literature, we first focus on the nearest contracts, as these contracts are often regarded as proxies for spot returns.

\subsubsection{Nearest contracts with strict position limits}

Under Panel A, only three out of 10 long-short strategies yield statistically significant profits on the nearest contracts. Most notably, the momentum strategy returns an astonishing 21.94 percent (10.97 percent if fully collateralized) per annum on average. This is followed by the term structure and volatility strategies, with annualized profits of 15.91 and 10.53 percent, respectively. In the presence of strict position limits and increased margins, commodities with higher past returns, roll-yields and spot price volatility systematically outperform commodities with lower past returns, roll-yields and spot price volatility (Erb \& Harvey, 2006; Miffre \& Rallis, 2007; Szymanowska et al., 2014; Fuertes, Miffre, \& Fernandez-Perez, 2015). At face value, the large momentum premium indicates strong price persistency in these markets. Gorton et al. (2013) demonstrate that past returns, roll-yields and volatilities are empirically related to inventory levels. Taken together, our results suggest that Chinese commodity futures behave according to the predictions of the Theory of Storage (Working, 1949).

However, these position limits and margins have significant impact on the behavior of market participants. For example, while we expect the skewness premia to be statistically 
indifferent from zero, the skewness strategy reports significant losses. The skewness strategy is motivated by investors' preferences for positive skewness under the cumulative prospect theory and the selective hedging practice. Fernandez-Perez et al. (2018) document a sizeable premium in the US by taking long (short) positions in the most negatively (positively) skewed commodities. On the contrary, we find that commodities with higher skewness outperform those with lower skewness, suggesting that position limits cause the skewness preferences to reverse. Alternatively, this may be explained by the level of sophistication of the market participants.

Due to strict position limits and higher margins, only the "true" hedgers remain in the front contract during the delivery month. From the perspective of the hedger, it is more favorable for commodities to be sold at a higher price for a producer, and to be bought at a lower price for a user, at delivery. Therefore, producers (users) with net-short (net-long) positions may prefer contracts with positive (negative) skewness, because such contracts could deliver large upward (downward) price movements favored by hedgers, despite a relatively small probability. Consequently, such "lottery-like" behavior can cause positively (negatively) skewed commodities to become over-sold (over-bought) in the front markets. Meanwhile, we find that relatively illiquid commodities underperform the more liquid ones (almost significant at $10 \%$ ), suggesting that traders do not receive a compensation for bearing liquidity risks, but instead they pay a price to hold illiquid commodities.

Strategies that do not report significant profits also present important findings. First, the results on value suggest that the reversion of long-term losers to winners is relatively weak in China, though returns to the value strategy are positive and generally consistent with Asness et al. (2013). Second, commodities with a higher (lower) inflation beta and lower (higher) currency beta are expected to earn higher (lower) returns relative to commodities with lower (higher) inflation beta and higher (lower) currency beta. It is plausible the absence of the FX 
premia is due to known issues surrounding the RMB data. The Chinese government has long been criticized for intervening the RMB currency markets to maintain tight control over the value of the RMB. ${ }^{17}$ Proven to be considerable forces on both the onshore and offshore RMB markets, these intervention activities may contaminate the informational content embedded in the correlation with commodity prices. We test this hypothesis and explore alternative explanations for the inflation results in the following sections.

Finally, Hong and Yogo (2012) find that open interests not only predict commodity returns but also the real economy. In their model of limited arbitrage by speculators, futures prices adjust to long or short excess hedging demand. The core assumption made by Hong and Yogo (2012) is that open interest will rise due to increasing hedging demand fueled by the anticipation of higher economic activities. However, in light of retail dominance and speculative trading, risk absorption capacity is unlikely to be an issue in China. Thus, the predictability of gross open interests is questionable in such settings. Recall the China Futures Association 2015 report, though capital under management by institutional investors constituted $44 \%$ of the market, it only contributed to $15.3 \%$ of the total trading volume (China Futures Association, 2015). Overall, findings in Panel A suggest that Chinese commodity futures prices behave very differently to the US.

\subsubsection{Distant contracts with alleviated limits}

We re-evaluate the performance of all strategies on the second, third, and fourth nearest contracts through Panels B to D. Consistent with our hypotheses, we find that that long-short premia are higher on front contracts and gradually deteriorate towards distant contracts. Position limits and time-varying margins create a regulation-induced "limits-to-arbitrage" in

\footnotetext{
${ }^{17}$ Zhang and Pan (2004) use adjusted foreign reserves as a proxy for exchange rate intervention by the government to estimate the "actual" exchange rate and find the RMB would have appreciated by $15-22 \%$ against US dollar if there was no government intervention during 1996-2003.
} 
the nearest contracts, and also lead to higher expected returns. Notably, the momentum profits have declined significantly relative to term structure, while the term structure premium is relatively stable across the curve.

Why are higher premia on the front contracts only present in a long-short but not longonly setting? We put forward the following explanations. Higher margins and position limits pushed the return spread of past winners and losers (or high vs low basis commodities) to become larger, although the term structure premia on the front is not statistically larger than that on distant contracts. This increases the momentum premia even when long-only premium is non-existent. Meanwhile, traders overreact to abundance (underreact to scarcity) signals due to lower spot volatility and compressed basis, leading them to over-sell in the spot market. Such overreaction pushes the price down while underreaction to scarcity induces a delayed response. On the other hand, overreaction to past returns will push the price of winner commodities even higher, and losers' prices even lower. Eventually, these mispricings are corrected at the new equilibrium. However, exacerbated by strict position limits which make arbitrage difficult, such systematic errors cause the long-short returns spread to become larger in the spot market. On the distant market, the overreaction is arguably stronger given the higher volumes. However, when position limits are alleviated, the returns decline as the market's ability to detect mispricing becomes less impaired, while the expected return also becomes lower due to lower margins. Thus, more efficient arbitrage reduces the long-short returns spread. Overall, margin-induced overreaction, position limit-induced limits-to-arbitrage both contribute to the higher long-short premia observed on the front contracts. Consequently, momentum profits reported by previous studies are likely "inflated".

Meanwhile, several new findings emerge from Panels B to D. First, the volatility premium is no longer significant, suggesting that investors are only compensated for taking on spot price volatility risks when position limits are at the strictest. When these limits are 
alleviated or when liquidity is more abundant, investors no longer receive such compensation in the second nearest contracts and beyond. This finding suggests that the compensation for high volatility in China is induced by the position limits, not the commodity's inability to hedge against intertemporal risks. Second, consistent with our hypothesis, while the hedging pressure premium is insignificant on the nearest contracts, it becomes statistically significant on the third nearest contracts, with an annual average return of $8.11 \%$. This suggests that the front contracts do not effectively facilitate the risk-transfer between hedgers and speculators. As a contract approaches maturity, the position limit initiates and the margin requirement increases significantly. Thus, most hedgers and speculators look beyond the nearest contracts to avoid a higher cost. However, hedgers who wish to stay hedged before taking delivery must bear additional costs. Finally, the significance of skewness and liquidity premia disappears on distant contracts, suggesting that skewness and Amihud liquidity are not priced in the crosssection (Boons \& Prado, 2019). Overall, findings presented in Table 4 suggest that position limits and time-varying margins have significant impacts on the trading behavior of market participants, causing the price dynamics to vary considerably across the futures curve.

Figure 3 illustrates the cumulative returns of one RMB invested in term structure, hedging pressure and momentum strategies, benchmarked against the passive long-only portfolio (AVG). We plot the cumulative performance of the third nearest contracts, as they are a more realistic representation of investment performance. Momentum generates the highest terminal value of $6.12 \mathrm{RMB}$ versus 4.96 and 2.54 for term structure and hedging pressure strategies, respectively. Momentum suffered considerable losses following the GFC. Notably, the persistence of momentum post-2010 is in sharp contrast with the previous literature (Bianchi et al., 2015; Bianchi, Drew, \& Fan, 2016), signaling a segmented market.

\subsection{Comparison with the US}


Since more than half of the commodities in our sample are not traded in the US, this raises comparability concerns. To rule out the possibility that the observed results are due to sample selection, we select 14 comparable commodities traded in both markets and re-examine the performance of all strategies in this "matched" sample. Panel A of Table 5 reports the results on Chinese markets whereas Panel B reports the US results. We employ the first and the third nearby contracts, since they reveal the highest trading volume on average in China and the US, respectively. We also report the performance on the term premia as per Szymanowska et al. (2014). Internet Appendix III details the estimation of spot and term premia. In addition, the cross-country correlations for each strategy are presented in Panel C.

Consistent with previous results, term structure, momentum and volatility strategies remain profitable on the front and third nearest contracts. Interestingly, the inflation strategy now reports $14.27 \%$ per annum return with a $t$-statistics of 2.83 on the third nearest contracts, suggesting that these 14 commodities are more closely associated with inflation. This is not surprising since most of them are food-related products. RBA (2017) stresses that the variations in China's CPI are primarily affected by food which constitutes roughly $30 \%$ of the CPI basket. Besides, the value premium becomes remarkably stronger, suggesting that long-term reversal is more pronounced among foodstuffs. However, the hedging pressure premia is no longer significant on the third nearest contracts, suggesting that the predictive power of hedging pressure is not uniform across sectors. Furthermore, the skewness and liquidity premia are consistently negative and statistically significant on the nearest contracts. In line with Szymanowska et al. (2014), the term premia for seven out of 10 strategies exhibit the opposite signs against the spot premia (see Internet Appendix IV for results on the spot and term premia).

To mitigate concerns that the observed results are due to differences in exchange rates, we also employ the US dollar-denominated prices within the Chinese sample. We find the majority of the results remain consistent, with the exception of the FX strategy. When the 
returns are measured in US dollars, the FX strategy reports statistically significant profits of $9.23 \%(t=1.88)$ on the third nearest contracts. This supports our argument that the failure of FX strategy is attributable to the government intervention of the RMB. These results are not reported in the paper but are available upon request.

Turning to the US results, the performance is generally poor. The hedging pressure strategy, constructed using the CoT report, reveals the strongest results. The predictability of hedging pressure is consistent with Basu and Miffre (2013), with an annual mean return of $16.65 \%(t=2.75)$. We also tested the hedging pressure signal in Appendix A but did not find any significant results. ${ }^{18}$ Whether the hedging ratio is a good proxy for hedging pressure is beyond the scope of the current paper, but these differences highlight the uniqueness of the Chinese market. The term structure and momentum strategies report inferior performance in the US sample. This is not surprising, as discussed in Bhardwaj et al. (2016), commodity markets have become more contangoed in the most recent decade. Given that momentum strategy implicitly buys (sells) the backwardated (contangoed) commodities, the imbalance between backwardated and contangoed markets contribute to the failure of these long-short strategies. Moreover, Bianchi et al. (2016) also document a noticeable decline in momentum profits. They argue that previously successful strategies tend to become less profitable due to the increased competition among market participants.

Furthermore, the value strategy reports a mean return of $13.01 \%$ p.a., stronger than those reported by Asness et al. (2013). Surprisingly, however, alternative risk premia strategies such as open interest, liquidity, FX, inflation and skewness do not report statistically significant profits in our US sample. This is in sharp contrast with Szymanowska et al. (2014) and

\footnotetext{
${ }^{18}$ Within the framework of the hedging pressure hypothesis, two conditions must be met for the ratio-based HP strategy to be feasible. First, hedgers should hold positions longer than speculators. Second, when speculators are outnumbered by hedgers, hedgers must be net short in those markets. However, Cheng and Xiong (2014) reveal that US hedgers frequently change their positions. This violates the first condition and could help explain why ratio-based HP strategy does not deliver significant profits in the US.
} 
Fernandez-Perez et al. (2018), who report seemingly robust profits using a longer time-series and a larger cross-section of commodities. This clearly suggests that alternative premia are sensitive to sample- and time-specifications, but it also implies that the recent "financialization" has had an enduring impact on commodity markets in the US. Moreover, consistent with our hypothesis, retail-dominance causes momentum to be significantly stronger in China.

As for the cross-country correlations in Panel $\mathrm{C}$, the majority of the results are insignificant at the 5\% level. However, we observe a low level of cross-country correlations on hedging pressure, momentum and FX premia on the third nearest contracts. Although neither the hedging pressure nor the FX strategy reports significant profits in the US and China, the positive correlations suggest the existence of commonalities. Particularly for the momentum strategy, as the cross-country correlation is also significant on the first nearest contracts. Furthermore, the spreading returns based on liquidity signal reveal negative cross-country correlations, confirming that the liquidity risk dynamics are distinct between the US and China. Overall, the findings presented in Table 5 highlight the uniqueness of the Chinese markets.

In Internet Appendix I, we conduct a direct side-by-side comparison of the "matched" sample. Overall, the findings suggest that the Chinese commodity markets are indeed different from the US. Unlike the results on a portfolio level, the majority of the commodities in China seem to be significantly correlated with their US counterparts on an individual contract level, with average correlations of 0.46 and 0.52 based on the front and the third nearest contracts, respectively. However, one may be misled by the moderate levels of returns correlations between two markets. The differences can be uncovered by comparing the term structure, hedging pressure and other price dynamics. First, on average, we do not find statistically significant term premia in individual commodities in China (Panel A). Second, we find significant differences in basis, spot volatility, hedging pressure, past returns, value and skewness characteristics (Panels B and C). Third, while spot volatility, past returns and value 
are somewhat correlated, basis, hedging pressure and skewness of the same commodities remain largely different. These findings reinforce our results on systematic long-short risk premia and indicate that Chinese commodity futures market is segmented from the US.

Our study can also be viewed as a true out-of-sample test on risk premia in commodity futures, given the market segmentation from the US. The findings present several implications to existing theories and empirics developed for the US market. First, in the presence of barriers to entry and retail-dominance, only term structure and momentum premia are robust to the influence of strict position limits, multileveled price limits and time-variant margins. This suggests that excessive speculation does not eliminate the risk premia, and that unique settings do not disrupt the pricing fundamentals underpinned by the theory of storage (Working, 1949). Second, we show that hedging pressure, volatility, liquidity and skewness premia can be distorted by position limits. When these limits are alleviated, volatility, liquidity and skewness premia are statistically indifferent from zero, while the hedging pressure premia becomes positive and significant. Therefore, our hedging pressure and skewness results imply that the hedging pressure hypothesis (Cootner, 1960) and the selective hedging practice (FernandezPerez et al., 2018) theories are potentially incomplete. Third, the absence of open interest, FX and inflation premia suggests the information content embedded in futures open interest, and correlations with currency and inflation are sensitive to excessive speculation, government intervention and economic structures. As a result, future research ought to explicitly account for these unique settings. We now move on to investigate the dynamics of the premia observed.

\subsection{Returns analysis}

\subsubsection{Correlations}

We first examine the Pearson correlations among long-only and long-short strategies. Table 6 reports correlations on the nearest contracts (Panel A) and third nearest contracts (Panel B). 
Panel A reveals that among the significant premia, volatility is not correlated with term structure and momentum premia. Term structure and momentum premia are positively correlated, as has been confirmed by Fernandez-Perez et al. (2018) and Bakshi et al. (2019). Fuertes et al. (2010) estimate an average correlation of 0.32 , our estimate of 0.47 suggests that term structure and momentum premia are more closely intertwined in China.

Furthermore, despite the absence of statistical significance, returns to unprofitable strategies exhibit significant correlations. First, the value premia are negatively correlated with term structure and momentum. This is consistent with Asness et al. (2013), in which they argue that the opposite exposures to liquidity risk are the primary driver of the negative correlation. Second, although the FX premium is statistically insignificant, it reports significant correlations with term structure, volatility, open interest and liquidity premia, implying that the value of RMB indeed plays an important role in Chinese commodity futures. Finally, the skewness premium appears to be unrelated to any premia, suggesting that skewness is not presently priced in China. These results are largely consistent on the third nearest contracts (in Panel B) with alleviated position limits, with one notable exception. The hedging pressure premium is now positively correlated with liquidity and value premia, and negatively correlated with volatility, open interest and FX premia. While the negative relation between hedging pressure and volatility is consistent with the previous literature, these results once again highlight that the risk-transfer mechanism varies significantly between the front and distant contracts. Moreover, the positive correlation of hedging pressure and liquidity implies that commodities with larger presence of hedgers also tend to be less liquid.

As for the interaction between long-only and long-short premia, the market portfolio appears to be correlated with term structure, volatility, open interest and FX strategies on both front and the third nearest contracts, although the hedging pressure and inflation premia 
(liquidity) are only correlated with the market portfolio on the third (first) nearest contracts. We now move on to investigate the sources of returns.

\subsubsection{Decomposing long-short portfolios}

Table 7 reports the performance of quartile portfolios for term structure, hedging pressure, momentum and volatility premia. First, when strategies are implemented on the nearest contracts, the return spreads on term structure and momentum premia are large. This suggests that the profits are not short sided, although the significance in short portfolios appears to be stronger than those in the long portfolios, particularly for the term structure premia. These findings are consistent with the previous literature (Fuertes et al., 2010; Bianchi et al., 2015). Second, it appears that the volatility premia on the nearest contracts are largely sourced from the short portfolio, suggesting that commodities with the lowest spot price volatility significantly underperform those with the highest spot price volatility. These findings are consistent on the third nearest contracts.

To address the concerns that our observed profits are compensation for high transaction costs, we compute the net returns. Following Fuertes et al. (2010), we first compute the portfolio turnover for all quartile portfolios and long-short portfolios and then apply a round trip transaction cost of $0.086 \%$ (Marshall et al., 2012). It is evident that portfolio turnovers vary across strategies, with the highest average turnover reported by the hedging pressure and the lowest being observed in the volatility premia. Interestingly, portfolio turnovers for momentum are considerably lower compared to the US, suggesting that winner (loser) commodities remain as winners (losers) over longer periods of time. This also helps to shed light on the weaker performance of the value premia. As a result, the profits to the long-short strategies are too large to be subsumed by transaction costs. Overall, findings presented in Table 7 highlight the importance of long-short positions in capturing risk premia in Chinese commodity futures. 


\subsubsection{Risks adjustments}

To examine whether the long-short premia can be explained by risk-taking, we employ commodity-specific (Panel A) and standard risk (Panel B) factors in Table 8. Panel A reports the regression results of long-short portfolios in a three-factor model proposed by Bakshi et al. (2019). Bakshi et al. (2019) demonstrate that market, carry and momentum factors are sufficient to describe the cross-sectional variations of commodity futures returns in the US. AVG represents the broad commodity market risk and CARRY is constructed by taking long positions in the five most backwardated commodities and short positions in the five most contangoed commodities. MOM is identical to our momentum premia. Results on both the first and the third nearest contracts are reported.

We first show that the term structure premium loads positively on MOM and AVG, but the intercepts remain significant. This suggests that the term structure premia cannot be fully explained by bearing systematic risks such as the broad market and momentum factors. When regressed on CARRY and AVG, momentum loads positively on CARRY but not AVG, with larger intercepts. This suggests that the predictability of momentum is stronger compared to the term structure, and double-sorting or integration will likely improve the risk-adjusted performance of momentum and term structure strategies. Furthermore, we find that the Bakshi et al. (2019) model cannot adequately explain the dynamics of the volatility strategy on the nearest contracts. While the hedging pressure (volatility) premium loads negatively (positively) on the AVG, neither strategies are related to CARRY or MOM. However, these loadings are not consistent on the third nearest contracts where the model explains their return variations relatively well. In particular, the hedging pressure premia is found to be positively related to momentum. Overall, carry and momentum factors cannot fully explain the long-short premia. 
Our findings are supported by He et al. (2019), who find a three-factor model is not able to fully explain the cross-sectional return variations in China. ${ }^{19}$

Following Bianchi et al. (2016), we conduct additional risk adjustments by employing a six-factor model in Panel B. We augment the model to reflect the market dynamics in China by employing the CSI 300 as the stock market risk (STOCK), Barclays China Aggregate index as a proxy for the bond market (BOND), the sample of commodities in this study as the representative of commodity market factor (AVG), as well as the China unexpected inflation rate (INFSHOCK), RMB effective exchange rate index return (FX), and unexpected industrial production (UIP). Similar to the three-factor model, these broad market and macroeconomic risks are poor at explaining the returns dynamics of long-short portfolios. While the AVG remains significant across the board, more than half of the intercepts remain largely significant and the $R^{2}$ s are generally low. This is with the exception of the HP strategy on the third nearest contracts. The hedging pressure premia is negatively related to the unexpected changes in industrial production.

Although macroeconomic shocks appear to be largely insignificant at explaining the long-short premia, we further investigate the lead-lag relationship through a vector autoregression (VAR) framework. Motivated by Hong and Yogo (2012), we focus on whether risk premia can help gauge the macroeconomic quantities three months ahead. Panel C reports the results on the first lag. Once again, we observe divergent results between the nearest and third nearest contracts. Nevertheless, our findings unveil a consistent positive lead-lag relationship for TS and MOM with the industrial production (IP), while the relationship with inflation is relatively weak. Interestingly, MOM not only exhibits consistent predictability on

\footnotetext{
${ }^{19}$ He et al. (2019) employ a three-factor model similar to our study but replace the MOM factor with a time-series momentum factor (TSMOM). For robustness, they also test a three-factor model with the MOM factor, but do not attain any improvements in cross-sectional pricing.
} 
the IP but also the unexpected IP. This is not entirely surprising as our sample is primarily consists of industrial and chemical commodities. Meanwhile, HP on the third nearest contracts is found to negatively predict both the IP and inflation. These findings suggest that commodity prices in China indeed contain important insights about the Chinese economy.

Overall, the findings presented in Table 8 suggest that the profitability of long-short strategies in China cannot be attributed to commodity-specific, broad markets nor nonetradable macroeconomic risks; however, long-short risk premia can help gauge the movement of Chinese economy in the near term.

\subsubsection{Liquidity, behavioral and sentiment factors}

Previous studies have demonstrated that the liquidity risk explains the momentum profits across asset classes (Sadka, 2006; Asness et al., 2013; Daskalaki, Kostakis, \& Skiadopoulos, 2014). Recently, Bianchi et al. (2016) document that momentum can be largely explained by the anchoring behavior of investors, proxied by the 52-week high. Motivated by these findings, we employ the Amihud Illiquidity factor (AI) and the 52-week high momentum factor (HMOM) in search for an alternative source of observed profits. Table 9 reports these regression results.

Panel A shows that the AI factor alone is unable to explain any premia. However, we find that the term structure and volatility premia exhibit negative exposure to liquidity risks. This confirms that lower liquidity (or higher illiquidity) signals lower (as oppose to higher) expected returns. Panel B reports the results on the behavioral factor. Consistent with Bianchi et al. (2016), the momentum premia is indeed related to the 52-week high momentum in China, with relatively high $R^{2}$ s. Since the intercepts remain large and significant, anchoring bias provides at least a partial explanation for the remarkable profits generated by the momentum strategy. Consistent with our hypothesis, this behavioral bias likely has been amplified in China 
due to the retail-dominance ( $\mathrm{Li}$, Zhang, et al., 2017). However, we fail to detect any significant relationship between the anchoring bias and other types of premia.

In addition to liquidity and behavioral factors, sentiment has been found to be a significant component that influences the broad financial markets. Studies have documented the connections of sentiments with stock returns (Baker \& Wurgler, 2007) and commodity futures returns (Gao \& Süss, 2015; Bianchi et al., 2016). Motivated by these findings, we employ the CBOE Crude Oil Volatility Index (OVX) and AlphaShares Chinese Volatility Index (CHIX) as proxies for market sentiment in China. The OVX measures the market expectation of 30-day volatility of crude oil prices. CHIX measures the implied volatility of options on the FTSE Xinhua China 25 and Hang Seng indices. The results presented in Panels C and D suggest that our observed premia cannot be subsumed by changes in market sentiments. Overall, the findings presented in Table 9 suggest that illiquidity and behavioral factors provide at least a partial explanation for the profitability of long-short strategies in China. Moreover, we find that higher liquidity (or lower illiquidity) leads to higher expected returns.

\subsection{Potential for diversification}

We now proceed to examine whether long-only and long-short strategies can serve as effective tools for diversification and inflation hedging in China. Figure 4 illustrates the pairwise correlations of strategy returns on the third nearest contracts with stocks, bonds and changes in unexpected inflation. First, commodities and stocks boast a significant positive correlation of 42.8\%. Although Basu and Miffre (2013) also estimate a positive correlation between longonly commodity portfolios and the S\&P500, the magnitude is much lower. Moreover, correlations of $9.1 \%$ and $-3.6 \%$ are documented with the unexpected inflation and the bond market, respectively. Yet neither of them is significantly different from zero. This contradicts with the notion that passive commodity vehicles can hedge unexpected inflations (Erb \& 
Harvey, 2006; Gorton \& Rouwenhorst, 2006). However, it may be premature to conclude that the commodity futures in China fail to hedge inflation at the current stage, as Gorton and Rouwenhorst (2006) argue that the inflation-hedging increases at longer horizons.

Nevertheless, for most of the long-short strategies, a zero correlation with the macro and financial variables cannot be rejected at the 5\% level, highlighting their diversification advantage over long-only investments. Moreover, the term structure strategy shows a statistically significant correlation of $26.4 \%$ with the stock market, considerably lower than the long-only portfolio. Interestingly, the hedging pressure strategy reveals a negative correlation with the CSI 300, making it a prime candidate for hedging against adverse movements in Chinese stocks. Overall, findings presented in Figure 4 suggest that long-short strategies are promising for portfolio diversification but not for inflation hedging in China.

Since correlations can be time-dependent, we compute dynamic correlations to address the concerns that unconditional correlations may lead to false conclusions about diversification. Figure 5 exhibits the time-varying correlation between the successful strategies and the Chinese stock market. The correlations are estimated using the ADCC-GARCH model of Cappiello, Engle, and Sheppard (2006). Consistent with previous discussions, the hedging pressure strategy exhibits relatively lower and negative correlations with the stock market compared to the other strategies. Moreover, the correlation between the momentum strategy and stocks is most volatile. Consistent with the previous literature, correlations are generally higher in periods of market stress in China. ${ }^{20}$ To add another dimension to the diversification potential over time, Figure 6 illustrates the performance across market conditions measured by the CSI300. On average, most strategies perform better (worse) during stock market growth (crisis)

\footnotetext{
${ }^{20}$ In addition to the bear markets globally in 2008-2009 and 2011-2012, the Shanghai stock market fell 30 percent in July 2015. The index fell again on 24 August 2015 ("Black Monday") by 8.48 percent. In January 2016, the market experienced another steep sell-off of 18 percent, and trading was halted on 4 January and 7 January 2016.
} 
periods. Confirming the correlation results, the broad market is in sync with the CSI300 from crisis to growth periods, whereas the hedging pressure reveals a reversed pattern. Moreover, the momentum strategy delivers the strongest performance when the market state is neutral, suggesting that momentum is sensitive to market states.

\subsection{Robustness tests}

We conduct an extensive suite of robustness tests including re-estimating long-short premia in the most liquid markets and randomly selected commodity sectors, by varying portfolio breakpoints and testing the likelihood of data-snooping.

To examine whether market liquidity impacts the long-short premia, we exclude the 10 least liquid commodities, sorted by the average trading volume over the sample period (Internet Appendix V). Since the liquidity strategy fails to deliver statistically significant returns, we expect strategies to perform better or at least unaffected when implemented in a more liquid sample. As a result, successful strategies (with the exception of volatility) indeed experience improvements in risk-adjusted returns. The weakened volatility premia imply that compensations to spot price volatility risk are limited to relatively more illiquid commodities. Furthermore, the performance generally deteriorates when position limits and margins are alleviated. While this is consistent with the full sample, the economic profits of momentum strategy remain strong both quantitatively and statistically. This implies that market liquidity matters less to momentum compared to the term structure strategy.

To examine whether the strategy performances are driven by specific sectors, we reevaluate the performance of strategies by excluding an entire sector of commodities at a time (Internet Appendix VI). While most of the unsuccessful strategies remain insignificant, several interesting dynamics emerge. First, the volatility strategy fails to deliver significant returns when grains or oilseeds are excluded, suggesting that the volatility premia is largely driven by 
grains or oilseeds commodities. Second, term structure and momentum premia are unaffected by sector specifications. Notably, the momentum premia are stronger when grains are excluded, suggesting that grains commodities are less prone to price continuation. Overall, the term structure and momentum premia are not due to concentrated allocations to specific commodities, but the volatility premium is sector-specific. These findings are better illustrated in Figure 7, which depicts the percentage of total trades each strategy assigns to every sector.

Finally, we conduct the data-snooping test using the White (2000) Reality Check (RC) and Hansen (2005) Superior Predictive Ability (SPA) test (Internet Appendix VII). The null hypothesis is that the average performance of the benchmark is as small as the minimum average performance across the strategies tested. We perform five groups of tests with block lengths of 2, 10 and 20 months. Within each block length, stationary and circular bootstraps are performed based on 10,000 replications. Overall, our results consistently suggest the success of strategies is not a result of data mining.

\section{Conclusion}

This paper examined the behavior of long-only and an exhaustive list of long-short risk premia in Chinese commodity futures. In the presence of retail-dominance, time-variant margins and strict position limits, the long-only premia are non-existent, whereas cross-sectional term structure and momentum premia are statistically and economically persistent. These premia cannot be attributed to aggregate market risks, none-tradable macroeconomic risks, market sentiments, currency or sample selection, transactions cost and data-snooping. However, illiquidity, anchoring bias, and regulation-induced limits-to-arbitrage provide a partial explanation. We also demonstrated that systematic strategies offer superior diversification benefits for Chinese stocks. Overall, the paper highlights the distinctiveness of the Chinese 
markets compared to the US. However, as China accelerates the liberalization of its capital markets, it remains to be seen whether such dissociation would continue in the future.

Our findings present several policy implications. First, we urge the CSRC to re-classify traders in accordance with their business purposes, in addition to individual and non-individual trading accounts. Similar to the CFTC, the classification may include but not limited to producers, processors, manufacturers, swap dealers and professional-managed money. Second, in order to definitively assess the efficient functioning of derivative markets, we highlight the need to collect and make available the positions data for futures and options contracts in each trading category to improve transparency. Third, as the evidence suggests, the hedging cost is escalated in the front contracts, we call for the exchanges to gradually loosen the position limits and margin requirements approaching delivery months, to better facilitate the effective transfer of risk. Last but not the least, sophisticated institutional investors provide liquidity to hedgers and other speculators, facilitate the efficient discovery of prices and the stabilization of market volatility. Thus, we restress the importance of institutional participation both domestically and internationally in addressing the potential perils of excessive speculation.

\section{Data Availability Statement:}

The data that support the findings of this study are available from the corresponding author upon reasonable request.

\section{References}

Allen, F., Qian, J. Q., \& Qian, M. (2006). China's financial system: past, present and future. In Brandt, L., Rawski, T (Eds.), China's Economic Transition: Origins, Mechanism, and Consequences. Cambridge University Press, Cambridge, UK.

Asness, C. S., Moskowitz, T. J., \& Pedersen, L. H. (2013). Value and momentum everywhere. The Journal of Finance, 68(3), 929-985.

Bai, C.-E., Lu, J., \& Tao, Z. (2006). The multitask theory of state enterprise reform: empirical evidence from China. American Economic Review, 96(2), 353-357. 
Baker, M., \& Wurgler, J. (2007). Investor sentiment in the stock market. The Journal of Economic Perspectives, 21(2), 129-151.

Bakshi, G., Gao, X., \& Rossi, A. G. (2019). Understanding the sources of risk underlying the cross section of commodity returns. Management Science, 65(2), 619-641.

Basu, D., \& Miffre, J. (2013). Capturing the risk premium of commodity futures: The role of hedging pressure. Journal of Banking \& Finance, 37(7), 2652-2664.

Bhardwaj, G., Gorton, G. B., \& Rouwenhorst, K. G. (2016). Investor interest and the returns to commodity investing. The Journal of Portfolio Management, 42(3), 44-55.

Bianchi, R. J., Drew, M. E., \& Fan, J. H. (2015). Combining momentum with reversal in commodity futures. Journal of Banking \& Finance, 59, 423-444.

Bianchi, R. J., Drew, M. E., \& Fan, J. H. (2016). Commodities momentum: A behavioral perspective. Journal of Banking \& Finance, 72, 133-150.

BlackRock. (2018). Factor investing: 2018 landscape. New York, USA: BlackRock.

Bloomberg. (2018a). 46 Million Tons of Apples a Day Keeps the Doctor Away. Retrieved on 16 May 2018 from https://www.bloomberg.com/opinion/articles/2018-05-16/46million-tons-of-apples-a-day-keeps-the-doctor-away

Bloomberg. (2018b). China sets new records for gobbling up the world's commodities. Retrieved on 18 January 2018 from https://www.bloomberg.com/news/articles/201801-12/world-s-commodity-engine-roars-to-another-record-with-xi-at-helm

Boons, M., \& Prado, M. P. (2019). Basis-Momentum. The Journal of Finance, 74(1), 239-279.

Brennan, M. J. (1958). The supply of storage. The American Economic Review, 48(1), 50-72.

Briese, S. (2012). Dodging the Pitfalls in COT Data. In The commitments of traders bible: how to profit from insider market intelligence. John Wiley \& Sons.

Campbell, J. Y., Grossman, S. J., \& Wang, J. (1993). Trading volume and serial correlation in stock returns. The Quarterly Journal of Economics, 108(4), 905-939.

Cappiello, L., Engle, R. F., \& Sheppard, K. (2006). Asymmetric dynamics in the correlations of global equity and bond returns. Journal of Financial Econometrics, 4(4), 537-572.

Chan, K. C., Fung, H.-G., \& Leung, W. K. (2004). Daily volatility behavior in Chinese futures markets. Journal of International Financial Markets, Institutions and Money, 14(5), 491-505.

Chen, G., Kim, K. A., Nofsinger, J. R., \& Rui, O. M. (2007). Trading performance, disposition effect, overconfidence, representativeness bias, and experience of emerging market investors. Journal of Behavioral Decision Making, 20(4), 425-451.

Cheng, I.-H., \& Xiong, W. (2014). Why do hedgers trade so much? The Journal of Legal Studies, 43(S2), S183-S207.

China Futures Association. (2015). China Futures Markets Annual Report: China Futures Association.

China Futures Association. (2016). China Futures Markets Annual Report: China Futures Association.

China Futures Association. (2019). China Futures: China Futures Association. 
Ciner, C. (2002). Information content of volume: An investigation of Tokyo commodity futures markets. Pacific-Basin Finance Journal, 10(2), 201-215.

Citi Group. (2016). China Commodities. China: Citi Group.

Cootner, P. H. (1960). Returns to speculators: Telser versus Keynes. Journal of Political Economy, 68(4), 396-404.

Daskalaki, C., Kostakis, A., \& Skiadopoulos, G. (2014). Are there common factors in individual commodity futures returns? Journal of Banking \& Finance, 40(1), 346-363.

De Long, J. B., Shleifer, A., Summers, L. H., \& Waldmann, R. J. (1990). Noise trader risk in financial markets. Journal of Political Economy, 98(4), 703-738.

De Roon, F. A., Nijman, T. E., \& Veld, C. (2000). Hedging pressure effects in futures markets. The Journal of Finance, 55(3), 1437-1456.

Demirer, R., Lien, D., \& Zhang, H. (2015). Industry herding and momentum strategies. PacificBasin Finance Journal, 32, 95-110.

Dhume, D. (2011). Essays on measuring and explaining commodities returns. PhD Thesis. Harvard University.

Duong, H. N., \& Kalev, P. S. (2008). The Samuelson hypothesis in futures markets: An analysis using intraday data. Journal of Banking \& Finance, 32(4), 489-500.

Erb, C. B., \& Harvey, C. R. (2006). The strategic and tactical value of commodity futures. Financial Analysts Journal, 62(2), 69-97.

Fan, J. H., Mo, D., \& Zhang, T. (2019). The 'Necessary Evil' in Chinese Commodity Markets. working paper. Griffith University. https://ssrn.com/abstract=3459898

Fan, J. H., Fernandez-Perez, A., Fuertes, A.-M., \& Miffre, J. (2020). Speculative pressure. Journal of Futures Markets. forthcoming.

Fernandez-Perez, A., Frijns, B., Fuertes, A.-M., \& Miffre, J. (2018). The skewness of commodity futures returns. Journal of Banking \& Finance, 86, 143-158.

FT. (2017). China commodities slip as copper sell-off continues. Retrieved on 15 December 2017 from https://www.ft.com/content/c31602a4-aabf-3eb2-9b97-80bc8811974b

Fuertes, A.-M., Miffre, J., \& Rallis, G. (2010). Tactical allocation in commodity futures markets: Combining momentum and term structure signals. Journal of Banking \& Finance, 34(10), 2530-2548.

Fuertes, A. M., Miffre, J., \& Fernandez-Perez, A. (2015). Commodity strategies based on momentum, term structure, and idiosyncratic volatility. Journal of Futures Markets, 35(3), 274-297.

Fung, H.-G., Leung, W. K., \& Xu, X. E. (2003). Information flows between the US and China commodity futures trading. Review of Quantitative Finance and Accounting, 21(3), 267-285.

Fung, H.-G., Tse, Y., Yau, J., \& Zhao, L. (2013). A leader of the world commodity futures markets in the making? The case of China's commodity futures. International Review of Financial Analysis, 27, 103-114.

Gao, L., \& Süss, S. (2015). Market sentiment in commodity futures returns. Journal of Empirical Finance, 33(1), 84-103. 
Gârleanu, N., \& Pedersen, L. H. (2011). Margin-based Asset Pricing and Deviations from the Law of One Price. The Review of Financial Studies, 24(6), 1980-2022.

Gilbert, S., Jones, S. K., \& Morris, G. H. (2006). The impact of skewness in the hedging decision. Journal of Futures Markets, 26(5), 503-520.

Gorton, G., \& Rouwenhorst, K. G. (2006). Facts and fantasies about commodity futures. Financial Analysts Journal, 62(2), 47-68.

Gorton, G. B., Hayashi, F., \& Rouwenhorst, K. G. (2013). The fundamentals of commodity futures returns. Review of Finance, 17(1), 35-105.

Griffin, J. M., Harris, J. H., \& Topaloglu, S. (2003). The dynamics of institutional and individual trading. The Journal of Finance, 58(6), 2285-2320.

Grinblatt, M., \& Keloharju, M. (2000). The investment behavior and performance of various investor types: a study of Finland's unique data set. Journal of Financial Economics, 55(1), 43-67.

Ham, H., Cho, H., Kim, H., \& Ryu, D. (2019). Time-series momentum in China's commodity futures market. Journal of Futures Markets. forthcoming.

Hammoudeh, S., Nguyen, D. K., Reboredo, J. C., \& Wen, X. (2014). Dependence of stock and commodity futures markets in China: implications for portfolio investment. Emerging Markets Review, 21, 183-200.

Hansen, P. R. (2005). A test for superior predictive ability. Journal of Business \& Economic Statistics, 23(4), 365-380.

He, C., Jiang, C., \& Molyboga, M. (2019). Risk premia in Chinese commodity markets. Journal of Commodity Markets, 15, 100075.

Hedegaard, E. (2014). Causes and consequences of margin levels in futures markets. working paper. Arizona State University.

Hicks, J. R. (1939). Value and capital. Oxford University Press.

Hirshleifer, D. (1989). Determinants of hedging and risk premia in commodity futures markets. Journal of Financial and Quantitative Analysis, 24(3), 313-331.

Hirshleifer, D. (1990). Hedging pressure and futures price movements in a general equilibrium model. Econometrica: Journal of the Econometric Society, 58(2), 411-428.

Hong, H., \& Yogo, M. (2012). What does futures market interest tell us about the macroeconomy and asset prices? Journal of Financial Economics, 105(3), 473-490.

Invesco. (2017). Invesco global factor investing study 2017. Atlanta, Georgia, USA: Invesco.

Janardanan, R., Qiao, X., \& Rouwenhorst, K. G. (2019). On commodity price limits. Journal of Futures Markets. forthcoming.

Jiang, Y., Ahmed, S., \& Liu, X. (2017). Volatility forecasting in the Chinese commodity futures market with intraday data. Review of Quantitative Finance and Accounting, 48(4), 1123-1173.

Kaldor, N. (1939). Speculation and economic stability. The Review of Economic Studies, 7(1), $1-27$.

Kang, J., \& Kwon, K. Y. (2017). Momentum in international commodity futures markets. Journal of Futures Markets, 37(8), 803-835. 
Kang, J., Liu, M.-H., \& Ni, S. X. (2002). Contrarian and momentum strategies in the China stock market: 1993-2000. Pacific-Basin Finance Journal, 10(3), 243-265.

Keynes, J. M. (1930). A Treatise on Money. London. Macmillan.

Li, B., Zhang, D., \& Zhou, Y. (2017). Do trend following strategies work in Chinese futures markets? Journal of Futures Markets, 37(12), 1226-1254.

Li, D., Nguyen, Q. N., Pham, P. K., \& Wei, S. X. (2011). Large foreign ownership and firmlevel stock return volatility in emerging markets. Journal of Financial and Quantitative Analysis, 46(4), 1127-1155.

Li, W., Rhee, G., \& Wang, S. S. (2017). Differences in herding: Individual vs. institutional investors. Pacific-Basin Finance Journal, 45, 174-185.

Liu, Q., \& An, Y. (2011). Information transmission in informationally linked markets: Evidence from US and Chinese commodity futures markets. Journal of International Money and Finance, 30(5), 778-795.

Liu, Q., Tse, Y., \& Zhang, L. (2018). Including commodity futures in asset allocation in China. Quantitative Finance, 18(9), 1487-1499.

Lucia, J. J., \& Pardo, A. (2010). On measuring speculative and hedging activities in futures markets from volume and open interest data. Applied Economics, 42(12), 1549-1557.

Marshall, B. R., Nguyen, N. H., \& Visaltanachoti, N. (2012). Commodity liquidity measurement and transaction costs. The Review of Financial Studies, 25(2), 599-638.

Miffre, J., \& Rallis, G. (2007). Momentum strategies in commodity futures markets. Journal of Banking \& Finance, 31(6), 1863-1886.

Nofsinger, J. R., \& Sias, R. W. (1999). Herding and feedback trading by institutional and individual investors. The Journal of Finance, 54(6), 2263-2295.

RBA. (2017). Underlying consumer price inflation in China. Reserve Bank of Australia. Retrieved from https://www.rba.gov.au/publications/bulletin/2017/dec/pdf/bu-1217-4underlying-consumer-price-inflation-in-china.pdf.

Robles, M., Torero, M., \& Von Braun, J. (2009). When speculation matters. International Food Policy Research Institute. Washington, DC.

Sadka, R. (2006). Momentum and post-earnings-announcement drift anomalies: The role of liquidity risk. Journal of Financial Economics, 80(2), 309-349.

Samuelson, P. A. (1965). Proof that properly anticipated prices fluctuate randomly. Industrial Management Review, 6(2), 41-49.

Stulz, R. M. (1996). Rethinking risk management. Journal of Applied Corporate Finance, 9(3), 8-25.

Szymanowska, M., de Roon, F. A., Nijman, T. E., \& van den Goorbergh, R. W. J. (2014). An anatomy of commodity futures risk premia. The Journal of Finance, 69(1), 453-482.

Tian, F., Yang, K., \& Chen, L. (2017). Realized volatility forecasting of agricultural commodity futures using the HAR model with time-varying sparsity. International Journal of Forecasting, 33(1), 132-152.

Tu, Z., Song, M., \& Zhang, L. (2013). Emerging impact of Chinese commodity futures market on domestic and global economy. China \& World Economy, 21(6), 79-99. 
VisualCapitalist. (2018). China's staggering demand for commodities. Retrieved on 10 May 2018 from http://www.visualcapitalist.com/chinas-staggering-demand-commodities/

Wang, X. L., Shi, K., \& Fan, H. X. (2006). Psychological mechanisms of investors in Chinese Stock Markets. Journal of Economic Psychology, 27(6), 762-780.

Webb, R. I. (1995). Futures trading in less ‘noisy' markets. Japan \& The World Economy, 7(2), 155-173.

Wellenreuther, C., \& Voelzke, J. (2019). Speculation and volatility-A time-varying approach applied on Chinese commodity futures markets. Journal of Futures Markets, 39(4), 405-417.

White, H. (2000). A reality check for data snooping. Econometrica, 68(5), 1097-1126.

Williams, J., Peck, A., Park, A., \& Rozelle, S. (1998). The emergence of a futures market: Mungbeans on the China Zhengzhou Commodity Exchange. The Journal of Futures Markets, 18(4), 427.

Willis Towers Watson. (2017). The world's 500 largest asset managers. London, United Kingdom: Willis Towers Watson.

Working, H. (1949). The theory of price of storage. The American Economic Review, 39(6), 1254-1262.

WSJ. (2016). Chinese traders roil commodity markets. Retrieved on 20 August 2017 from https://www.wsj.com/articles/chinese-traders-roil-commodity-markets-1470698606

Xin, Y., Chen, G., \& Firth, M. (2006). The efficiency of the Chinese commodity futures markets: development and empirical evidence. China \& World Economy, 14(2), 7992.

Yang, J., Yang, Z., \& Zhou, Y. (2012). Intraday price discovery and volatility transmission in stock index and stock index futures markets: Evidence from China. Journal of Futures Markets, 32(2), 99-121.

Zhang, F., \& Pan, Z. (2004). Determination of China's long-run nominal exchange rate and official intervention. China Economic Review, 15(3), 360-365.

Zhao, Y., \& Wan, D. (2018). Institutional high frequency trading and price discovery: Evidence from an emerging commodity futures market. Journal of Futures Markets, 38(2), 243270.

\section{Data Citation:}

[Chinese Futures markets data]; Not publicly available; data set can be acquired paying a data license fee in Thomson Reuters Datastream.

[US Futures markets data]; Not publicly available; data set can be acquired paying a data license fee in Commodity Research Bureau (CRB).

[Macroeconomic data]; Not publicly available; data set can be acquired by paying a data license fee in Bloomberg.

[Commitment of Traders reports]; Publicly available; data set can be obtained from Commodity Futures Trading Commission (CFTC) website (https://www.cftc.gov/data). 


\section{Appendix A Sorting variables}

\begin{tabular}{|c|c|c|c|c|}
\hline Premia & Acronym & Signals & Definition & References \\
\hline Term Structure & $\mathrm{TS}$ & $\operatorname{Roll}_{i, t}=\operatorname{LN}\left(F_{i t, F r o n t}\right)-\operatorname{LN}\left(F_{i t, 2}\right)$ & $\begin{array}{l}F_{i t, F r o n t} \text { represents the price of the front contract for commodity } i \text { at } \\
\text { time } t \text {, and } F_{i t, 2} \text { denotes the price of the second nearest contract of } \\
\text { commodity } i \text { at time } t\end{array}$ & $\begin{array}{l}\text { Erb \& Harvey (2006); Gorton \& } \\
\text { Rouwenhorst (2006); Bakshi et al. (2019) }\end{array}$ \\
\hline Hedging Pressure & HP & Ratio $_{i, t}^{\text {Hedge }}=\frac{\left|\Delta O I_{i, t}\right|}{\operatorname{Vol}_{i, t}}$ & $\begin{array}{l}\Delta O I_{i, t} \text { denotes the change of monthly open interest for commodity } i \text { at } \\
\text { time } t \text {, and } V o l_{i, t} \text { denotes the total monthly volume of commodity } i \text { at } \\
\text { time } t \text {. The hedging ratio ranges from } 0 \text { to } 1 .\end{array}$ & $\begin{array}{l}\text { Bessembinder (1992); De Roon et al. } \\
\text { (2000); Basu \& Miffre (2013) }\end{array}$ \\
\hline Momentum & MOM & $M O M_{i, t}=\left(\frac{1}{12}\right) \sum_{j=0}^{11} r_{i, t-j}$ & $r_{i, t-j}$ denotes the log return of commodity $i$ in the month $t-j$. & $\begin{array}{l}\text { Erb \& Harvey (2006); Miffre \& Rallis } \\
\text { (2007); Asness et al. (2013) }\end{array}$ \\
\hline Volatility & VOLA & $C V_{i, t}=\frac{\sigma^{2}{ }_{i, t}}{\left|\mu_{i, t}\right|}$ & $\begin{array}{l}\sigma^{2}{ }_{i, t} \text { denotes the variance of front contract (daily return) for } \\
\text { commodity } i \text { at time } t \text { over the past } 36 \text { months, and }\left|\mu_{i, t}\right| \text { represents the } \\
\text { absolute value of the prior 36-month average daily return at time } t \text {. }\end{array}$ & $\begin{array}{l}\text { Dhume (2011); Szymanowska et al. } \\
\text { (2014); Fernandez-Perez, Fuertes, \& } \\
\text { Miffre (2019). }\end{array}$ \\
\hline Open Interest & OI & $\Delta O I_{\Delta i, t}=O I_{i, t}-O I_{i, t-1}$ & $\begin{array}{l}O I_{i, t} \text { represents the aggregate open interests along the futures curve of } \\
\text { commodity } i \text { at time } t\end{array}$ & $\begin{array}{l}\text { Hong \& Yogo (2012); Szymanowska et } \\
\text { al. (2014) }\end{array}$ \\
\hline Liquidity & LIQ & Amivest $_{i, t}=\frac{1}{D} \sum \frac{V o l_{i, d}}{\left|r_{i, d}\right|}$ & $\begin{array}{l}V o l_{i, d} \text { and } r_{i, d} \text { denote the daily RMB volume and return of commodity } \\
i \text { at time } d, \text { respectively. } D \text { is the number of days in the past } 2 \text { months }\end{array}$ & $\begin{array}{l}\text { Marshall et al. (2012); Szymanowska et } \\
\text { al. (2014) }\end{array}$ \\
\hline Currency & FX & $\beta_{i, t}^{F X}=\frac{\operatorname{Cov}\left(r_{i, t(42)}, r_{F X, t(42)}\right)}{\operatorname{Var}\left(r_{F X, t(42)}\right)}$ & $\begin{array}{l}r_{i, t(42)} \text { is the prior } 42 \text { monthly returns of commodity } i \text { at time } t, \\
r_{F X, t(42)} \text { represents the prior } 42 \text { monthly effective RMB exchange } \\
\text { index returns at time } t . \operatorname{Cov}\left(r_{i, t(42)}, r_{F X, t(42)}\right) \text { denotes the covariance } \\
\text { and } \operatorname{Var}\left(r_{F X, t(42)}\right) \text { is the variance of } r_{F X, t(42)} \text {. }\end{array}$ & $\begin{array}{l}\text { Erb \& Harvey (2006); Szymanowska et } \\
\text { al. (2014) }\end{array}$ \\
\hline Inflation & INF & $\beta_{i, t}^{I N F}=\frac{\operatorname{Cov}\left(r_{i, t(42)}, r_{c, t(42)}\right)}{\operatorname{Var}\left(r_{c, t(42)}\right)}$ & $\begin{array}{l}r_{i, t(42)} \text { is the prior } 42 \text { monthly returns of commodity } i \text { at time } t, \\
r_{I N F, t(42)} \text { represents the prior } 42 \text { monthly unexpected inflation rates at } \\
\text { time } t . \operatorname{Cov}\left(r_{i, t(42)}, r_{I N F, t(42)}\right) \text { denotes the covariance and } \\
\operatorname{Var}\left(r_{I N F, t(42)}\right) \text { is the variance of } r_{I N F, t(42)} \text {. }\end{array}$ & $\begin{array}{l}\text { Bodie \& Rosansky (1980); Erb \& Harvey } \\
\text { (2006); Gorton \& Rouwenhorst (2006); } \\
\text { Szymanowska et al. (2014) }\end{array}$ \\
\hline Skewness & SKEW & $\operatorname{Skew}_{i, t}=\frac{\frac{1}{D} \sum_{d=1}^{D}\left(r_{i, d}-\mu_{i, t}\right)^{3}}{\sigma_{i, t}^{3}}$ & $\begin{array}{l}r_{i, d} \text { denotes the daily return of commodity } i \text { at time } d, \mu_{i} \text { represents the } \\
\text { prior } 12 \text {-month average daily return of commodity } i \text { at time } t \text {, } \\
\sigma_{i} \text { stands for the standard deviation of the past } 12 \text {-month daily return } \\
\text { at time } t \text {, and } \mathrm{D} \text { is the number of days in the past } 12 \text { months }\end{array}$ & Fernandez-Perez et al. (2018) \\
\hline Value & VAL & Value $_{i, t}=\ln \frac{\frac{1}{D} \sum_{d=1}^{D} F_{i, d}}{F_{i, t}}$ & $\begin{array}{l}\text { value }_{i, t} \text { is the } \log \text { of the average daily price of commodity } i \text { from } 3.5 \\
\text { to } 4.5 \text { years ago divided by the price at time } t \text {, and } D \text { is the number of } \\
\text { days between } 3.5 \text { and } 4.5 \text { years ago }\end{array}$ & $\begin{array}{l}\text { Asness } \text { et al. (2013); Fernandez-Perez et } \\
\text { al. (2019) }\end{array}$ \\
\hline
\end{tabular}




\section{Table 1 Contracts specification}

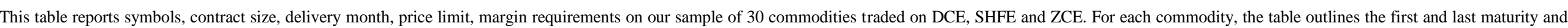

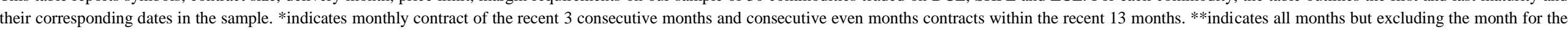
Chinese New Year holiday. *** indicates delivery months of 1,3,5,7,9,11, and all months after the 2018 May contract.

\begin{tabular}{|c|c|c|c|c|c|c|c|c|c|c|c|}
\hline Exchange & Sector & Commodity & Symbol & Contract Size & Delivery Month & Price Limit & Margin & First Contract & First Price Date & End Contract & End Price Date \\
\hline$\overline{\text { DCE }}$ & Grains & No.1 Soybean & $\mathrm{A}$ & 10 Tons/Contract & $1,3,5,7,9,11$ & $\pm 4 \%$ & $5 \%$ & 2003 Mar & $2002 / 03 / 29$ & 2017 May & $2017 / 04 / 28$ \\
\hline DCE & Grains & No.2 Soybean & $\mathrm{B}$ & 10 Tons/Contract & $* * *$ & $\pm 4 \%$ & $5 \%$ & 2005 July & $2004 / 12 / 31$ & 2017 May & $2017 / 04 / 28$ \\
\hline DCE & Grains & Corn & $\mathrm{C}$ & 10 Tons/Contract & $1,3,5,7,9,11$ & $\pm 4 \%$ & $5 \%$ & 2005 Jan & $2004 / 09 / 30$ & 2017 May & $2017 / 04 / 28$ \\
\hline DCE & Industrial & LLDPE & $\mathrm{L}$ & 5 Tons/Contract & all & $\pm 4 \%$ & $5 \%$ & 2007 Oct & $2007 / 07 / 31$ & 2017 June & $2017 / 05 / 31$ \\
\hline DCE & Industrial & $\mathrm{PVC}$ & $\mathrm{V}$ & 5 Tons/Contract & all & $\pm 4 \%$ & $5 \%$ & 2009 Sep & $2009 / 05 / 29$ & 2017 June & $2017 / 05 / 31$ \\
\hline DCE & Industrial & Metallurgical Coke & $\mathrm{J}$ & 100 Tons/Contract & all & $\pm 4 \%$ & $5 \%$ & $2011 \mathrm{Sep}$ & $2011 / 04 / 29$ & 2017 June & $2017 / 05 / 31$ \\
\hline DCE & Industrial & Coking Coal & $\mathrm{JM}$ & 60 Tons/Contract & all & $\pm 4 \%$ & $5 \%$ & 2013 July & $2013 / 03 / 29$ & 2017 June & $2017 / 05 / 31$ \\
\hline DCE & Oil Seeds & Soybean Meal & M & 10 Tons/Contract & $1,3,5,7,8,9,11,12$ & $\pm 4 \%$ & $5 \%$ & $2000 \mathrm{Nov}$ & $2000 / 07 / 31$ & 2017 May & $2017 / 04 / 28$ \\
\hline DCE & Oil Seeds & RBD Palm Olein & $\mathrm{P}$ & 10 Tons/Contract & all & $\pm 4 \%$ & $5 \%$ & 2008 Jan & $2007 / 10 / 31$ & 2017 June & $2017 / 05 / 31$ \\
\hline DCE & Oil Seeds & Soybean Oil & $\mathrm{Y}$ & 10 Tons/Contract & $1,3,5,7,8,9,11,12$ & $\pm 4 \%$ & $5 \%$ & $2006 \mathrm{Mar}$ & $2006 / 01 / 31$ & 2017 May & $2017 / 04 / 28$ \\
\hline SHFE & Energy & Fuel Oil & $\mathrm{FU}$ & 50 Tons/Contract & ** & $\pm 5 \%$ & $8 \%$ & 2005 Jan & $2004 / 08 / 31$ & 2017 June & $2017 / 05 / 31$ \\
\hline SHFE & Industrial & Natural Rubber & RU & 10 Ton/Contract & $1,3,4,5,6,7,8,9,10,11$ & $\pm 3 \%$ & $5 \%$ & $1995 \mathrm{Sep}$ & $1995 / 07 / 31$ & 2017 June & $2017 / 05 / 31$ \\
\hline SHFE & Metal & Aluminum & $\mathrm{AL}$ & 5 Tons/Contract & all & $\pm 3 \%$ & $5 \%$ & $1994 \mathrm{Feb}$ & $1993 / 11 / 30$ & 2017 June & $2017 / 05 / 31$ \\
\hline SHFE & Metal & Gold & $\mathrm{AU}$ & 1 Kilogram/Contract & * & $\pm 3 \%$ & $4 \%$ & 2008 June & $2008 / 01 / 31$ & 2017 June & $2017 / 05 / 31$ \\
\hline SHFE & Metal & Copper & $\mathrm{CU}$ & 5 Tons/Contract & all & $\pm 3 \%$ & $5 \%$ & 1993 June & $1993 / 05 / 31$ & 2017 June & $2017 / 05 / 31$ \\
\hline SHFE & Metal & Lead & PB & 5 Tons/Contract & all & $\pm 4 \%$ & $5 \%$ & 2011 Sep & $2011 / 03 / 31$ & 2017 June & $2017 / 05 / 31$ \\
\hline SHFE & Metal & Steel Rebar & $\mathrm{RB}$ & 10 Tons/Contract & all & $\pm 3 \%$ & $5 \%$ & 2009 Sep & $2009 / 03 / 31$ & 2017 June & $2017 / 05 / 31$ \\
\hline SHFE & Metal & Steel Wire Rod & WR & 10 Ton/Contract & all & $\pm 5 \%$ & $7 \%$ & 2009 Sep & $2009 / 03 / 31$ & 2017 June & $2017 / 05 / 31$ \\
\hline SHFE & Metal & Zinc & $\mathrm{ZN}$ & 5 Tons/Contract & all & $\pm 4 \%$ & $5 \%$ & 2007 July & $2007 / 03 / 30$ & 2017 June & $2017 / 05 / 31$ \\
\hline SHFE & Metal & Silver & AG & 15 Kilograms/Contract & all & $\pm 3 \%$ & $4 \%$ & $2012 \mathrm{Sep}$ & $2012 / 05 / 31$ & 2017 June & $2017 / 05 / 31$ \\
\hline ZCE & Energy & Methanol & MA & 10 Tons/Contract & all & $\pm 4 \%$ & $5 \%$ & 2012 Mar & $2011 / 10 / 31$ & 2017 June & $2017 / 05 / 31$ \\
\hline ZCE & Grains & White Sugar & SR & 10 Tons/Contract & $1,3,5,7,9,11$ & $\pm 4 \%$ & $6 \%$ & 2006 May & $2006 / 01 / 31$ & 2017 May & $2017 / 04 / 28$ \\
\hline $\mathrm{ZCE}$ & Grains & Strong Gluten Wheat & WH & 20 Tons/Contract & $1,3,5,7,9,11$ & $\pm 4 \%$ & $5 \%$ & 2003 May & $2003 / 03 / 31$ & 2017 May & $2017 / 04 / 28$ \\
\hline $\mathrm{ZCE}$ & Grains & Common Wheat & $\mathrm{PM}$ & 50 Tons/Contract & $1,3,5,7,9,11$ & $\pm 4 \%$ & $5 \%$ & 1994 Jan & $1993 / 12 / 31$ & 2017 May & $2017 / 04 / 28$ \\
\hline ZCE & Industrial & Cotton No.1 & $\mathrm{CF}$ & 5 Tons/Contract & $1,3,5,7,9,11$ & $\pm 4 \%$ & $5 \%$ & 2004 Nov & $2004 / 06 / 30$ & 2017 May & $2017 / 04 / 28$ \\
\hline $\mathrm{ZCE}$ & Industrial & PTA & $\mathrm{TA}$ & 5 Tons/Contract & all & $\pm 4 \%$ & $5 \%$ & $2007 \mathrm{Feb}$ & $2006 / 12 / 29$ & 2017 June & $2017 / 05 / 31$ \\
\hline ZCE & Industrial & Flat Glass & FG & 20 Tons/Contract & all & $\pm 4 \%$ & $5 \%$ & 2013 Mar & $2012 / 12 / 31$ & 2017 June & $2017 / 05 / 31$ \\
\hline ZCE & Oil Seeds & Rapeseed Oil & OI & 10 Tons/Contract & $1,3,5,7,9,11$ & $\pm 4 \%$ & $5 \%$ & 2007 July & $2007 / 06 / 29$ & 2017 May & $2017 / 04 / 28$ \\
\hline $\mathrm{ZCE}$ & Oil Seeds & Rapeseed Meal & $\mathrm{RM}$ & 10 Tons/Contract & $1,3,5,7,8,9,11$ & $\pm 4 \%$ & $5 \%$ & 2013 May & $2012 / 12 / 31$ & 2017 May & $2017 / 04 / 28$ \\
\hline ZCE & Oil Seeds & Rapeseed & $\mathrm{RS}$ & 10 Tons/Contract & $7,8,9,11$ & $\pm 4 \%$ & $5 \%$ & 2013 July & $2012 / 12 / 31$ & 2016 Nov & $2016 / 10 / 31$ \\
\hline
\end{tabular}


Table 2 Summary statistics

This table reports the summary statistics. We compute annualized returns (Panel A), standard deviations (Panel B), trading volume (Panel C) and Amihud illiquidity for returns on $m^{\text {th }}$ nearest to maturity contracts, where $m=1,2,3$ and 4 . Trading volume (expressed in thousands) is the monthly average number of contracts traded. The Amihud illiquidity (AI) measure is defined as Amihud (2002), where AI is the ratio of returns by turnover (=price x contract size x volume) in RMB. AI is expressed in basis point per one-million-RMB trade. Diff reports the difference between the front and the third nearest contracts. Sig denotes the $p$-values of the difference-in-mean tests. Bold indicates significance at $10 \%$ or better. The sample period covers February 2004 to May 2017.

\begin{tabular}{|c|c|c|c|c|c|c|c|c|c|c|c|c|c|}
\hline \multirow[b]{2}{*}{ Sectors } & \multirow[b]{2}{*}{ Commodities } & \multicolumn{4}{|c|}{$m^{\text {th }}$ nearest contract } & \multirow[b]{2}{*}{ Diff } & \multirow[b]{2}{*}{ Sig } & \multicolumn{5}{|c|}{$m^{\text {th }}$ nearest contract } & \multirow[b]{2}{*}{ Sig } \\
\hline & & $1^{\text {st }}$ & $2^{\text {nd }}$ & $3^{\text {rd }}$ & $4^{\text {th }}$ & & & $1^{\mathrm{st}}$ & $2^{\text {nd }}$ & $3^{\text {rd }}$ & $4^{\text {th }}$ & Diff & \\
\hline & & \multicolumn{4}{|c|}{ Panel A: Annualized returns (\%) } & & & \multicolumn{4}{|c|}{ Panel B: Annualized standard (\%) } & & \\
\hline \multirow[t]{2}{*}{ Energy } & Methanol & -12.8 & -7.5 & -9.2 & -4.9 & -4.10 & 0.69 & 27.1 & 24.4 & 22.9 & 22.9 & -1.32 & 0.12 \\
\hline & Fuel Oil & -11.3 & -5.9 & -0.7 & -7.2 & -10.05 & 0.93 & 32.5 & 28.8 & 27.5 & 28.0 & -0.43 & 0.36 \\
\hline Grains & Sugar & -0.9 & -2.3 & -4.2 & -3.7 & 3.75 & 0.07 & 19.7 & 19.2 & 20.2 & 20.6 & -0.92 & 0.00 \\
\hline & Strong Wheat & -9.5 & -6.9 & -6.7 & -5.0 & -2.18 & 0.81 & 12.0 & 10.5 & 9.9 & 10.3 & 0.84 & 0.98 \\
\hline & Common Wheat & -16.1 & -9.3 & -5.6 & -3.3 & -11.63 & 1.00 & 12.9 & 10.1 & 9.6 & 9.5 & 1.91 & 1.00 \\
\hline & No.1 Soybean & -4.2 & -0.1 & 3.6 & 1.7 & -6.59 & 0.98 & 16.4 & 14.8 & 16.3 & 16.8 & -1.37 & 0.00 \\
\hline & No.2 Soybean & 8.7 & 3.7 & 5.6 & 3.0 & 3.18 & 0.25 & 20.6 & 15.8 & 16.3 & 18.3 & 1.47 & 0.97 \\
\hline & Corn & -4.6 & -1.5 & -0.3 & -1.9 & -4.61 & 0.95 & 13.1 & 11.1 & 10.1 & 11.0 & 0.23 & 0.73 \\
\hline Oilseeds & Rapeseed Oil & -6.0 & -4.4 & -2.3 & -5.5 & -1.60 & 0.66 & 17.8 & 19.7 & 21.4 & 22.0 & -9.09 & 0.15 \\
\hline & Rapeseed Meal & 11.5 & 11.6 & 11.4 & 9.6 & 0.63 & 0.47 & 27.9 & 22.9 & 22.5 & 20.5 & 0.72 & 0.88 \\
\hline & Rapeseed & -3.9 & -5.0 & -10.5 & -6.1 & 5.47 & 0.18 & 12.2 & 12.9 & 14.9 & 17.3 & -3.06 & 0.00 \\
\hline & Soybean Meal & 11.9 & 10.5 & 7.9 & 6.4 & 5.10 & 0.06 & 24.1 & 21.5 & 21.8 & 21.3 & -0.23 & 0.28 \\
\hline & Palm Olein & -12.4 & -16.9 & -9.6 & -6.0 & -3.68 & 0.74 & 23.2 & 27.2 & 26.1 & 25.9 & 0.65 & 0.77 \\
\hline & Soybean Oil & -1.1 & -1.6 & 0.9 & 0.8 & -0.19 & 0.52 & 23.5 & 22.5 & 22.4 & 22.1 & 1.69 & 1.00 \\
\hline Industrial & Cotton & -2.0 & -2.0 & -2.4 & -1.8 & 0.14 & 0.48 & 18.4 & 17.7 & 18.0 & 17.9 & -1.18 & 0.00 \\
\hline & Flat Glass & 9.2 & 9.8 & 3.1 & -0.4 & 5.33 & 0.29 & 25.9 & 16.5 & 17.7 & 15.8 & 3.45 & 1.00 \\
\hline & Natural Rubber & -7.7 & -5.0 & -4.8 & -5.6 & -1.12 & 0.67 & 30.5 & 31.5 & 32.3 & 32.2 & -2.07 & 0.00 \\
\hline & LLDPE & 3.6 & -1.0 & -2.1 & -4.0 & 5.47 & 0.12 & 28.5 & 28.6 & 28.8 & 31.7 & -1.13 & 0.03 \\
\hline & PVC & -10.6 & -3.9 & -3.8 & -5.0 & -5.98 & 0.87 & 16.0 & 17.4 & 18.2 & 17.2 & -0.57 & 0.26 \\
\hline & PTA & -7.6 & -9.0 & -9.3 & -6.3 & 2.06 & 0.15 & 26.0 & 25.1 & 25.2 & 23.7 & -2.16 & 0.08 \\
\hline & Coking Coke & -13.7 & -12.9 & -13.0 & -5.9 & 0.17 & 0.49 & 36.8 & 32.0 & 31.9 & 31.6 & 0.70 & 0.65 \\
\hline & Coking Coal & 10.5 & -9.5 & 3.8 & -3.2 & 7.84 & 0.21 & 32.0 & 25.3 & 29.2 & 27.3 & -0.99 & 0.27 \\
\hline Metal & Aluminum & -2.1 & -2.7 & -3.2 & -2.7 & 1.13 & 0.14 & 15.5 & 15.0 & 15.0 & 15.2 & -0.83 & 0.00 \\
\hline & Gold & 1.3 & 1.0 & -2.8 & 6.4 & 1.40 & 0.24 & 19.7 & 19.3 & 19.5 & 19.0 & 1.16 & 0.99 \\
\hline & Copper & 10.3 & 11.2 & 9.2 & 8.5 & 1.64 & 0.07 & 28.4 & 28.9 & 29.5 & 29.9 & -0.97 & 0.00 \\
\hline & Lead & -3.7 & -3.1 & -2.1 & -2.1 & -0.08 & 0.52 & 20.3 & 20.2 & 20.0 & 19.8 & -0.40 & 0.05 \\
\hline & Steel Rebar & -7.8 & -7.5 & -6.3 & -3.5 & -3.90 & 0.84 & 28.3 & 24.3 & 23.3 & 23.4 & 0.42 & 0.84 \\
\hline & Steel Wire Rod & -11.3 & -5.3 & -2.0 & -7.6 & -9.53 & 0.96 & 15.3 & 17.8 & 18.4 & 16.5 & -3.79 & 0.00 \\
\hline & Zinc & -4.9 & -6.2 & -5.8 & -5.6 & 1.04 & 0.14 & 26.9 & 27.2 & 27.6 & 27.8 & -0.50 & 0.00 \\
\hline & Silver & -13.0 & -11.8 & -10.6 & -8.7 & -0.27 & 0.58 & 23.9 & 24.3 & 24.6 & 25.1 & -0.04 & 0.45 \\
\hline & & Panel & :Tradir & volume & & & & Panel D: $A$ & hud illiq & ity & & & \\
\hline Energy & Methanol & 391 & 3034 & 4301 & 4374 & -4710 & 0.04 & 917.6 & 777.6 & 335.5 & 723.3 & 576.3 & 0.03 \\
\hline & Fuel Oil & 100 & 655 & 965 & 87 & -1016 & 0.00 & 211.7 & 57.7 & 151.1 & 160.3 & 24.7 & 0.38 \\
\hline Grains & Sugar & 932 & 3739 & 7263 & 6005 & -6382 & 0.00 & 1.8 & 1.8 & 2.2 & 2.4 & -0.6 & 0.79 \\
\hline & Strong Wheat & 70 & 364 & 830 & 681 & -776 & 0.00 & 43.2 & 20.7 & 31.6 & 33.7 & -2.9 & 0.66 \\
\hline & Common Wheat & 9 & 20 & 64 & 50 & -56 & 0.02 & 240.5 & 101.0 & 68.2 & 106.9 & 131.1 & 0.05 \\
\hline & No.1 Soybean & 287 & 1229 & 2253 & 1553 & -1992 & 0.00 & 6.0 & 9.1 & 12.3 & 27.1 & -6.2 & 0.98 \\
\hline & No.2 Soybean & 2 & 3 & 16 & 11 & -14 & 0.09 & 476.3 & 265.7 & 197.8 & 328.3 & 268.0 & 0.01 \\
\hline & Corn & 477 & 1205 & 2439 & 1895 & -2087 & 0.00 & 7.4 & 3.8 & 5.3 & 3.4 & 2.4 & 0.06 \\
\hline Oilseeds & Rapeseed Oil & 178 & 548 & 762 & 260 & -643 & 0.00 & 122.8 & 79.4 & 88.4 & 126.7 & 33.9 & 0.24 \\
\hline & Rapeseed Meal & 3314 & 11125 & 13786 & 8051 & -10388 & 0.00 & 18.6 & 10.9 & 6.2 & 5.1 & 12.8 & 0.06 \\
\hline & Rapeseed & 2 & 2 & 64 & 0 & -70 & 0.06 & 293.8 & 484.1 & 89.2 & 442.4 & 203.4 & 0.05 \\
\hline & Soybean Meal & 809 & 3490 & 6478 & 6238 & -5776 & 0.00 & 23.3 & 13.0 & 6.6 & 8.4 & 16.8 & 0.03 \\
\hline & Palm Olein & 71 & 833 & 1286 & 1916 & -1046 & 0.00 & 283.0 & 243.3 & 111.8 & 117.5 & 176.0 & 0.02 \\
\hline & Soybean Oil & 193 & 1039 & 2574 & 2819 & -2354 & 0.00 & 62.0 & 53.0 & 28.8 & 33.0 & 30.1 & 0.04 \\
\hline Industrial & Cotton & 246 & 1186 & 2199 & 1200 & -1982 & 0.00 & 1.1 & 0.7 & 1.3 & 0.7 & -0.2 & 0.61 \\
\hline & Flat Glass & 206 & 1343 & 3581 & 3281 & -3390 & 0.00 & 453.4 & 224.6 & 118.3 & 156.7 & 350.6 & 0.12 \\
\hline & Natural Rubber & 460 & 1985 & 3262 & 3439 & -2799 & 0.00 & 1.1 & 1.3 & 1.4 & 2.1 & -0.4 & 0.86 \\
\hline & LLDPE & 181 & 1941 & 2558 & 2396 & -2403 & 0.00 & 183.3 & 114.5 & 101.2 & 82.6 & 60.5 & 0.17 \\
\hline & PVC & 77 & 313 & 461 & 257 & -380 & 0.01 & 445.3 & 583.5 & 548.0 & 689.8 & -87.1 & 0.64 \\
\hline & PTA & 324 & 3094 & 3296 & 3344 & -3005 & 0.00 & 28.1 & 22.6 & 22.9 & 44.7 & 5.5 & 0.26 \\
\hline & Coking Coke & 115 & 614 & 1090 & 2114 & -921 & 0.00 & 135.4 & 68.4 & 100.4 & 92.9 & 39.1 & 0.21 \\
\hline & Coking Coal & 91 & 798 & 1455 & 1524 & -1432 & 0.00 & 446.9 & 987.5 & 618.7 & 427.6 & -180.9 & 0.71 \\
\hline Metal & Aluminum & 210 & 956 & 873 & 248 & -687 & 0.00 & 0.1 & 0.0 & 0.0 & 0.0 & 0.0 & 0.00 \\
\hline & Gold & 131 & 273 & 473 & 496 & -361 & 0.01 & 8.1 & 4.7 & 2.5 & 4.3 & 5.3 & 0.00 \\
\hline & Copper & 452 & 2489 & 3164 & 1453 & -2735 & 0.00 & 0.0 & 0.0 & 0.0 & 0.0 & 0.0 & 0.00 \\
\hline & Lead & 107 & 178 & 31 & 4 & 54 & 0.98 & 0.5 & 0.7 & 41.2 & 38.2 & -40.7 & 0.85 \\
\hline & Steel Rebar & 503 & 4334 & 9063 & 12210 & -8578 & 0.00 & 4.8 & 2.4 & 3.1 & 2.2 & 1.6 & 0.12 \\
\hline & Steel Wire Rod & 18 & 8 & 9 & 2 & 12 & 0.86 & 1038.5 & 1297.1 & 1454.6 & 747.0 & -518.4 & 0.81 \\
\hline & Zinc & 415 & 2904 & 3351 & 1282 & -3008 & 0.00 & 0.1 & 0.0 & 0.0 & 0.2 & 0.1 & 0.00 \\
\hline & Silver & 1577 & 2764 & 3983 & 4189 & -2661 & 0.06 & 0.9 & 2.3 & 2.9 & 5.5 & -2.0 & 1.00 \\
\hline
\end{tabular}


Table 3 Performance of long-only investments

This table reports the performance of the broad market and sectors. Panel A reports the results over the sample period from February 2004 to May 2017 whereas Panel B reports the extended sample from 1992. AVG represents the broad market of 30 commodities. Energy, Grains, Industrials, Metals and Oilseeds report the performance of each commodity sector as classified in Table 2. All portfolios are equally-weighted and rebalanced monthly. For each portfolio, we report returns on $m^{\text {th }}$ nearest to maturity contracts, where $m=1,2,3$ and 4. Not all commodities started trading prior to our sample period in 2004.

\begin{tabular}{|c|c|c|c|c|c|c|}
\hline & AVG & Energy & Grains & Industrials & Metals & Oilseeds \\
\hline \multicolumn{7}{|l|}{ Panel A: 2004-2017 } \\
\hline & \multicolumn{6}{|c|}{ First nearest contract $(m=1)$} \\
\hline Annualized arithmetic mean & -0.0285 & -0.0859 & -0.0551 & -0.0349 & 0.0125 & 0.0276 \\
\hline$t$-statistics & -0.84 & -1.15 & -2.06 & -0.67 & 0.24 & 0.55 \\
\hline Annualized volatility & 0.1234 & 0.2616 & 0.0974 & 0.1908 & 0.1886 & 0.1817 \\
\hline \multirow[t]{2}{*}{ Sharpe Ratio } & -0.2306 & -0.3283 & -0.5661 & -0.1831 & 0.0664 & 0.1519 \\
\hline & \multicolumn{6}{|c|}{ Second nearest contract $(m=2)$} \\
\hline Annualized arithmetic mean & -0.0219 & -0.0313 & -0.0341 & -0.0387 & 0.0169 & 0.0036 \\
\hline$t$-statistics & -0.61 & -0.44 & -1.32 & -0.73 & 0.33 & 0.07 \\
\hline Annualized volatility & 0.1311 & 0.2549 & 0.0934 & 0.1932 & 0.1883 & 0.1965 \\
\hline \multirow[t]{2}{*}{ Sharpe Ratio } & -0.1673 & -0.1228 & -0.3647 & -0.2004 & 0.0899 & 0.0182 \\
\hline & \multicolumn{6}{|c|}{ Third nearest contract $(m=3)$} \\
\hline Annualized arithmetic mean & -0.0139 & -0.0105 & -0.0193 & -0.0442 & 0.0135 & 0.0087 \\
\hline$t$-statistics & -0.36 & -0.15 & -0.70 & -0.78 & 0.25 & 0.16 \\
\hline Annualized volatility & 0.1407 & 0.2478 & 0.0990 & 0.2043 & 0.1934 & 0.2026 \\
\hline \multirow[t]{2}{*}{ Sharpe Ratio } & -0.0987 & -0.0426 & -0.1944 & -0.2162 & 0.0696 & 0.0430 \\
\hline & \multicolumn{6}{|c|}{ Fourth nearest contract $(m=4)$} \\
\hline Annualized arithmetic mean & -0.0124 & -0.0329 & -0.0187 & -0.0487 & 0.0179 & -0.0012 \\
\hline$t$-statistics & -0.31 & -0.47 & -0.62 & -0.86 & 0.33 & -0.02 \\
\hline Annualized volatility & 0.1449 & 0.2491 & 0.1072 & 0.2044 & 0.1935 & 0.2020 \\
\hline Sharpe Ratio & -0.0855 & -0.1323 & -0.1745 & -0.2383 & 0.0925 & -0.0059 \\
\hline \multicolumn{7}{|l|}{ Panel B: 1992-2017 } \\
\hline & \multicolumn{6}{|c|}{ First nearest contract $(m=1)$} \\
\hline Annualized arithmetic mean & -0.0299 & -0.0859 & -0.0906 & -0.0202 & 0.0042 & 0.0419 \\
\hline$t$-statistics & -1.24 & -1.15 & -3.36 & -0.44 & 0.12 & 0.89 \\
\hline Annualized volatility & 0.1182 & 0.2616 & 0.1299 & 0.2126 & 0.1670 & 0.1930 \\
\hline \multirow[t]{2}{*}{ Sharpe Ratio } & -0.2527 & -0.3283 & -0.6970 & -0.0952 & 0.0250 & 0.2169 \\
\hline & \multicolumn{6}{|c|}{ Second nearest contract $(m=2)$} \\
\hline Annualized arithmetic mean & -0.0234 & -0.0313 & -0.0590 & -0.0419 & 0.0030 & 0.0135 \\
\hline$t$-statistics & -0.89 & -0.44 & -2.29 & -0.87 & 0.09 & 0.28 \\
\hline Annualized volatility & 0.1282 & 0.2549 & 0.1233 & 0.2246 & 0.1706 & 0.1989 \\
\hline \multirow[t]{2}{*}{ Sharpe Ratio } & -0.1823 & -0.1228 & -0.4785 & -0.1866 & 0.0179 & 0.0680 \\
\hline & \multicolumn{6}{|c|}{ Second nearest contract $(m=3)$} \\
\hline Annualized arithmetic mean & -0.0172 & -0.0105 & -0.0253 & -0.0530 & -0.0023 & 0.0261 \\
\hline$t$-statistics & -0.62 & -0.15 & -0.90 & -1.05 & -0.06 & 0.53 \\
\hline Annualized volatility & 0.1347 & 0.2478 & 0.1339 & 0.2310 & 0.1753 & 0.2013 \\
\hline \multirow[t]{2}{*}{ Sharpe Ratio } & -0.1278 & -0.0426 & -0.1889 & -0.2293 & -0.0132 & 0.1294 \\
\hline & \multicolumn{6}{|c|}{ Fourth nearest contract $(m=4)$} \\
\hline Annualized arithmetic mean & -0.0179 & -0.0329 & -0.0106 & -0.0555 & -0.0072 & 0.0207 \\
\hline$t$-statistics & -0.62 & -0.47 & -0.37 & -1.07 & -0.19 & 0.42 \\
\hline Annualized volatility & 0.1396 & 0.2491 & 0.1375 & 0.2334 & 0.1797 & 0.1990 \\
\hline Sharpe Ratio & -0.1280 & -0.1323 & -0.0773 & -0.2378 & -0.0399 & 0.1040 \\
\hline
\end{tabular}




\section{Table 4 Performance of long-short strategies}

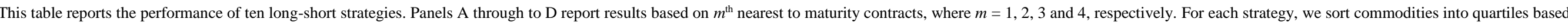

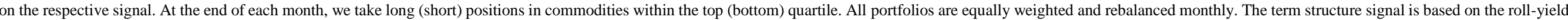

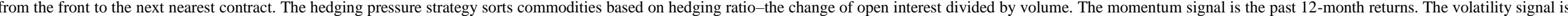

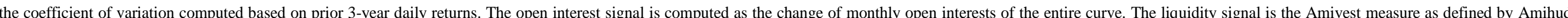

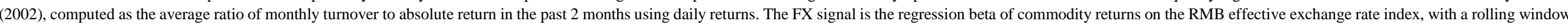

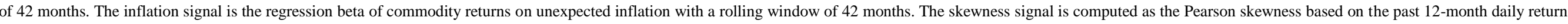
Finally, the value signal is the $\log$ of the average daily prices from 3.5 to 4.5 years ago divided by the price at each time $t$. The sample period covers February 2004 through to May 2017.

\begin{tabular}{|c|c|c|c|c|c|c|c|c|c|c|}
\hline & $\begin{array}{r}\text { Term } \\
\text { Structure }\end{array}$ & $\begin{array}{l}\text { Hedging } \\
\text { Pressure }\end{array}$ & Momentum & Volatility & $\begin{array}{r}\text { Open } \\
\text { Interest }\end{array}$ & Liquidity & FX & $\begin{array}{r}\text { Inflation } \\
\text { Shocks }\end{array}$ & Skewness & Value \\
\hline \multicolumn{11}{|c|}{ Panel A: First nearest contract $(m=1)$} \\
\hline Annualized arithmetic mean & 0.1591 & 0.0285 & 0.2194 & 0.1053 & -0.0367 & -0.0684 & 0.0477 & 0.0222 & -0.0958 & 0.0748 \\
\hline$t$-statistics & 3.24 & 0.73 & 4.13 & 2.43 & -0.94 & -1.43 & 0.83 & 0.44 & -2.32 & 1.13 \\
\hline Annualized volatility & 0.1790 & 0.1416 & 0.1866 & 0.1394 & 0.1421 & 0.1736 & 0.1805 & 0.1599 & 0.1453 & 0.1961 \\
\hline Sharpe Ratio & 0.8891 & 0.2010 & 1.1757 & 0.7555 & -0.2582 & -0.3942 & 0.2645 & 0.1387 & -0.6596 & 0.3814 \\
\hline Sortino Ratio & 1.0041 & 0.3219 & 2.1373 & 1.1409 & -0.3579 & -0.5722 & 0.2890 & 0.2039 & -0.9312 & 0.7939 \\
\hline Skewness & -1.7586 & -0.0058 & 0.1996 & -0.3185 & -0.5605 & 0.0855 & -1.5333 & -0.1431 & 0.1775 & 1.6645 \\
\hline Kurtosis & 14.4057 & 3.1096 & 4.1832 & 4.6964 & 3.8109 & 4.2825 & 12.0713 & 4.4294 & 4.1239 & 11.2184 \\
\hline 99\%VaR(Cornish-Fisher) & 0.2705 & 0.1269 & 0.2070 & 0.1344 & 0.1092 & 0.1655 & 0.2329 & 0.1504 & 0.1375 & 0.3281 \\
\hline \multicolumn{11}{|c|}{ Panel B: Second nearest contract $(m=2)$} \\
\hline Annualized arithmetic mean & 0.1753 & 0.0273 & 0.1738 & 0.0689 & -0.0558 & 0.0290 & 0.0104 & -0.0005 & 0.0270 & 0.0857 \\
\hline$t$-statistics & 3.94 & 0.74 & 3.59 & 1.59 & -1.52 & 0.60 & 0.17 & -0.01 & 0.71 & 1.42 \\
\hline Annualized volatility & 0.1614 & 0.1341 & 0.1695 & 0.1390 & 0.1326 & 0.1759 & 0.1873 & 0.1514 & 0.1335 & 0.1791 \\
\hline Sharpe Ratio & 1.0860 & 0.2035 & 1.0252 & 0.4959 & -0.4210 & 0.1646 & 0.0555 & -0.0031 & 0.2024 & 0.4784 \\
\hline Sortino Ratio & 1.3365 & 0.3665 & 1.8392 & 0.6107 & -0.5369 & 0.2523 & 0.0571 & -0.0046 & 0.2984 & 1.0848 \\
\hline Skewness & -1.2063 & 0.3781 & 0.4011 & -1.1411 & -1.0737 & 0.0942 & -2.2592 & 0.1091 & -0.3505 & 2.3314 \\
\hline Kurtosis & 11.6339 & 3.5553 & 5.2736 & 9.4102 & 9.9717 & 5.5141 & 14.1756 & 4.1316 & 4.0679 & 15.8853 \\
\hline 99\% VaR(Cornish-Fisher) & 0.2152 & 0.1381 & 0.2067 & 0.1581 & 0.1464 & 0.1910 & 0.2792 & 0.1487 & 0.1159 & 0.3426 \\
\hline \multicolumn{11}{|c|}{ Panel C: Third nearest contract $(m=3)$} \\
\hline Annualized arithmetic mean & 0.1379 & 0.0811 & 0.1671 & 0.0485 & -0.0311 & 0.0088 & 0.0153 & 0.0477 & 0.0152 & 0.0992 \\
\hline$t$-statistics & 3.01 & 2.06 & 3.10 & 1.07 & -0.95 & 0.22 & 0.26 & 1.00 & 0.42 & 1.61 \\
\hline Annualized volatility & 0.1660 & 0.1421 & 0.1882 & 0.1440 & 0.1183 & 0.1457 & 0.1842 & 0.1475 & 0.1272 & 0.1812 \\
\hline Sharpe Ratio & 0.8308 & 0.5709 & 0.8880 & 0.3370 & -0.2628 & 0.0605 & 0.0830 & 0.3232 & 0.1197 & 0.5476 \\
\hline Sortino Ratio & 0.8823 & 1.0223 & 1.5867 & 0.3916 & -0.3922 & 0.1024 & 0.0919 & 0.5486 & 0.1707 & 1.2821 \\
\hline Skewness & -2.3344 & 1.4611 & 0.2985 & -1.5046 & 0.0817 & 0.2074 & -1.6907 & 0.1588 & -0.5253 & 2.4826 \\
\hline Kurtosis & 20.2724 & 12.2774 & 4.4897 & 11.8426 & 5.8944 & 3.4807 & 10.1077 & 3.8560 & 3.8952 & 16.4701 \\
\hline 99\%VaR(Cornish-Fisher) & 0.3288 & 0.2510 & 0.2129 & 0.1845 & 0.1268 & 0.1415 & 0.2117 & 0.1482 & 0.1033 & 0.3488 \\
\hline \multicolumn{11}{|c|}{ Panel D: Fourth nearest contract $(m=4)$} \\
\hline Annualized arithmetic mean & 0.1169 & -0.0078 & 0.1526 & 0.0478 & -0.0553 & -0.0137 & 0.0081 & 0.0200 & -0.0098 & 0.0980 \\
\hline$t$-statistics & 2.57 & -0.21 & 2.75 & 1.02 & -1.64 & -0.42 & 0.15 & 0.41 & -0.25 & 1.57 \\
\hline Annualized volatility & 0.1639 & 0.1348 & 0.1932 & 0.1480 & 0.1211 & 0.1173 & 0.1718 & 0.1517 & 0.1377 & 0.1826 \\
\hline Sharpe Ratio & 0.7129 & -0.0576 & 0.7901 & 0.3227 & -0.4570 & -0.1167 & 0.0471 & 0.1315 & -0.0715 & 0.5369 \\
\hline Sortino Ratio & 0.7469 & -0.1013 & 1.3665 & 0.3787 & -0.6244 & -0.1819 & 0.0517 & 0.1915 & -0.1066 & 1.1867 \\
\hline Skewness & -2.0513 & 0.4482 & 0.2071 & -1.3812 & -0.3862 & -0.1116 & -1.6516 & -0.1599 & -0.1580 & 2.5280 \\
\hline Kurtosis & 16.3461 & 4.1660 & 4.1648 & 11.1886 & 8.4230 & 2.8749 & 9.4287 & 4.8733 & 3.6408 & 16.0866 \\
\hline 99\% VaR(Cornish-Fisher) & 0.2719 & 0.1435 & 0.2082 & 0.1827 & 0.1331 & 0.0965 & 0.1887 & 0.1464 & 0.1191 & 0.3447 \\
\hline
\end{tabular}




\section{Table 5 Comparison between the US and China}

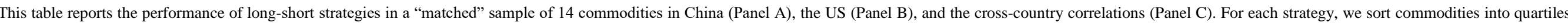

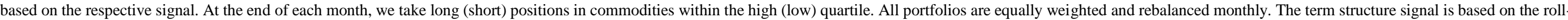

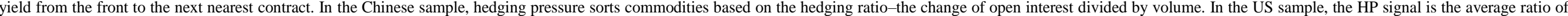

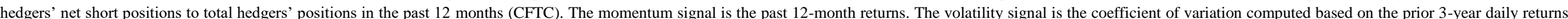

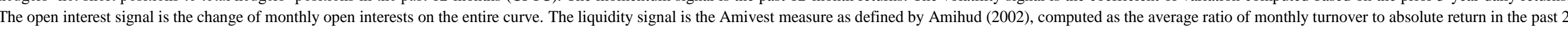

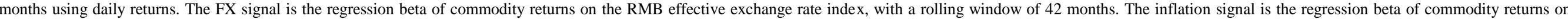

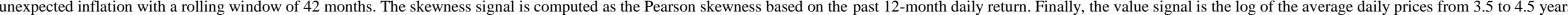

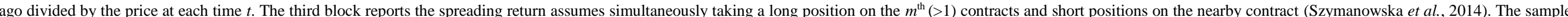
period for both markets covers February 2004 through to May 2017. * in Panel C denotes significance at 5\% level or better.

\begin{tabular}{|c|c|c|c|c|c|c|c|c|c|c|}
\hline & $\begin{array}{r}\text { Term } \\
\text { Structure } \\
\end{array}$ & $\begin{array}{l}\text { Hedging } \\
\text { Pressure }\end{array}$ & Momentum & Volatility & $\begin{array}{r}\text { Open } \\
\text { Interest } \\
\end{array}$ & Liquidity & FX & $\begin{array}{r}\text { Inflation } \\
\text { Shocks } \\
\end{array}$ & Skewness & Value \\
\hline Panel A: China & \multicolumn{10}{|c|}{ First nearest contract $(m=1)$} \\
\hline Annualized arithmetic mean & 0.1179 & -0.0050 & 0.2206 & 0.1324 & 0.0050 & -0.0854 & 0.0396 & -0.0135 & -0.1133 & 0.1738 \\
\hline$t$-statistics & 2.18 & -0.11 & 3.71 & 2.47 & 0.10 & -1.68 & 0.69 & -0.23 & -2.27 & 2.44 \\
\hline Annualized volatility & 0.1972 & 0.1701 & 0.2086 & 0.1720 & 0.1737 & 0.1849 & 0.1805 & 0.1885 & 0.1753 & 0.2107 \\
\hline \multirow[t]{2}{*}{ Sharpe Ratio } & 0.5979 & -0.0295 & 1.0574 & 0.7699 & 0.0285 & -0.4620 & 0.2195 & -0.0719 & -0.6463 & 0.8251 \\
\hline & \multicolumn{10}{|c|}{ Third nearest contract $(m=3)$} \\
\hline Annualized arithmetic mean & 0.0985 & 0.0149 & 0.1649 & 0.0900 & 0.0136 & -0.0375 & 0.0756 & 0.1427 & 0.0254 & 0.1999 \\
\hline$t$-statistics & 1.79 & 0.33 & 3.02 & 1.67 & 0.35 & -0.74 & 1.41 & 2.83 & 0.56 & 3.18 \\
\hline Annualized volatility & 0.1978 & 0.1639 & 0.1904 & 0.1721 & 0.1335 & 0.1816 & 0.1669 & 0.1567 & 0.1582 & 0.1853 \\
\hline \multirow[t]{2}{*}{ Sharpe Ratio } & 0.4977 & 0.0908 & 0.8661 & 0.5228 & 0.1016 & -0.2064 & 0.4529 & 0.9107 & 0.1606 & 1.0788 \\
\hline & \multicolumn{10}{|c|}{ Spreading returns $(m=3)$} \\
\hline Annualized arithmetic mean & -0.0075 & -0.0006 & -0.0462 & -0.0151 & -0.0032 & 0.0089 & -0.0228 & -0.0148 & 0.0096 & 0.0173 \\
\hline$t$-statistics & -0.39 & -0.04 & -2.28 & -0.73 & -0.14 & 0.48 & -0.91 & -0.63 & 0.69 & 0.78 \\
\hline Annualized volatility & 0.0699 & 0.0515 & 0.0706 & 0.0658 & 0.0806 & 0.0671 & 0.0776 & 0.0732 & 0.0488 & 0.0645 \\
\hline Sharpe Ratio & -0.1079 & -0.0118 & -0.6550 & -0.2295 & -0.0391 & 0.1322 & -0.2944 & -0.2023 & 0.1971 & 0.2679 \\
\hline Panel B: The US & \multicolumn{10}{|c|}{ First nearest contract $(m=1)$} \\
\hline Annualized arithmetic mean & 0.0672 & 0.1665 & 0.1046 & -0.0829 & 0.0029 & -0.0098 & -0.0443 & 0.0181 & 0.0416 & 0.1301 \\
\hline$t$-statistics & 1.08 & 2.75 & 1.59 & -1.43 & 0.05 & -0.19 & -0.68 & 0.25 & 0.72 & 1.89 \\
\hline Annualized volatility & 0.2276 & 0.2099 & 0.2307 & 0.1851 & 0.2160 & 0.1918 & 0.2044 & 0.2271 & 0.2017 & 0.1906 \\
\hline Sharpe Ratio & 0.2951 & 0.7935 & 0.4534 & -0.4479 & 0.0136 & -0.0513 & -0.2170 & 0.0795 & 0.2064 & 0.6829 \\
\hline$t$-statistics & 0.73 & 1.59 & 1.28 & -0.22 & 0.33 & -0.03 & -1.22 & 0.96 & -0.72 & 1.52 \\
\hline Annualized volatility & 0.1887 & 0.1707 & 0.2154 & 0.1585 & 0.1899 & 0.1714 & 0.1877 & 0.1960 & 0.1933 & 0.1650 \\
\hline \multirow[t]{2}{*}{ Sharpe Ratio } & 0.1998 & 0.4598 & 0.3642 & -0.0690 & 0.0935 & -0.0093 & -0.3868 & 0.3042 & -0.2055 & 0.5497 \\
\hline & \multicolumn{10}{|c|}{ Spreading returns $(m=3)$} \\
\hline Annualized arithmetic mean & -0.0143 & -0.0367 & -0.0046 & 0.0426 & 0.0047 & 0.0030 & 0.0089 & -0.0101 & -0.0133 & -0.0043 \\
\hline$t$-statistics & -1.06 & -3.12 & -0.36 & 3.80 & 0.44 & 0.27 & 0.80 & -0.70 & -1.17 & -0.36 \\
\hline Annualized volatility & 0.0495 & 0.0408 & 0.0450 & 0.0359 & 0.0370 & 0.0410 & 0.0353 & 0.0454 & 0.0401 & 0.0333 \\
\hline Sharpe Ratio & -0.2893 & -0.8998 & -0.1012 & 1.1877 & 0.1266 & 0.0739 & 0.2534 & -0.2216 & -0.3330 & -0.1290 \\
\hline Panel C: Cross-country correlations & \multicolumn{10}{|c|}{ First nearest contract $(m=1)$} \\
\hline Pearson's correlation & 0.0425 & -0.0131 & $0.3516^{*}$ & 0.0230 & 0.1172 & 0.0376 & 0.0672 & 0.0243 & 0.1118 & 0.1718 \\
\hline Pearson's correlation & 0.1318 & $0.2155^{*}$ & $0.3275^{*}$ & 0.0695 & \multicolumn{2}{|c|}{$\begin{array}{cc}\text { Third nearest contract }(m=3) \\
0.0495 & -0.0129\end{array}$} & $0.2747 *$ & -0.0384 & 0.1109 & 0.0950 \\
\hline & & & & & \multicolumn{2}{|c|}{ Spreading returns $(m=3)$} & & & & \\
\hline Pearson's correlation & 0.0156 & 0.0501 & -0.1427 & -0.0212 & 0.0945 & $-0.2024 *$ & -0.1112 & -0.0890 & 0.0764 & -0.0367 \\
\hline
\end{tabular}




\section{Table 6 Correlations of strategies}

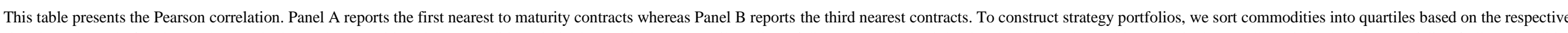

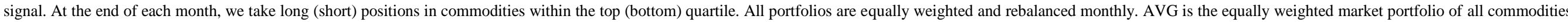

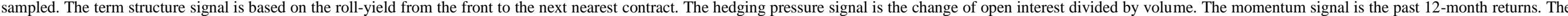

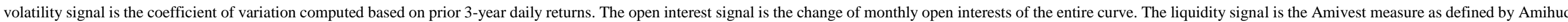

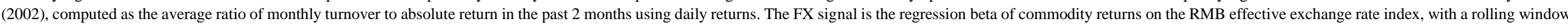

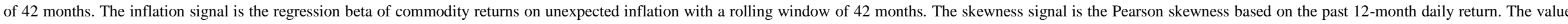
signal is the $\log$ of the average daily prices from 3.5 to 4.5 years ago divided by the price at each time $t$. The sample period covers February 2004 through to May 2017 . *denotes significance at $5 \%$ level or better.

\begin{tabular}{|c|c|c|c|c|c|c|c|c|c|c|}
\hline & \multirow[b]{2}{*}{ AVG } & \multirow{2}{*}{$\begin{array}{r}\text { Term } \\
\text { Structure }\end{array}$} & \multicolumn{2}{|l|}{ Hedging } & \multicolumn{3}{|c|}{ Open } & \multicolumn{3}{|c|}{ Inflation } \\
\hline & & & Pressure & Momentum & Volatility & Interest & Liquidity & FX & Shocks & Skewness \\
\hline \multicolumn{11}{|c|}{ Panel A: First nearest contract $(m=1)$} \\
\hline Term Structure & $0.3980^{*}$ & & & & & & & & & \\
\hline Hedging Pressure & -0.2368 & -0.1267 & & & & & & & & \\
\hline Momentum & 0.2689 & $0.4673 *$ & -0.0498 & & & & & & & \\
\hline Volatility & $0.4361 *$ & 0.2639 & -0.0817 & 0.1445 & & & & & & \\
\hline Open Interest & $0.3368 *$ & 0.1120 & -0.1517 & -0.0697 & 0.1744 & & & & & \\
\hline Liquidity & $-0.4152^{*}$ & -0.2184 & 0.2001 & -0.2757 & -0.2054 & -0.1443 & & & & \\
\hline FX & $0.6226^{*}$ & $0.4475^{*}$ & -0.1493 & 0.0200 & $0.4930^{*}$ & $0.3872 *$ & $-0.5278^{*}$ & & & \\
\hline Inflation Shocks & 0.2075 & -0.2077 & -0.0285 & -0.1587 & 0.1124 & 0.0833 & 0.0453 & 0.1304 & & \\
\hline Skewness & -0.0584 & -0.0315 & -0.0794 & -0.0505 & 0.0235 & -0.0263 & 0.0277 & -0.0968 & 0.0719 & \\
\hline Value & -0.0423 & $-0.4474 *$ & -0.0964 & $-0.3641^{*}$ & -0.1897 & -0.0759 & -0.0189 & -0.0216 & $0.4009 *$ & 0.0651 \\
\hline \multicolumn{11}{|c|}{ Panel B: Third nearest contract $(m=3)$} \\
\hline Term Structure & $0.4591 *$ & & & & & & & & & \\
\hline Hedging Pressure & $-0.4198^{*}$ & -0.1541 & & & & & & & & \\
\hline Momentum & 0.2573 & $0.4467^{*}$ & 0.0622 & & & & & & & \\
\hline Volatility & $0.4725^{*}$ & $0.4402 *$ & $-0.4832 *$ & 0.1308 & & & & & & \\
\hline $\mathrm{FX}$ & $0.6142 *$ & $0.5206^{*}$ & $-0.3181 *$ & -0.0510 & $0.4373 *$ & $0.3967 *$ & $-0.3999 *$ & & & \\
\hline Inflation Shocks & $0.6098^{*}$ & 0.2643 & -0.2197 & 0.0766 & $0.3182 *$ & 0.2636 & -0.2731 & $0.5241^{*}$ & & \\
\hline Skewness & -0.0577 & -0.0408 & 0.0689 & 0.0741 & -0.0067 & -0.0763 & -0.0550 & -0.0748 & 0.2209 & \\
\hline Value & -0.2742 & $-0.5365^{*}$ & $0.4338^{*}$ & $-0.3806^{*}$ & $-0.4521^{*}$ & -0.2373 & -0.0558 & -0.2731 & 0.0307 & 0.2026 \\
\hline
\end{tabular}




\section{Table 7 Decomposing long-short strategy returns}

This table reports the performance of quartile portfolios for term structure, hedging pressure, momentum and volatility strategies. The term structure signal is based on the roll-yield from the front to the next nearest contract. The hedging pressure signal is the change of open interest divided by volume. The momentum signal is the past 12-month returns. The volatility signal is the coefficient of variation computed based on prior 3-year daily returns. Portfolio turnover is estimated following Fuertes et al. (2010). The transaction cost is based on Marshall et al. (2012) of 0.086\%. The sample period covers February 2004 through to May 2017.

\begin{tabular}{|c|c|c|c|c|c|c|c|c|c|c|}
\hline & \multicolumn{5}{|c|}{ First nearest contract $(m=1)$} & \multicolumn{5}{|c|}{ Third nearest contract $(m=3)$} \\
\hline & Q1 & Q2 & Q3 & Q4 & L-S & Q1 & Q2 & Q3 & Q4 & L-S \\
\hline & \multicolumn{10}{|c|}{ Term Structure } \\
\hline Annualized arithmetic mean & -0.0902 & -0.0846 & -0.0187 & 0.0689 & 0.1591 & -0.0627 & -0.0561 & -0.0130 & 0.0752 & 0.1379 \\
\hline$t$-statistics & -2.77 & -2.13 & -0.43 & 1.28 & 3.24 & -1.71 & -1.34 & -0.29 & 1.32 & 3.01 \\
\hline Annualized volatility & 0.1185 & 0.1448 & 0.1594 & 0.1961 & 0.1790 & 0.1327 & 0.1518 & 0.1606 & 0.2066 & 0.1660 \\
\hline Sharpe Ratio & -0.7611 & -0.5844 & -0.1172 & 0.3516 & 0.8891 & -0.4724 & -0.3696 & -0.0808 & 0.3640 & 0.8308 \\
\hline Skewness & 0.1385 & -1.5115 & -0.2338 & -2.2903 & -1.7586 & 0.3370 & -1.5845 & -0.5048 & -2.3509 & -2.3344 \\
\hline Kurtosis & 3.0586 & 10.1581 & 5.8269 & 17.9179 & 14.4057 & 4.8093 & 10.7171 & 5.5657 & 19.0136 & 20.2724 \\
\hline Portfolio Turnover & 5.8929 & 7.7477 & 7.1403 & 6.4591 & 6.1760 & 5.8929 & 7.7477 & 7.1403 & 6.4591 & 6.1760 \\
\hline \multirow[t]{2}{*}{ Net Return } & & & & & 0.1485 & & & & & 0.1273 \\
\hline & \multicolumn{10}{|c|}{ Hedging Pressure } \\
\hline Annualized arithmetic mean & -0.0559 & -0.0309 & -0.0093 & -0.0274 & 0.0285 & -0.0393 & -0.0274 & -0.0398 & 0.0418 & 0.0811 \\
\hline$t$-statistics & -1.24 & -0.71 & -0.26 & -0.70 & 0.73 & -0.83 & -0.57 & -0.91 & 1.09 & 2.06 \\
\hline Annualized volatility & 0.1635 & 0.1576 & 0.1313 & 0.1426 & 0.1416 & 0.1705 & 0.1749 & 0.1592 & 0.1385 & 0.1421 \\
\hline Sharpe Ratio & -0.3416 & -0.1959 & -0.0709 & -0.1920 & 0.2010 & -0.2305 & -0.1564 & -0.2502 & 0.3020 & 0.5709 \\
\hline Skewness & -0.8427 & -0.0797 & -0.0585 & -1.5840 & -0.0058 & -1.0495 & -2.0923 & -1.7621 & 0.2545 & 1.4611 \\
\hline Kurtosis & 8.2819 & 7.5533 & 3.4108 & 12.6302 & 3.1096 & 8.6554 & 14.7000 & 15.3652 & 3.8278 & 12.2774 \\
\hline Portfolio Turnover & 8.2413 & 8.8764 & 8.4778 & 8.3861 & 8.3717 & 7.4118 & 8.1497 & 8.7088 & 8.1125 & 7.7622 \\
\hline \multirow[t]{2}{*}{ Net Return } & & & & & 0.0142 & & & & & 0.0677 \\
\hline & \multicolumn{10}{|c|}{ Momentum } \\
\hline Annualized arithmetic mean & -0.0992 & -0.0632 & -0.0075 & 0.1202 & 0.2194 & -0.0654 & -0.0013 & -0.0135 & 0.1017 & 0.1671 \\
\hline$t$-statistics & -2.61 & -1.95 & -0.16 & 2.13 & 4.13 & -1.55 & -0.03 & -0.31 & 1.69 & 3.10 \\
\hline Annualized volatility & 0.1337 & 0.1136 & 0.1684 & 0.1983 & 0.1866 & 0.1473 & 0.1429 & 0.1528 & 0.2094 & 0.1882 \\
\hline Sharpe Ratio & -0.7420 & -0.5562 & -0.0447 & 0.6063 & 1.1757 & -0.4439 & -0.0093 & -0.0882 & 0.4859 & 0.8880 \\
\hline Skewness & -0.1082 & 0.2815 & -2.9240 & -0.2729 & 0.1996 & -0.5550 & -0.8747 & -1.7779 & -0.2653 & 0.2985 \\
\hline Kurtosis & 5.0310 & 3.7031 & 25.1664 & 5.5433 & 4.1832 & 7.2530 & 8.6591 & 12.8271 & 5.9367 & 4.4897 \\
\hline Portfolio Turnover & 2.3491 & 5.0439 & 4.4620 & 2.2355 & 2.2923 & 2.6832 & 5.3246 & 4.6689 & 2.3516 & 3.7571 \\
\hline \multirow[t]{2}{*}{ Net Return } & & & & & 0.2155 & & & & & 0.1606 \\
\hline & \multicolumn{10}{|c|}{ Volatility } \\
\hline Annualized arithmetic mean & -0.0711 & -0.0195 & -0.0234 & 0.0343 & 0.1053 & -0.0225 & 0.0038 & -0.0050 & 0.0260 & 0.0485 \\
\hline$t$-statistics & -2.26 & -0.38 & -0.47 & 0.72 & 2.43 & -0.67 & 0.07 & -0.09 & 0.49 & 1.07 \\
\hline Annualized volatility & 0.1009 & 0.1640 & 0.1601 & 0.1526 & 0.1394 & 0.1079 & 0.1690 & 0.1781 & 0.1688 & 0.1440 \\
\hline Sharpe Ratio & -0.7042 & -0.1190 & -0.1464 & 0.2245 & 0.7555 & -0.2087 & 0.0224 & -0.0283 & 0.1541 & 0.3370 \\
\hline Skewness & 0.5579 & -0.5986 & -0.6136 & -0.4562 & -0.3185 & 0.9368 & -0.9302 & -0.9148 & -1.4799 & -1.5046 \\
\hline Kurtosis & 3.9551 & 6.4202 & 6.5832 & 5.6247 & 4.6964 & 5.4497 & 7.5363 & 7.7109 & 10.6690 & 11.8426 \\
\hline Portfolio Turnover & 1.4355 & 4.0798 & 4.3291 & 2.6215 & 2.0285 & 1.4355 & 4.0798 & 4.3291 & 2.6215 & 2.0285 \\
\hline Net Return & & & & & 0.1018 & & & & & 0.0450 \\
\hline
\end{tabular}




\section{Table 8 Risks adjustments}

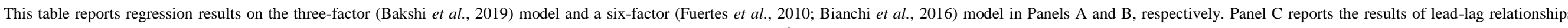

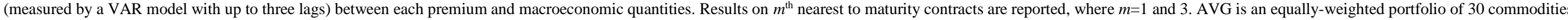

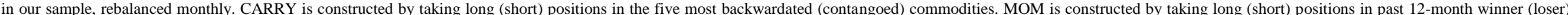

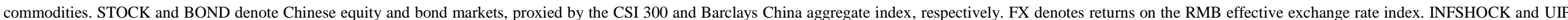

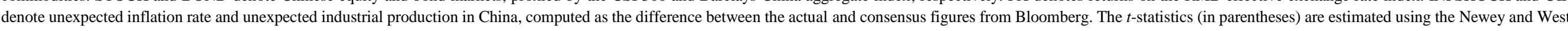
(1987) procedure $(* * * \mathrm{p}<0.01, * * \mathrm{p}<0.05, * \mathrm{p}<0.1)$. The sample period covers February 2004 through to May 2017.

\begin{tabular}{|c|c|c|c|c|c|c|c|c|}
\hline & Terr & (TS) & Hedg & (HP) & Mor & DM) & Vol & \\
\hline & $m=1$ & $m=3$ & $m=1$ & $m=3$ & $m=1$ & $m=3$ & $m=1$ & $m=3$ \\
\hline Panel A: Com & & & & & & & & \\
\hline AVG & $\begin{array}{c}0.471^{*} \\
(1.67)\end{array}$ & $\begin{array}{c}0.484^{* *} * \\
(2.10)\end{array}$ & $\begin{array}{c}-0.371 * * * \\
(-4.52)\end{array}$ & $\begin{array}{c}-0.433^{* * * *} \\
(-3.38)\end{array}$ & $\begin{array}{l}0.267 \\
(1.47)\end{array}$ & $\begin{array}{l}0.190 \\
(1.07)\end{array}$ & $\begin{array}{c}0.452^{* * * *} \\
(3.55)\end{array}$ & $\begin{array}{c}0.368 * * \\
(2.45)\end{array}$ \\
\hline MOM & $\begin{array}{c}0.356 * * * \\
(4.35)\end{array}$ & $\begin{array}{c}0.291 * * * \\
(3.79)\end{array}$ & $\begin{array}{l}0.022 \\
(0.32)\end{array}$ & $\begin{array}{c}0.162 * * \\
(2.48)\end{array}$ & & & $\begin{array}{l}0.023 \\
(0.24)\end{array}$ & $\begin{array}{l}-0.027 \\
(-0.30)\end{array}$ \\
\hline Constant & $\begin{array}{c}0.007 * * \\
(2.00)\end{array}$ & $\begin{array}{c}0.008 * * \\
(2.33)\end{array}$ & $\begin{array}{l}0.002 \\
(0.67)\end{array}$ & $\begin{array}{l}0.005 \\
(1.55)\end{array}$ & $\begin{array}{c}0.014 * * \\
(2.50)\end{array}$ & $\begin{array}{c}0.010^{* *} \\
(2.06)\end{array}$ & $\begin{array}{c}0.009 * * \\
(2.20)\end{array}$ & $\begin{array}{l}0.003 \\
(0.61)\end{array}$ \\
\hline Observations & 148 & 146 & 148 & 146 & 148 & 146 & 124 & 122 \\
\hline Adj. R2 & 0.310 & 0.355 & 0.082 & 0.238 & 0.138 & 0.131 & 0.173 & 0.257 \\
\hline Panel B: Stan & & & & & & & & \\
\hline STOCK & $\begin{array}{l}0.053 \\
(1.30)\end{array}$ & $\begin{array}{c}0.070^{* * *} \\
(2.41)\end{array}$ & $\begin{array}{l}-0.040 \\
(-1.06)\end{array}$ & $\begin{array}{l}0.019 \\
(0.45)\end{array}$ & $\begin{array}{l}-0.018 \\
(-0.32)\end{array}$ & $\begin{array}{l}-0.042 \\
(-0.77)\end{array}$ & $\begin{array}{l}-0.003 \\
(-0.09)\end{array}$ & $\begin{array}{l}0.000 \\
(0.01)\end{array}$ \\
\hline BOND & $\begin{array}{l}0.322 \\
(0.41)\end{array}$ & $\begin{array}{l}0.215 \\
(0.29)\end{array}$ & $\begin{array}{l}0.079 \\
(0.17)\end{array}$ & $\begin{array}{l}0.665 \\
(1.36)\end{array}$ & $\begin{array}{l}1.143 \\
(1.44)\end{array}$ & $\begin{array}{l}1.372 * \\
(1.68)\end{array}$ & $\begin{array}{l}0.252 \\
(0.51)\end{array}$ & $\begin{array}{l}0.377 \\
(0.68)\end{array}$ \\
\hline AVG & $\begin{array}{c}0.535 * * \\
(2.05)\end{array}$ & $\begin{array}{c}0.520^{* * * *} \\
(2.66)\end{array}$ & $\begin{array}{c}-0.340 * * * \\
(-3.37)\end{array}$ & $\begin{array}{c}-0.423 * * \\
(-2.45)\end{array}$ & $\begin{array}{c}0.429 * * \\
(2.40)\end{array}$ & $\begin{array}{c}0.430 * * * \\
(2.75)\end{array}$ & $\begin{array}{c}0.531 * * * \\
(3.71)\end{array}$ & $\begin{array}{c}0.468 * * \\
(2.38)\end{array}$ \\
\hline INFSHOCK & $\begin{array}{l}0.337 \\
(0.24)\end{array}$ & $\begin{array}{l}-0.287 \\
(-0.30)\end{array}$ & $\begin{array}{l}-1.355 \\
(-1.28)\end{array}$ & $\begin{array}{l}-0.160 \\
(-0.16)\end{array}$ & $\begin{array}{l}1.039 \\
(0.64)\end{array}$ & $\begin{array}{l}-0.028 \\
(-0.03)\end{array}$ & $\begin{array}{l}-0.469 \\
(-0.46)\end{array}$ & $\begin{array}{l}-0.535 \\
(-0.54)\end{array}$ \\
\hline $\mathrm{FX}$ & $\begin{array}{l}-0.098 \\
(-0.29)\end{array}$ & $\begin{array}{l}-0.028 \\
(-0.09)\end{array}$ & $\begin{array}{l}-0.362 \\
(-1.35)\end{array}$ & $\begin{array}{l}-0.103 \\
(-0.45)\end{array}$ & $\begin{array}{l}-0.239 \\
(-0.50)\end{array}$ & $\begin{array}{l}0.001 \\
(0.00)\end{array}$ & $\begin{array}{l}0.152 \\
(0.77)\end{array}$ & $\begin{array}{l}-0.254 \\
(-1.15)\end{array}$ \\
\hline UIP & $\begin{array}{l}0.178 \\
(0.69)\end{array}$ & $\begin{array}{l}0.052 \\
(0.22)\end{array}$ & $\begin{array}{l}0.223 \\
(1.16)\end{array}$ & $\begin{array}{c}-0.346^{* *} \\
(-2.17)\end{array}$ & $\begin{array}{l}-0.212 \\
(-0.58)\end{array}$ & $\begin{array}{l}-0.268 \\
(-0.92)\end{array}$ & $\begin{array}{l}-0.146 \\
(-0.89)\end{array}$ & $\begin{array}{l}-0.072 \\
(-0.52)\end{array}$ \\
\hline Constant & $\begin{array}{c}0.013 * * * \\
(2.68)\end{array}$ & $\begin{array}{c}0.011^{* *} \\
(2.39)\end{array}$ & $\begin{array}{l}0.004 \\
(1.20)\end{array}$ & $\begin{array}{l}0.004 \\
(1.16)\end{array}$ & $\begin{array}{c}0.016^{* * *} \\
(2.70)\end{array}$ & $\begin{array}{c}0.010^{*} \\
(1.71)\end{array}$ & $\begin{array}{c}0.009 * * \\
(2.23)\end{array}$ & $\begin{array}{l}0.004 \\
(0.87)\end{array}$ \\
\hline Observations & 148 & 146 & 148 & 146 & 148 & 146 & 124 & 122 \\
\hline Adj. R2 & 0.164 & 0.243 & 0.117 & 0.205 & 0.063 & 0.070 & 0.158 & 0.196 \\
\hline Panel C: Leac & & & & & & & & \\
\hline IP & $\begin{array}{c}8.632 * * * \\
(3.15)\end{array}$ & $\begin{array}{c}8.886^{* * * *} \\
(3.01)\end{array}$ & $\begin{array}{l}-1.382 \\
(-0.40)\end{array}$ & $\begin{array}{c}-8.272 * * \\
(-2.34)\end{array}$ & $\begin{array}{c}6.350 * * * \\
(3.23)\end{array}$ & $\begin{array}{c}6.153^{* * *} \\
(3.13)\end{array}$ & $\begin{array}{l}3.685 \\
(1.31)\end{array}$ & $\begin{array}{c}4.775^{*} \\
(1.71)\end{array}$ \\
\hline UIP & $\begin{array}{c}4.932 * * \\
(2.10)\end{array}$ & $\begin{array}{l}3.991 \\
(1.58)\end{array}$ & $\begin{array}{l}-3.753 \\
(-1.24)\end{array}$ & $\begin{array}{l}-2.667 \\
(-0.89)\end{array}$ & $\begin{array}{c}5.607 * * * \\
(3.04)\end{array}$ & $\begin{array}{c}5.726 * * * \\
(3.09)\end{array}$ & $\begin{array}{l}-0.031 \\
(-0.01)\end{array}$ & $\begin{array}{l}2.378 \\
(0.89)\end{array}$ \\
\hline INF & $\begin{array}{l}1.806^{*} \\
(1.90)\end{array}$ & $\begin{array}{l}1.851^{*} \\
(1.80)\end{array}$ & $\begin{array}{l}0.345 \\
(0.28)\end{array}$ & $\begin{array}{c}-2.837 * * \\
(-2.34)\end{array}$ & $\begin{array}{l}0.294 \\
(0.32)\end{array}$ & $\begin{array}{l}0.291 \\
(0.33)\end{array}$ & $\begin{array}{l}-0.069 \\
(-0.05)\end{array}$ & $\begin{array}{l}-0.066 \\
(-0.05)\end{array}$ \\
\hline INFSHOCK & $\begin{array}{l}1.017^{*} \\
(1.71)\end{array}$ & $\begin{array}{l}0.824 \\
(1.28) \\
\end{array}$ & $\begin{array}{l}-0.404 \\
(-0.53)\end{array}$ & $\begin{array}{c}-2.639 * * * \\
(-3.62)\end{array}$ & $\begin{array}{l}0.150 \\
(0.32) \\
\end{array}$ & $\begin{array}{l}-0.059 \\
(-0.13)\end{array}$ & $\begin{array}{l}-0.224 \\
(-0.35)\end{array}$ & $\begin{array}{l}0.189 \\
(0.29)\end{array}$ \\
\hline
\end{tabular}




\section{Table 9 Liquidity, behavioral and sentiment factors}

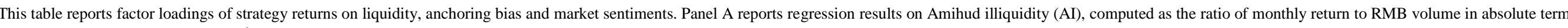

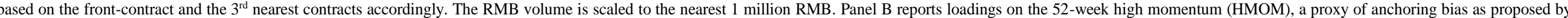

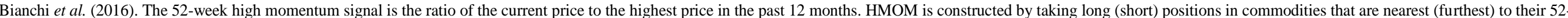

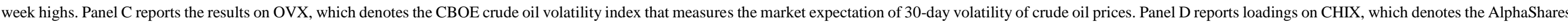

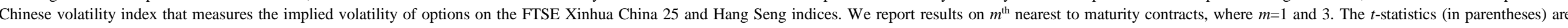
estimated using the Newey and West (1987) procedure $(* * * \mathrm{p}<0.01, * * \mathrm{p}<0.05, * \mathrm{p}<0.1)$. The sample period covers February 2004 through to May 2017.

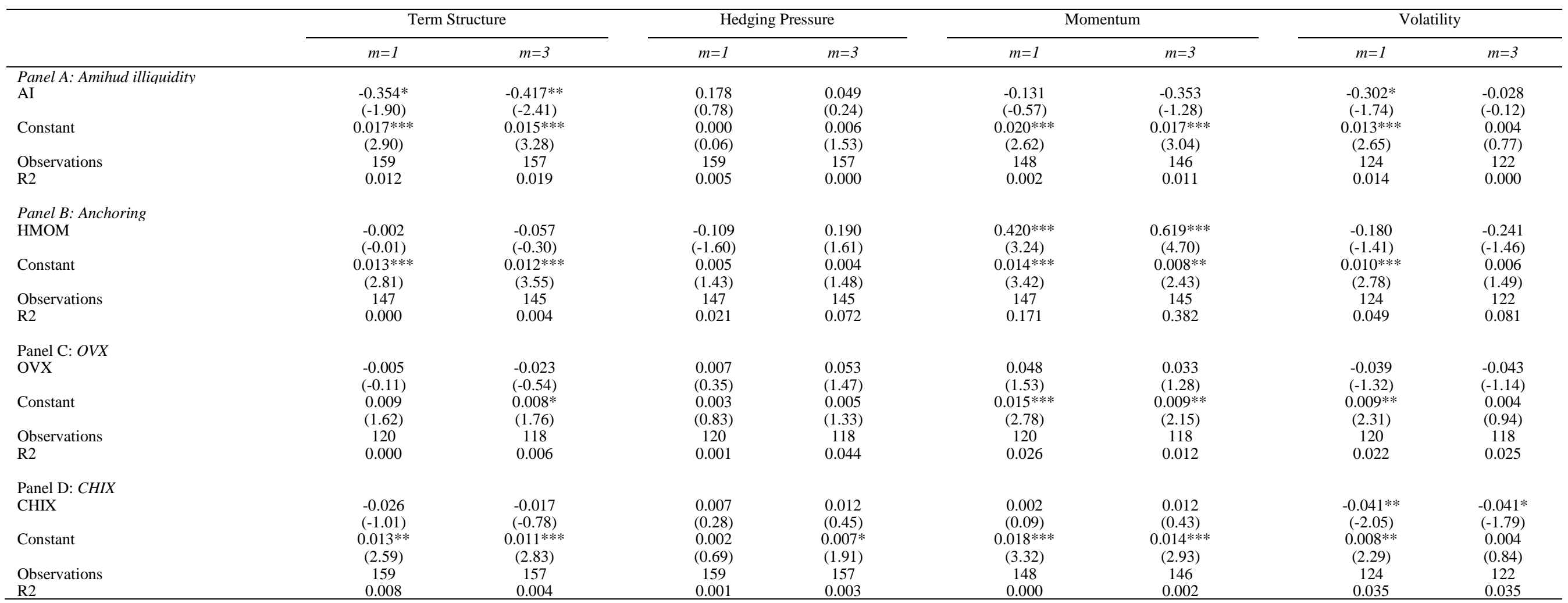




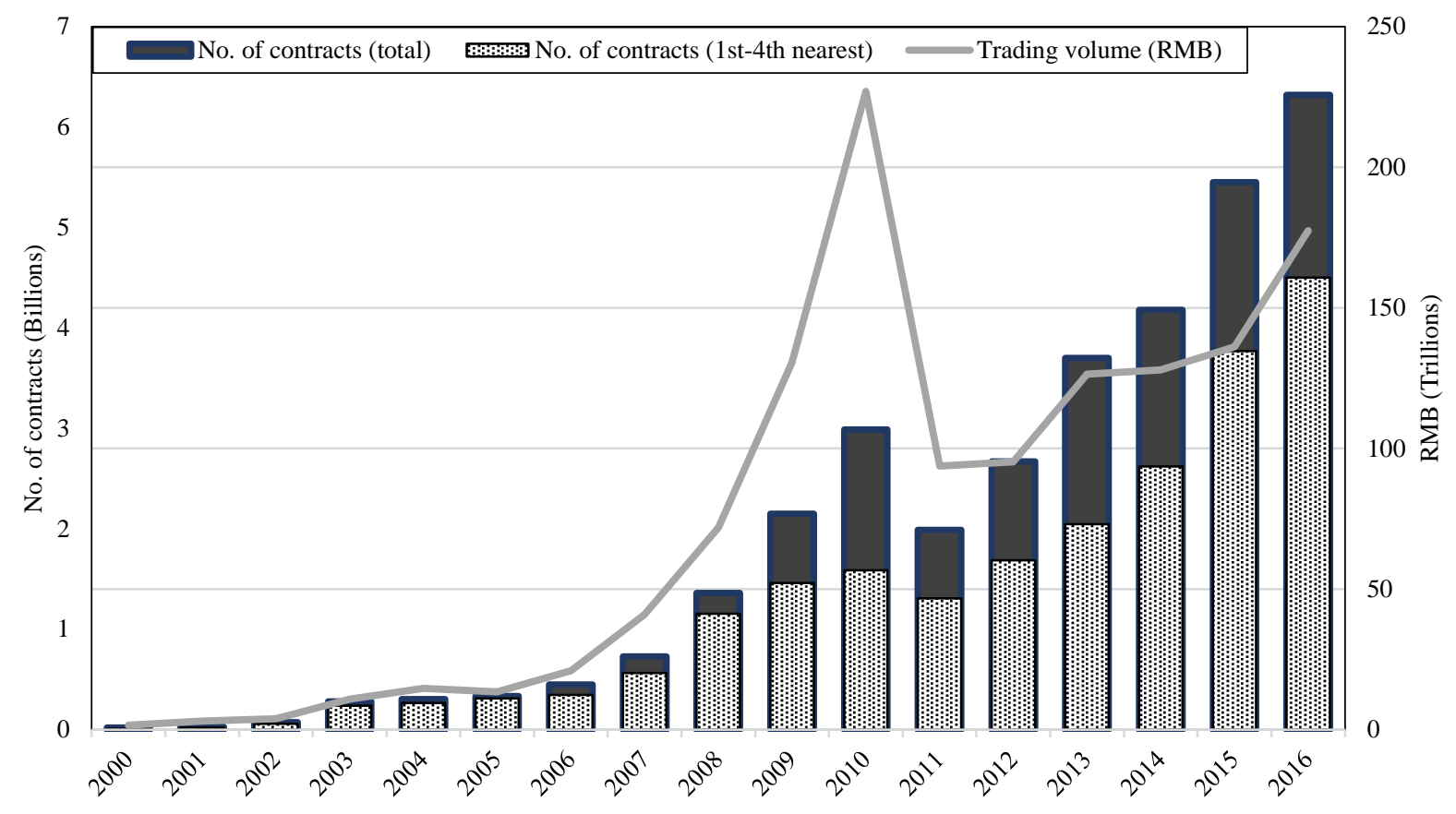

Figure 1 Annual trading volumes

This figure illustrates the annual trading volume of commodity futures in China. The line plot exhibits the total trading volume (expressed in trillions of RMB) of 48 commodity futures contracts which progressively entered the market. The solid bar plot represents the total number of contracts traded across the futures curve based on our sample of 30 commodities whereas the patterned bars plot the number of contracts from $1^{\text {st }}$ to $4^{\text {th }}$ nearest to maturity contracts. Data on annual RMB trading volume are obtained from the China Futures Association. 

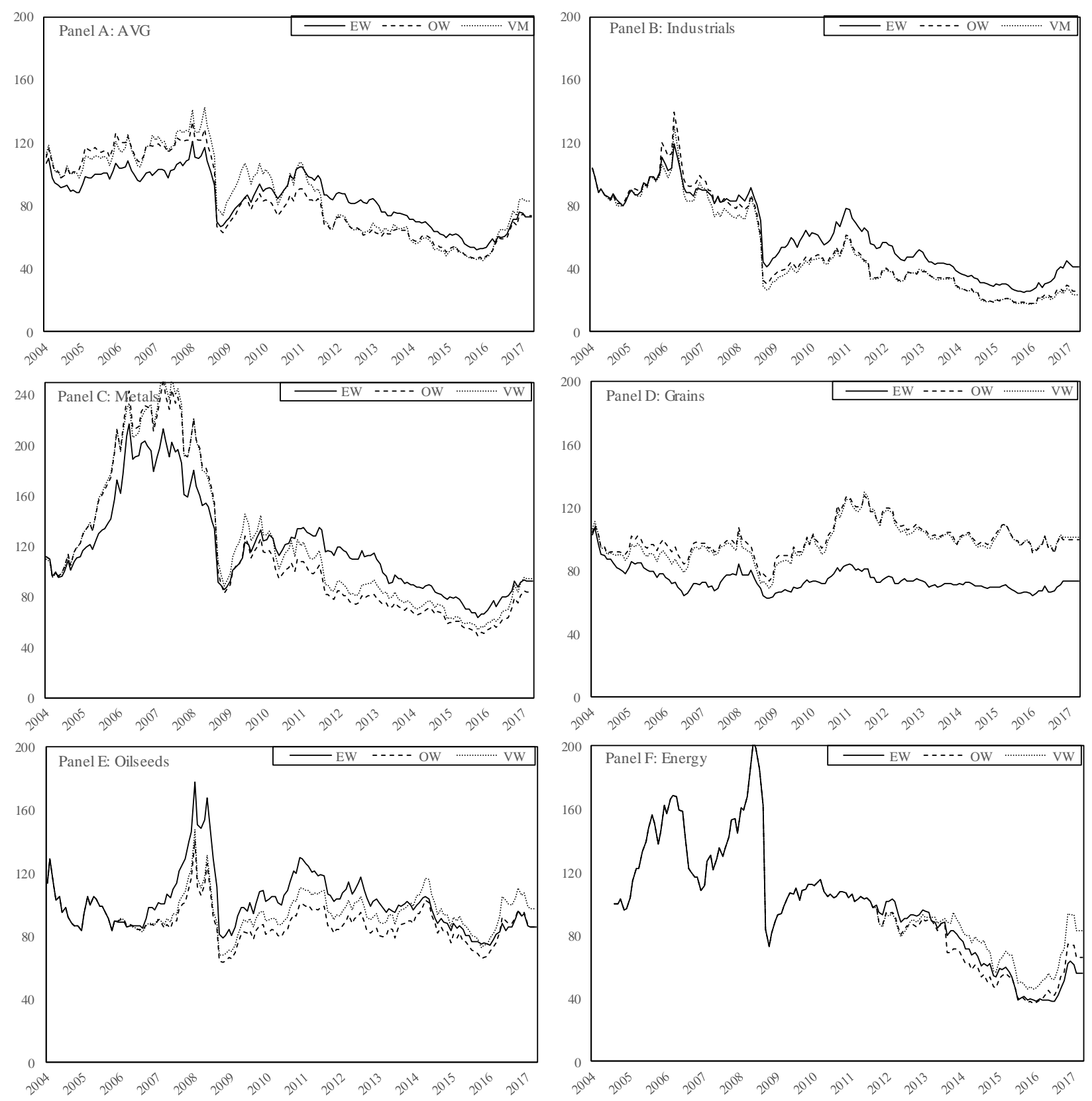

Figure 2 Performance of passive long-only investments

This figure illustrates the cumulative performance of the passive long-only commodity portfolios in China. Panel A exhibits the broad market performance (AVG). Panels B through to F illustrate the performance of industrials, metals, grains, oilseeds and energies, respectively. Within each panel, we construct equal-weighted, open interest- and volumeweighted portfolios, respectively. The unit value index (UVI) at time $t$ is computed as $U V I_{t}=U V I_{t-1}\left(1+R_{t}\right)$, with an initial value of 100. $R_{t}$ denotes the index return at time $t$. For equally-weighted portfolios, $R_{t}=\frac{1}{N} \sum r_{t, i}$ where $N$ is the number of commodities at time $t$ and $r_{t, i}$ is the return of commodity $i$ at time $t$. For open interest- and volume-weighted portfolios, the $R_{t}=\sum \frac{a_{t, i}}{A_{t}} r_{t, i}$ where $a_{t, i}$ denotes the open interest or volume of commodity $i$ at time $t$ and $A_{t}$ is the open interest of all commodities at time $t$. All the portfolios are constructed based on the third nearest to maturity contracts. The sample period covers 2004 through to 2017. 


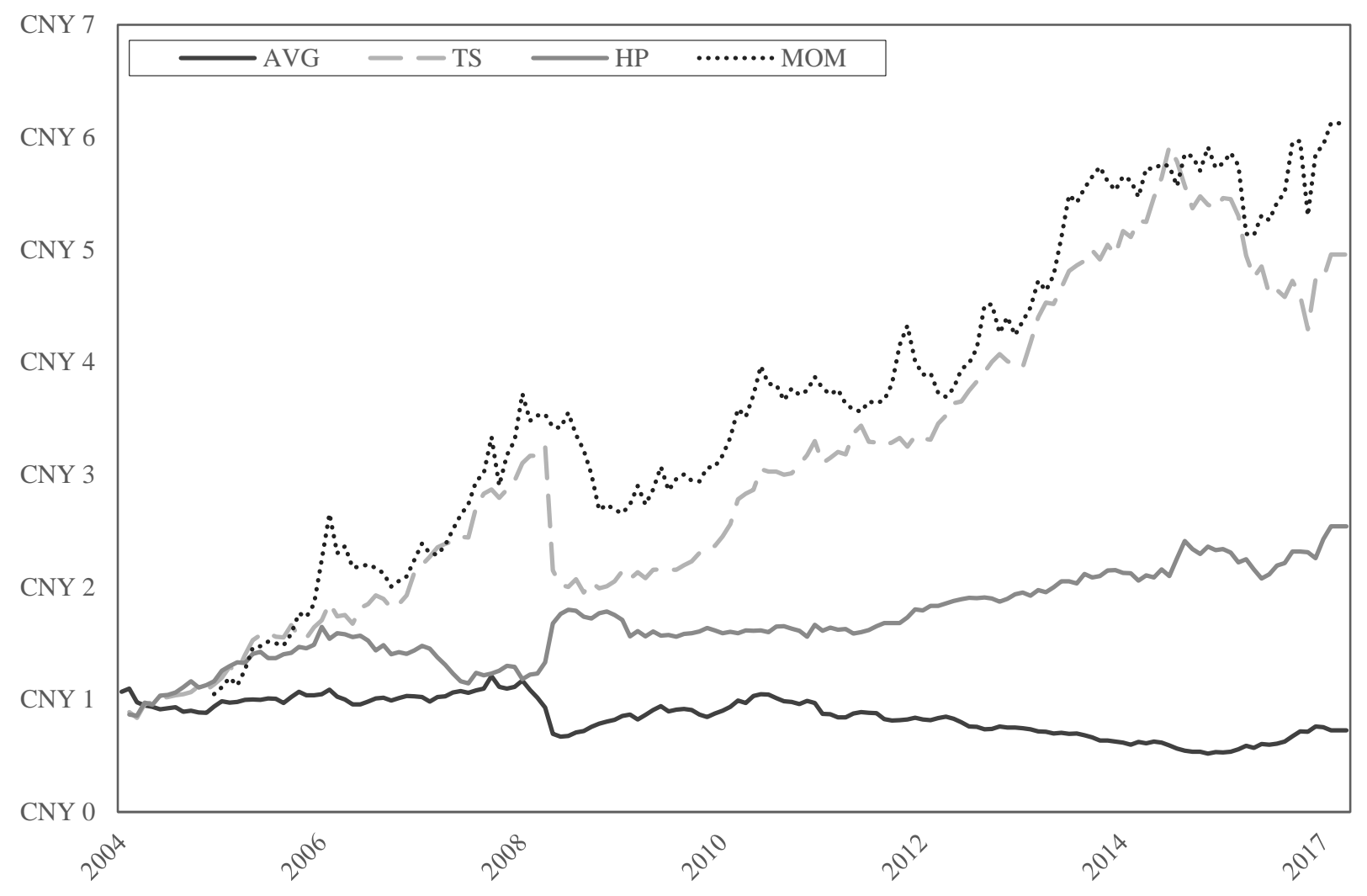

Figure 3 Cumulative returns

This figure illustrates the future value of 1 RMB invested in long-only and long-short strategies. AVG denotes the equally-weighted portfolio of 30 commodities. To construct strategy portfolios, we sort commodities into quartiles based on the respective signal. At the end of each month, we take long (short) positions in commodities within the top (bottom) quartile. All portfolios are equally weighted and rebalanced monthly. The term structure signal is the rollyield from the front to the next nearest contract. The hedging pressure signal is the change of open interest divided by volume. The momentum signal is past 12 -month returns. All portfolios are evaluated based on the third nearest contracts. The sample period covers February 2004 through to May 2017. 


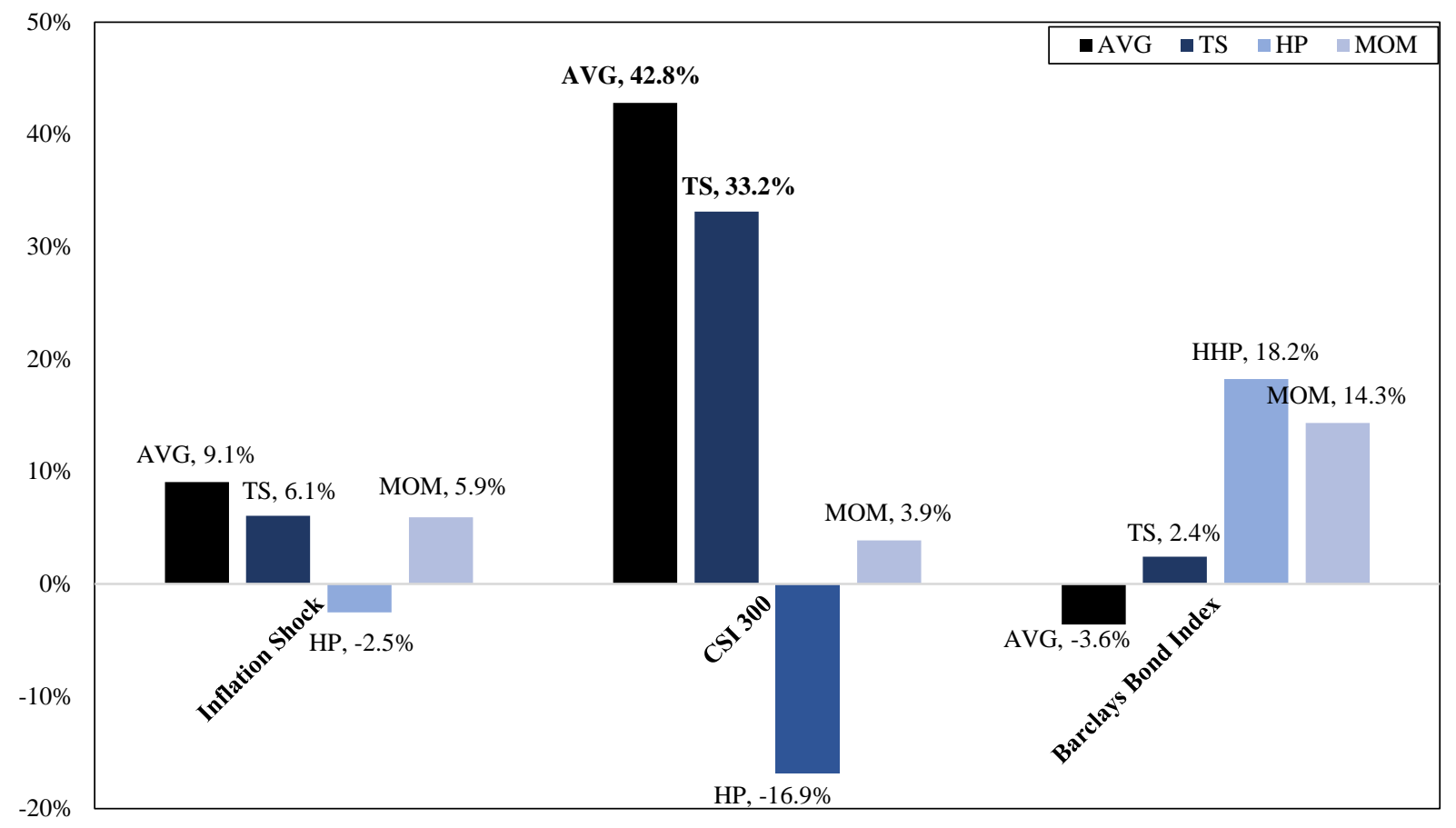

Figure 4 Correlations with stocks, bonds and inflation

This figure illustrates the pairwise correlations of strategy returns with equity, bond returns and changes in unexpected inflation. The inflation shock is the difference between actual and forecasted inflation estimated by Bloomberg. The CSI 300 consists of top 300 stocks traded on the Shanghai and Shenzhen stock exchanges. The Barclays China Aggregate Index covers fixed-rate treasury, government and corporate bonds. AVG denotes the equally-weighted portfolio of 30 commodities. TS, HP and MOM denote the term structure, hedging pressure and momentum strategies, respectively. All portfolios are evaluated based on the third nearest contracts. The sample period covers February 2004 through to May 2017. Bold indicates significance at $5 \%$ level or better.

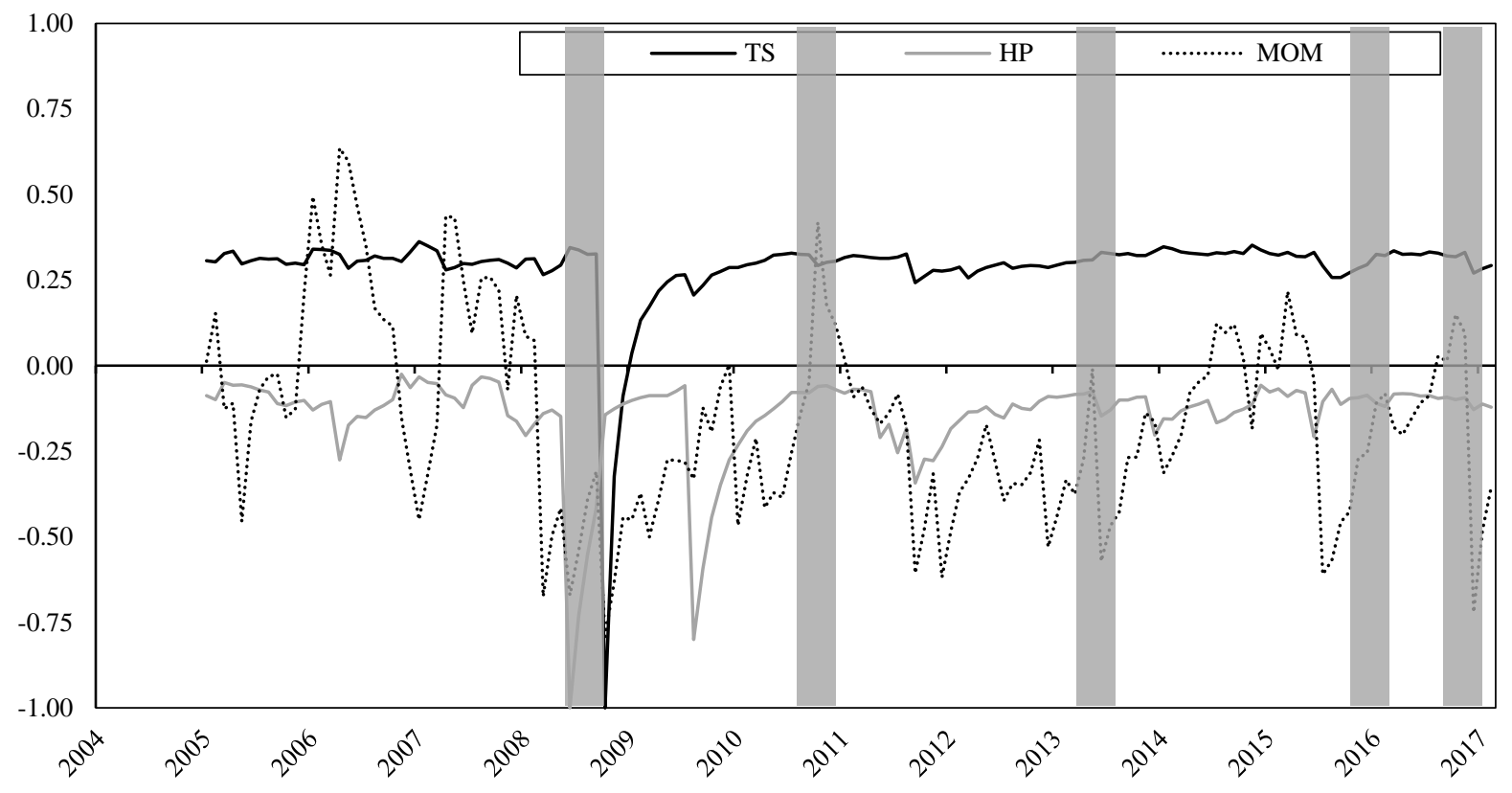

Figure 5 Time-varying correlation

This figure illustrates the dynamic correlations between long-short strategies returns and the CSI 300 . The correlations are estimated using the ADCC-GARCH $(1,1)$ model. TS, HP and MOM denote the term structure, hedging pressure and momentum strategies, respectively. The shaded areas represent periods of stock market stress. The sample period covers February 2004 through to May 2017. 


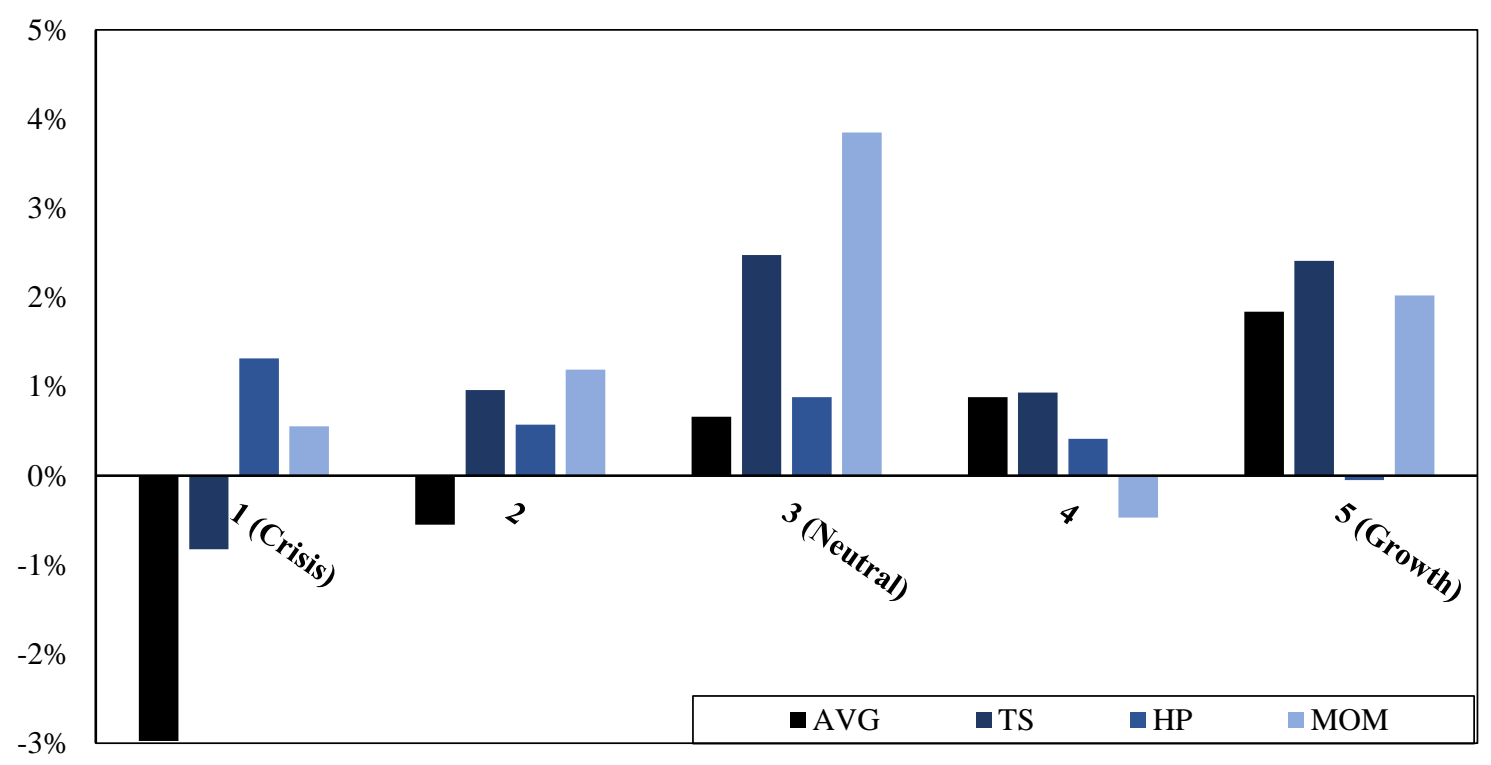

Figure 6 Extreme market conditions

This figure demonstrates the performance of long-only and long-short strategies under five different market conditions measured by the CSI300 index whose returns are sorted into quintiles (Q1-5). Crisis (Growth) represents periods when the CSI300 reported the lowest (highest) average monthly return. AVG denotes the equally weighted portfolio of 30 commodities. TS, HP and MOM denote the term structure, hedging pressure and momentum strategies, respectively. All commodity portfolios are evaluated based on the third nearest contracts. The sample period covers February 2004 through to May 2017.
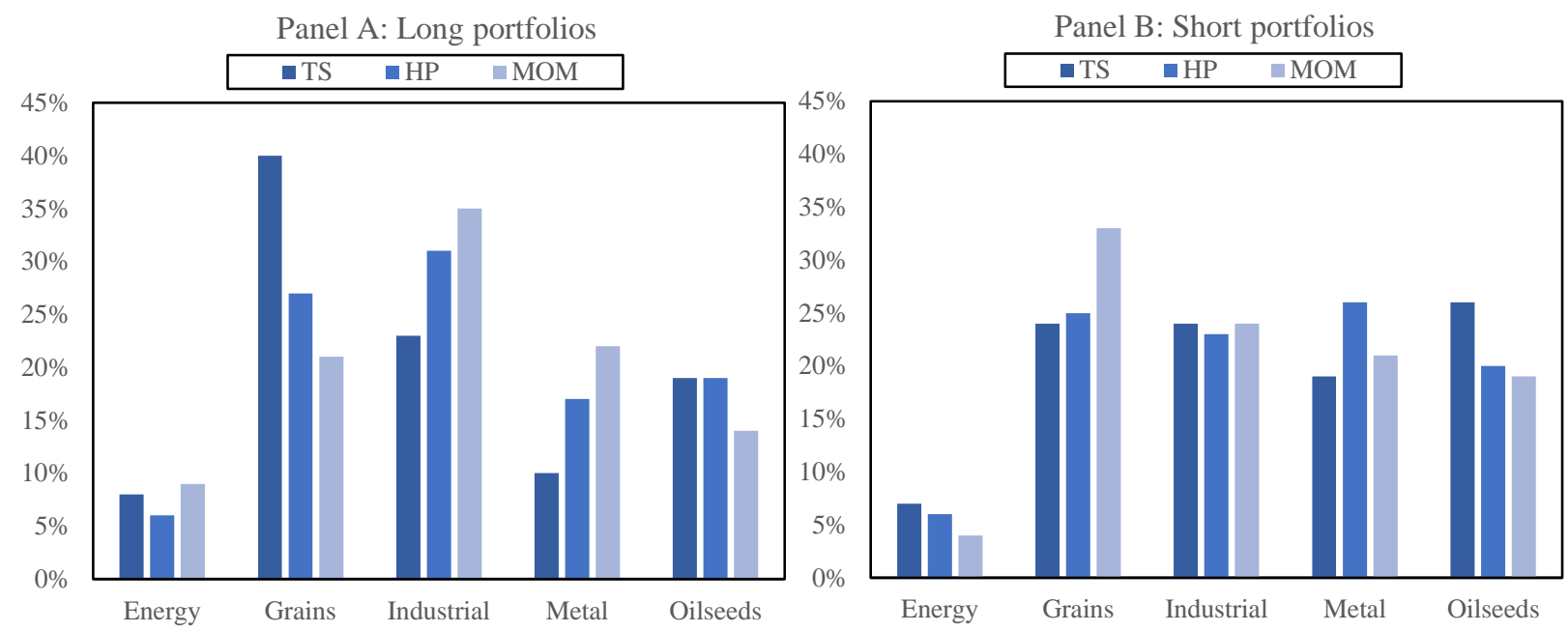

Figure 7 Percentage of total trades

This figure illustrates the percentage of total trades of long-short strategies. Panel A exhibits long portfolios whereas Panel B exhibits short portfolios. TS, HP and MOM denote the term structure, hedging pressure and momentum strategies, respectively. All strategies are evaluated based on the third nearest contracts. The sample period covers February 2004 through to May 2017. 


\title{
Internet Appendix
}

\section{The Untold Story of Commodity Futures in China}

\author{
John Hua Fan* and Tingxi Zhang
}

December 2019

Journal of Futures Markets, forthcoming

*Corresponding author. Address: Department of Accounting, Finance and Economics, Griffith Business School, Griffith University, Nathan Campus, 170 Kessels Road, Nathan, Queensland 4111, Australia. Tel: +61 (0)7 3735 3948; Fax: +61 (0)7 3735 7760; E-mail: j.fan@ griffith.edu.au. 


\section{Appendix I Matched sample of Chinese and US commodities}

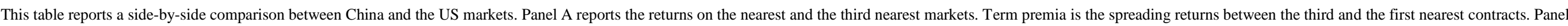

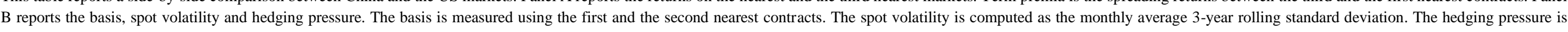

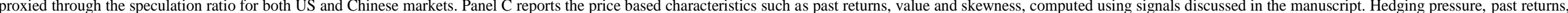

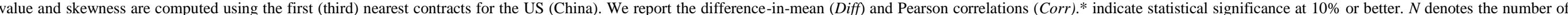
overlapping observations in both markets. For soybean and wheats, we use the same commodity in the other market to measure the difference and correlations.

\begin{tabular}{|c|c|c|c|c|c|c|c|c|c|c|c|c|c|c|c|c|}
\hline \multirow{2}{*}{\multicolumn{2}{|c|}{ Panel A: Risk premia }} & $\mathrm{CN}$ & US & Diff & Corr. & $N$ & $\mathrm{CN}$ & US & Diff & Corr. & $N$ & $\mathrm{CN}$ & US & Diff & Corr. & $N$ \\
\hline & & \multicolumn{5}{|c|}{ 1st Nearby $(\%)$} & \multicolumn{5}{|c|}{ 3rd Nearby $(\%)$} & \multicolumn{5}{|c|}{ Term premia (\%) } \\
\hline Corn & Corn & -0.38 & 0.05 & -0.43 & 0.11 & 151 & -0.03 & 0.32 & -0.35 & $0.35^{*}$ & 147 & 0.21 & $0.12 *$ & 0.09 & -0.11 & 147 \\
\hline No.1 Soybean & Soybean & -0.35 & 0.92 & $-1.27 *$ & $0.48^{*}$ & 159 & 0.30 & 0.79 & -0.48 & $0.67 *$ & 155 & $0.27 *$ & -0.15 & $0.42^{*}$ & -0.05 & 155 \\
\hline No. 2 Soybean & & 0.73 & & -0.35 & $0.43^{*}$ & 148 & 0.47 & & -0.48 & $0.62 *$ & 144 & -0.23 & & -0.08 & 0.08 & 144 \\
\hline Coal & Coal & 0.09 & -1.22 & 1.31 & 0.11 & 44 & -0.11 & -1.46 & 1.35 & 0.16 & 44 & -0.25 & -0.14 & -0.11 & -0.09 & 44 \\
\hline Strong Wheat & SRW Wheat & -0.80 & -0.69 & -0.11 & $0.18^{*}$ & 159 & -0.56 & -0.28 & -0.28 & $0.26^{*}$ & 155 & 0.10 & $0.19^{*}$ & -0.09 & -0.01 & 155 \\
\hline \multirow{2}{*}{ Common Wheat } & HRW Wheat & -1.35 & -0.19 & -1.16 & 0.10 & 159 & -0.47 & -0.03 & -0.43 & $0.19^{*}$ & 153 & $0.54 *$ & 0.05 & $0.49^{*}$ & -0.04 & 153 \\
\hline & HRS Wheat & & 0.63 & $-1.98 *$ & 0.09 & 159 & & 0.23 & -0.69 & $0.17^{*}$ & 153 & & $-0.29 *$ & $0.83^{*}$ & 0.02 & 153 \\
\hline Soybean Meal & Soybean meal & 0.99 & 1.53 & -0.53 & $0.63 *$ & 159 & 0.66 & 1.21 & -0.55 & $0.75^{*}$ & 154 & -0.21 & $-0.28 *$ & 0.07 & -0.04 & 154 \\
\hline Soybean Oil & Soybean oil & -0.09 & 0.07 & -0.16 & $0.71 *$ & 135 & 0.08 & 0.16 & -0.08 & $0.86^{*}$ & 131 & -0.05 & 0.00 & -0.04 & 0.06 & 131 \\
\hline Cotton & Cotton & -0.17 & 0.42 & -0.59 & $0.51 *$ & 154 & -0.20 & 0.33 & -0.52 & $0.64 *$ & 150 & -0.01 & -0.05 & 0.04 & $0.17 *$ & 150 \\
\hline Sugar & Sugar & -0.07 & -0.31 & 0.24 & $0.48^{*}$ & 135 & -0.35 & 0.24 & -0.58 & $0.48^{*}$ & 131 & -0.16 & $0.23^{*}$ & $-0.39^{*}$ & $-0.14 *$ & 131 \\
\hline Fuel Oil & Heating oil & -0.94 & -0.13 & -0.81 & $0.38 *$ & 142 & -0.06 & 0.19 & -0.25 & $0.45^{*}$ & 151 & 0.39 & $0.10^{*}$ & 0.30 & 0.09 & 140 \\
\hline Gold & Gold & 0.10 & 0.32 & -0.22 & $0.91^{*}$ & 109 & -0.23 & 0.24 & -0.47 & $0.60 *$ & 95 & -0.08 & 0.03 & -0.11 & -0.12 & 91 \\
\hline Copper & Copper & 0.86 & 1.05 & -0.19 & $0.89 *$ & 160 & 0.77 & 0.99 & -0.22 & $0.92 *$ & 158 & -0.02 & $-0.06^{*}$ & 0.04 & -0.07 & 158 \\
\hline \multirow[t]{2}{*}{ Silver } & Silver & -1.08 & -0.78 & -0.30 & $0.88 *$ & 59 & -0.88 & -0.54 & -0.34 & $0.70 *$ & 57 & 0.02 & 0.04 & -0.02 & -0.21 & 55 \\
\hline & Average & -0.18 & 0.12 & -0.44 & 0.46 & & -0.04 & 0.17 & -0.29 & 0.52 & & 0.04 & -0.02 & 0.10 & -0.03 & \\
\hline \multicolumn{2}{|c|}{ Panel B: Commodity characteristics } & \multicolumn{5}{|c|}{ Basis (\%) } & \multicolumn{5}{|c|}{ Spot Volatility (\%) } & \multicolumn{5}{|c|}{ Hedging Pressure (\%) } \\
\hline Corn & Corn & -0.93 & -1.94 & 1.01 & -0.01 & 150 & 0.62 & 1.93 & $-1.31^{*}$ & -0.09 & 116 & 7.2 & 9.5 & $-2.2^{*}$ & -0.11 & 147 \\
\hline No.1 Soybean & Soybean & -0.53 & 0.43 & $-0.95^{*}$ & $0.14 *$ & 157 & 0.87 & 1.57 & $-0.70 *$ & $0.82^{*}$ & 122 & 8.6 & 8.1 & 0.5 & 0.07 & 155 \\
\hline No.2 Soybean & & 0.73 & & 0.43 & $0.21 *$ & 147 & 1.20 & & $-0.38 *$ & $0.86^{*}$ & 113 & 12.0 & & $4.1 *$ & -0.08 & 136 \\
\hline Coal & Coal & -0.57 & -0.54 & -0.03 & -0.08 & 43 & 1.29 & 0.73 & $0.56^{*}$ & 0.11 & 8 & 6.5 & 2.5 & $4.0 *$ & -0.03 & 31 \\
\hline Strong Wheat & SRW Wheat & -2.06 & -2.77 & 0.72 & 0.09 & 157 & 0.69 & 2.12 & $-1.43^{*}$ & -0.11 & 122 & 10.7 & 10.4 & 0.3 & $-0.14 *$ & 152 \\
\hline \multirow{2}{*}{ Common Wheat } & HRW Wheat & -2.79 & -1.61 & $-1.19 *$ & 0.04 & 157 & \multirow[t]{2}{*}{0.84} & 1.92 & $-1.08 *$ & 0.01 & 122 & \multirow[t]{2}{*}{13.5} & 15.0 & -1.5 & -0.03 & 131 \\
\hline & HRS Wheat & & -0.08 & $-2.72 *$ & -0.01 & 157 & & 1.80 & $-0.96 *$ & $0.17 *$ & 122 & & 16.0 & -2.5 & 0.07 & 131 \\
\hline Soybean Meal & Soybean meal & 1.38 & 1.24 & 0.14 & 0.13 & 157 & 1.15 & 1.79 & $-0.64 *$ & $0.87^{*}$ & 122 & 9.0 & 9.8 & -0.8 & 0.02 & 154 \\
\hline Soybean Oil & Soybean oil & -0.19 & -0.74 & 0.55 & $-0.32 *$ & 134 & 1.26 & 1.50 & $-0.24 *$ & $0.97 *$ & 100 & 10.9 & 10.9 & 0.0 & -0.08 & 130 \\
\hline Cotton & Cotton & -0.20 & -0.90 & 0.69 & $0.25 *$ & 153 & 0.82 & 1.79 & $-0.97 *$ & $0.72 *$ & 120 & 7.7 & 21.3 & $-13.7 *$ & $0.14 *$ & 150 \\
\hline Sugar & Sugar & -0.37 & -1.04 & 0.67 & $0.23 *$ & 134 & 0.98 & 2.05 & $-1.07 *$ & $0.84 *$ & 100 & 4.2 & 6.7 & $-2.5^{*}$ & 0.14 & 130 \\
\hline Fuel Oil & Heating oil & -1.24 & -0.63 & -0.61 & 0.07 & 142 & 1.60 & 1.90 & $-0.30 *$ & $0.40 *$ & 118 & 8.9 & 7.5 & 1.4 & $-0.16^{*}$ & 142 \\
\hline Gold & Gold & -0.02 & -0.07 & 0.05 & -0.04 & 109 & 1.16 & 1.17 & -0.01 & $0.86 *$ & 77 & 7.7 & 9.4 & -1.6 & -0.08 & 95 \\
\hline Copper & Copper & 0.48 & 0.20 & $0.28^{*}$ & $0.25 *$ & 159 & 1.42 & 1.88 & $-0.46^{*}$ & $0.98^{*}$ & 123 & 5.4 & 11.9 & $-6.6^{*}$ & $0.15^{*}$ & 158 \\
\hline \multirow[t]{2}{*}{ Silver } & Silver & -0.40 & -0.10 & $-0.29 *$ & $-0.29 *$ & 58 & 1.26 & 1.72 & $-0.46 *$ & $0.86 *$ & 25 & 8.0 & 8.1 & -0.1 & 0.16 & 57 \\
\hline & Average & \multirow{2}{*}{\multicolumn{5}{|c|}{$\begin{array}{cc}-0.61 & -0.08 \\
\text { Past returns }(\%)\end{array}$}} & 1.08 & 1.70 & -0.63 & 0.55 & & 8.6 & 10.5 & -1.4 & 0.00 & \\
\hline Panel C: Price-b & racteristics & & & & & & & & lue $(\%)$ & & & & & wness & & \\
\hline Corn & Corn & $\begin{array}{l}-1.11 \\
\end{array}$ & 0.87 & -1.99 & $0.46^{*}$ & 136 & -15.8 & -4.9 & -10.9 & $0.84 *$ & 94 & 0.029 & 0.082 & -0.05 & $0.26^{*}$ & 136 \\
\hline No.1 Soybean & Soybean & 3.28 & 11.95 & $-8.66^{*}$ & $0.79 *$ & 143 & -13.2 & -15.7 & 2.5 & $0.87 *$ & 102 & -0.085 & -0.080 & -0.01 & $0.39 *$ & 143 \\
\hline No. 2 Soybean & & 4.16 & & $-9.39 *$ & $0.79 *$ & 133 & -3.7 & & $7.3 *$ & $0.89^{*}$ & 91 & -0.251 & & $-0.18^{*}$ & $0.19 *$ & 133 \\
\hline Coal & Coal & -15.71 & -15.24 & -0.46 & -0.18 & 33 & & & & & & -0.119 & -1.609 & 1.49 & -0.09 & 32 \\
\hline Strong Wheat & SRW Wheat & -6.51 & -6.72 & 0.21 & $0.33^{*}$ & 143 & -18.9 & -2.5 & $-16.4 *$ & $0.41 *$ & 102 & -0.209 & 0.182 & $-0.39 *$ & $-0.18 *$ & 143 \\
\hline Common Wheat & HRW Wheat & -5.06 & 0.31 & -5.37 & 0.10 & 143 & -20.0 & -1.6 & $-18.4 *$ & $0.49 *$ & 102 & -0.341 & 0.179 & $-0.52 *$ & $-0.19 *$ & 143 \\
\hline & HRS Wheat & & 11.19 & $-16.24 *$ & $0.16^{*}$ & 143 & & -2.5 & $-17.5^{*}$ & $0.45^{*}$ & 102 & & 0.394 & $-0.74 *$ & 0.09 & 143 \\
\hline Soybean Meal & Soybean meal & 7.78 & 20.26 & $-12.47 *$ & $0.79 *$ & 143 & -6.8 & -21.8 & $15.0^{*}$ & $0.89 *$ & 102 & -0.024 & 0.088 & $-0.11 *$ & $0.45^{*}$ & 143 \\
\hline Soybean Oil & Soybean oil & -0.57 & 1.08 & -1.65 & $0.93^{*}$ & 120 & 12.1 & 8.5 & 3.6 & $0.95^{*}$ & 78 & -0.239 & 0.159 & $-0.40 *$ & $0.27 *$ & 120 \\
\hline Cotton & Cotton & -3.41 & 6.39 & $-9.80^{*}$ & $0.86^{*}$ & 139 & -1.7 & -8.5 & 6.8 & $0.88^{*}$ & 98 & -0.165 & -0.075 & -0.09 & $0.19^{*}$ & 140 \\
\hline Sugar & Sugar & -1.83 & -0.64 & -1.19 & $0.66^{*}$ & 120 & -17.6 & -7.6 & -10.0 & $0.92 *$ & 78 & 0.016 & 0.003 & 0.01 & $0.71 *$ & 120 \\
\hline Fuel Oil & Heating oil & -3.89 & -1.22 & -2.67 & $0.74 *$ & 140 & 2.9 & 5.5 & -2.6 & $0.81 *$ & 98 & -0.227 & 0.080 & $-0.31^{*}$ & -0.06 & 140 \\
\hline Gold & Gold & -0.74 & 5.26 & $-6.00^{*}$ & $0.94 *$ & 99 & 2.0 & 3.1 & -1.1 & $0.99 *$ & 56 & -0.216 & -0.248 & 0.03 & $0.83^{*}$ & 99 \\
\hline Copper & Copper & 7.41 & 15.60 & $-8.20 *$ & $0.93 *$ & 146 & 5.1 & 1.0 & 4.1 & $0.88 *$ & 105 & -0.267 & -0.048 & $-0.22 *$ & $0.33^{*}$ & 146 \\
\hline Silver & Silver & -13.93 & -11.02 & -2.91 & $0.93^{*}$ & 47 & 34.7 & 28.2 & 6.4 & $0.94 *$ & 5 & -0.101 & -0.155 & 0.05 & $0.76^{*}$ & 47 \\
\hline & Average & -2.15 & 2.72 & -5.79 & 0.61 & & -3.14 & -1.43 & -2.22 & 0.79 & & -0.157 & -0.075 & -0.095 & 0.26 & \\
\hline
\end{tabular}




\section{Appendix II Delivery warehouses}

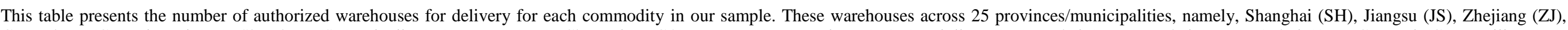

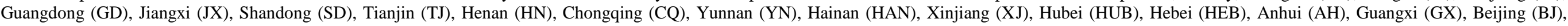
Liaoning (LN), Shaanxi (SAX), Fujian (FJ), Sichuan (SC), Neimeng (NM), Shanxi (SX), Jilin (JL) and Heilongjiang (HLJ). * indicates municipalities.

\begin{tabular}{|c|c|c|c|c|c|c|c|c|c|c|c|c|c|c|c|c|c|c|c|c|c|c|c|c|c|c|c|c|}
\hline Exchange & Sector & Commodity & $\mathrm{SH}^{*}$ & JS & $\mathrm{ZJ}$ & GD & JX & SD & $\mathrm{TJ}^{*}$ & $\mathrm{HN}$ & CQ & YN & HAN & $\mathrm{XJ}$ & HUB & HEB & $\mathrm{AH}$ & GX & $\mathrm{BJ}^{*}$ & $\mathrm{LN}$ & SAX & FJ & $\mathrm{SC}$ & $\mathrm{NM}$ & SX & $\mathrm{JL}$ & HLJ & Total \\
\hline DCE & Grains & No.1 Soybean & & & & & & & & & & & & & & & & & & 6 & & & & 1 & & 1 & 7 & 15 \\
\hline DCE & Grains & No.2 Soybean & & 1 & & & & 3 & & & & & & & & & & & & 3 & & & & & & & & 7 \\
\hline DCE & Grains & Corn & & & & & & & & & & & & & & & & & & 9 & & & & 1 & & 6 & 3 & 19 \\
\hline DCE & Industrial & LLDPE & 6 & 2 & 5 & 5 & & 3 & 4 & & 1 & & & & & & & & & & & & & & & & & 26 \\
\hline DCE & Industrial & PVC & 6 & 3 & 4 & 4 & & & & & & & & & & & & & & & & & & & & & & 17 \\
\hline DCE & Industrial & Metallurgical Coke & & 2 & & & & 4 & 3 & & & & & & & 7 & & & & & & & & & 5 & & & 21 \\
\hline DCE & Industrial & Coking Coal & & 1 & & & & 2 & 2 & & & & & & & 3 & & & & & & & & & 2 & & & 10 \\
\hline DCE & Oil Seeds & Soybean Meal & & 11 & & 9 & & 3 & 4 & & & & & & & & & & & & & & & & & & & 27 \\
\hline DCE & Oil Seeds & RBD Palm Olein & & 9 & & 5 & & & 5 & & & & & & & & & & & & & & & & & & & 19 \\
\hline DCE & Oil Seeds & Soybean Oil & & 9 & 1 & & & 5 & 5 & & & & & & & 2 & & & & & & & & & & & & 22 \\
\hline SHFE & Energy & Fuel Oil & 1 & & 2 & 5 & & & & & & & & & & & & & & & & & & & & & & 8 \\
\hline SHFE & Industrial & Natural Rubber & 9 & & & & & 8 & 2 & & & 1 & 2 & & & & & & & & & & & & & & & 22 \\
\hline SHFE & Metal & Aluminum & 13 & 8 & 5 & 5 & & 3 & 3 & 6 & 2 & & & & & & & & & & & & & & & & & 45 \\
\hline SHFE & Metal & Gold & & & & & & & & & & & & & & & & & & & & & & & & & & 39 \\
\hline SHFE & Metal & Copper & 13 & 5 & 2 & 2 & 1 & & & & & & & & & & & & & & & & & & & & & 23 \\
\hline SHFE & Metal & Lead & 6 & 2 & 3 & 3 & & & 3 & & & & & & & & & & & & & & & & & & & 17 \\
\hline SHFE & Metal & Steel Rebar & 2 & 4 & 3 & 1 & & & 1 & & & & & & & & & & & & & & & & & & & 11 \\
\hline SHFE & Metal & Steel Wire Rod & & 3 & 2 & & & & 2 & & & & & & & & & & & & & & & & & & & 7 \\
\hline SHFE & Metal & Zinc & 10 & 4 & 4 & 4 & & & & & & & & & & & & & & & & & & & & & & 22 \\
\hline SHFE & Metal & Silver & 2 & & & & & & & & & & & & & & & & & & & & & & & & & 2 \\
\hline ZCE & Energy & Methanol & & 13 & & 3 & & 2 & & 1 & & & & & & 2 & & & & & & 1 & & 2 & & & & 24 \\
\hline ZCE & Grains & White Sugar & & 3 & 1 & 2 & & 4 & 2 & 1 & & 3 & & & 1 & 4 & & 8 & 2 & 2 & 2 & & & & & & & 35 \\
\hline ZCE & Grains & Strong Gluten Wheat & & 2 & & & & 2 & & 5 & & & & & & 4 & & & & & 1 & & & & & & & 14 \\
\hline ZCE & Grains & Common Wheat & & 2 & & & & 2 & & 5 & & & & & & 3 & 1 & & & & 1 & & & & & & & 14 \\
\hline ZCE & Industrial & Cotton No.1 & & 5 & 1 & & & 4 & & 4 & & & & 3 & 2 & 1 & 1 & & & & & & & & & & & 21 \\
\hline ZCE & Industrial & PTA & & 10 & 10 & & & & & & & & & & & & & & & 2 & & 1 & & & & & & 23 \\
\hline ZCE & Industrial & Flat Glass & & & 1 & & & 4 & & & & & & & 3 & 8 & & & & & & & & & 1 & & & 17 \\
\hline ZCE & Oil Seeds & Rapeseed Oil & & 5 & & 2 & & & & & 1 & & & & 2 & & 2 & 3 & & & 1 & 3 & 3 & & & & & 22 \\
\hline $\mathrm{ZCE}$ & Oil Seeds & Rapeseed Meal & & 2 & & 2 & & & & & & & & & 3 & & 2 & 3 & & & & 3 & 1 & & & & & 16 \\
\hline ZCE & Oil Seeds & Rapeseed & & 2 & & & & & & & & & & & 3 & & 2 & & & & & & 1 & & & & & 8 \\
\hline
\end{tabular}




\section{Appendix III Alternative returns measurements}

Following Szymanowska et al. (2014), we measure holding, short roll, spreading and excess holding.

Holding represents holding a contract $i$ at time $t$ until its maturity. For an $m^{\text {th }}(\mathrm{m}=1,2,3,4)$ exposure, holding means to hold the $m^{\text {th }}$ contract until maturity, then roll over to the next $m^{\text {th }}$ contract. We define the holding return as

$$
r_{t \rightarrow t+n}^{(n)}=\ln P_{t+n}-\ln P_{t}
$$

Where $r_{t \rightarrow t+n}^{(n)}$ represents the return of buying a futures contract maturing in $n$ periods at time $t$ and holding it until time $t+n$ (maturity). $P_{t+n}$ and $P_{t}$ denote the prices at which the contract is sold at time $t+n$ and bought at time $t$.

Short Roll represents buying a contract maturing in the next period for $n$ consecutive periods. Therefore, short roll return for $n$ periods can be written as

$$
\text { Short roll }=\sum_{j=1}^{n} r_{t+j}^{(1)}
$$

An $n$-period short roll return can be interpreted as the sum of the return of investing a one-period contract during this $n$-period time. The concept of "one-period contract" in Szymanowska et al. (2014) does not necessarily refer to a contract maturing in the next month but corresponds to the $m^{\text {th }}$ series exposure in this paper. $r_{t+j}^{(1)}$ stands for the return of a futures contract that is the nearest to maturity along the curve at time $t+j$. Similarly, $r_{t+j}^{(m)}$ represents the return of an $m^{t h}$ contract at time $t+j$. It is important to clarify the difference between the rolling procedure behind holding and short roll (the technique applied in the main body of the paper). The holding roll is to maintain a position regardless the contract's status on the curve, while our rolling (or short roll) constantly ensures the contract property of being the $m^{\text {th }}$ nearest contract is valid. Therefore, holding strategy implemented on the nearest contract is the same as the short roll strategy applied to front contract, which implies there are no term premia in the nearby contract.

Spreading Return is a proxy for term premia. Since no term premia exist in the front contract, we will take the third nearby contract as an example. First, spreading return is based on the short roll. As defined by Szymanowska et al. (2014), spreading is a combination of taking long position(s) on distant contract(s) and short position(s) on nearby contract(s). To isolate the term premia from an investment on the third nearest contracts, we long the third nearest and short the second nearest contract. This implicitly suggests a time-varying risk embedded in the term premia, since the term structure may not be perfectly linear. Ultimately, spreading return for $m^{\text {th }}$ exposure can be expressed as

$$
\text { Spreading }=\frac{1}{m} \sum_{m=1}^{n} \sum_{j=1}^{n}\left(r_{t+j}^{m}-r_{t+j}^{1}\right)
$$

Where $\frac{1}{m}$ scales the term premia earned at different points of futures curve to per unit of maturity.

Excess holding is an alternative measurement for term premia. It is the difference between $m^{\text {th }}$ holding and $m^{\text {th }}$ short roll. Recall that holding strategy does not involve rolling before the maturity, $m^{\text {th }}$ holding will evolve from $m^{\text {th }}$ short roll to the $1^{\text {st }}$ short roll as maturity approaches from a short-roll perspective. As a result, excess holding is earning the term premia from $m^{\text {th }},(m-1)^{\text {th }}$ to $2^{\text {nd }}$ consecutively, until it becomes the nearby contract. In contrast, the spreading return earns $\frac{1}{m}$ of each of the $m^{\text {th }}$ term premia at each point in time. Excess holding can be written as

$$
\text { Excess holding }=r_{t \rightarrow t+n}^{(n)}-\sum_{j=1}^{n} r_{t+j}^{(1)}
$$




\section{Appendix IV Decomposing risk premia}

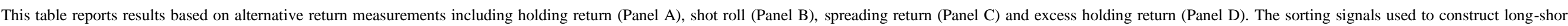

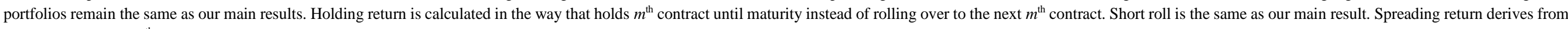

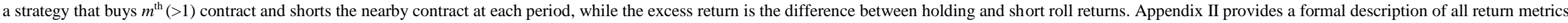

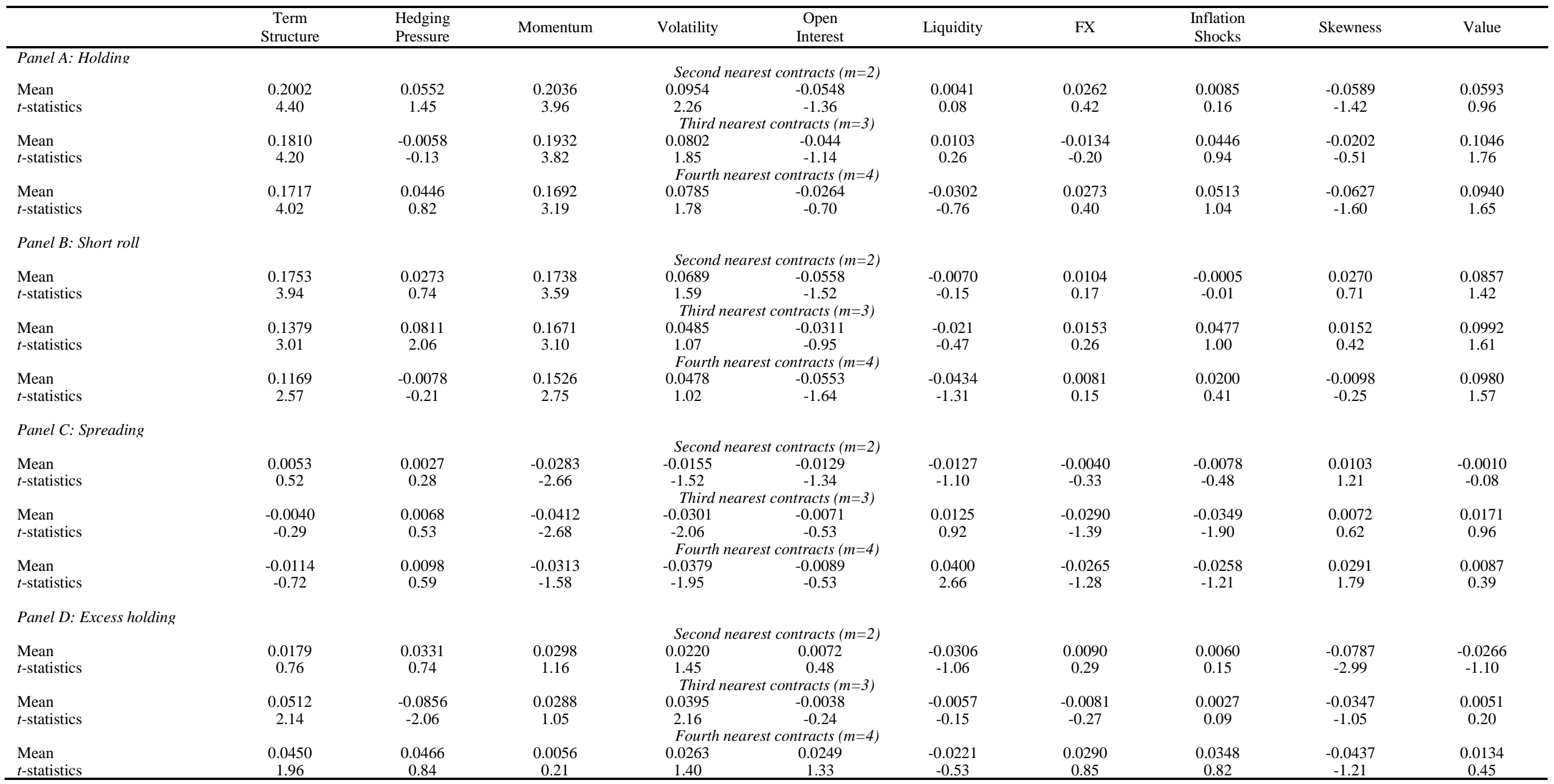




\section{Appendix V Market liquidity}

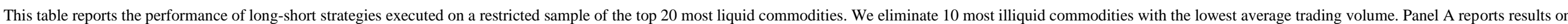

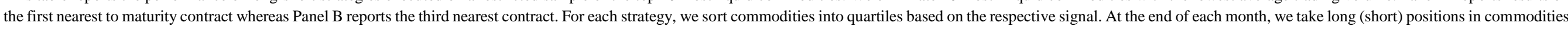

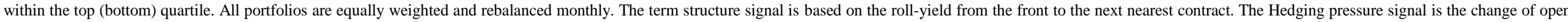

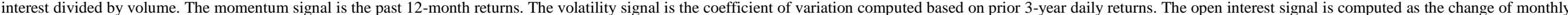

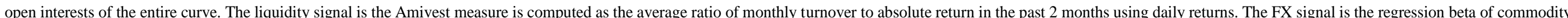

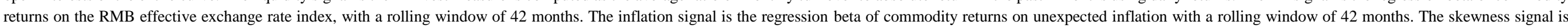

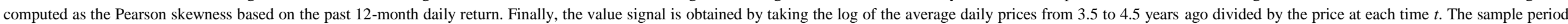
covers February 2004 through to May 2017.

\begin{tabular}{|c|c|c|c|c|c|c|c|c|c|c|}
\hline & $\begin{array}{r}\text { Term } \\
\text { Structure }\end{array}$ & $\begin{array}{l}\text { Hedging } \\
\text { Pressure }\end{array}$ & Momentum & Volatility & $\begin{array}{r}\text { Open } \\
\text { Interest }\end{array}$ & Liquidity & FX & $\begin{array}{r}\text { Inflation } \\
\text { Shocks }\end{array}$ & Skewness & Value \\
\hline \multicolumn{10}{|c|}{ Panel A: First nearest contract $(m=1)$} & 0.0165 \\
\hline$t$-statistics & 3.71 & 0.22 & 3.46 & 1.56 & -0.72 & 0.39 & -1.02 & -0.60 & -1.77 & 0.24 \\
\hline Annualized geometric mean & 0.1726 & -0.0028 & 0.1958 & 0.0599 & -0.0485 & 0.0029 & -0.0961 & -0.0554 & -0.1085 & -0.0033 \\
\hline Annualized volatility & 0.1857 & 0.1602 & 0.2223 & 0.1454 & 0.1699 & 0.1901 & 0.2173 & 0.1931 & 0.1822 & 0.2053 \\
\hline Annualized downside volatility & 0.1086 & 0.0889 & 0.1227 & 0.0961 & 0.1219 & 0.1190 & 0.1918 & 0.1350 & 0.1269 & 0.1083 \\
\hline Sharpe Ratio & 1.0204 & 0.0612 & 0.9864 & 0.4838 & -0.1988 & 0.1083 & -0.3259 & -0.1911 & -0.5032 & 0.0806 \\
\hline Sortino Ratio & 1.9041 & 0.1108 & 1.9791 & 0.7561 & -0.2728 & 0.1745 & -0.3575 & -0.2686 & -0.6925 & 0.1539 \\
\hline Skewness & 0.1675 & 0.3559 & 0.9417 & -0.0134 & -0.5772 & 0.5855 & -1.2530 & 0.2866 & -0.2111 & 1.5780 \\
\hline Max monthly gain & 0.1982 & 0.1563 & 0.3756 & 0.1361 & 0.1152 & 0.2259 & 0.1692 & 0.2466 & 0.1236 & 0.3216 \\
\hline Max monthly loss & -0.1734 & -0.0951 & -0.1840 & -0.1053 & -0.1813 & -0.1650 & -0.3128 & -0.2264 & -0.1966 & -0.1360 \\
\hline 99\% VaR(Cornish-Fisher) & 0.203 & 0.1592 & 0.3441 & 0.1410 & 0.1355 & 0.2310 & 0.2123 & 0.2451 & 0.1483 & 0.3270 \\
\hline$\%$ of positive months & 0.6352 & 0.4528 & 0.6351 & 0.5968 & 0.5127 & 0.4747 & 0.4831 & 0.4576 & 0.4324 & 0.4717 \\
\hline Maximum Drawdown & -0.2917 & -0.4981 & -0.3399 & -0.2035 & -0.5346 & -0.5363 & -0.6604 & -0.4667 & -0.8342 & -0.4044 \\
\hline Drawdown Length (months) & 4 & 82 & 12 & 4 & 89 & 95 & 16 & 23 & 117 & 44 \\
\hline Max Run-up (consecutive) & 0.5410 & 0.1020 & 0.5717 & 0.3430 & 0 & 0.4068 & 0 & 0.2306 & 0.3750 & 0.3216 \\
\hline Run-up Length (months) & 9 & 1 & 3 & 5 & 0 & 3 & 0 & 2 & 7 & 1 \\
\hline Max $12 \mathrm{M}$ rolling return & 0.6805 & 0.3859 & 0.9828 & 0.5451 & 0.2640 & 0.4851 & 0.6626 & 0.3541 & 0.6002 & 0.4008 \\
\hline Min $12 \mathrm{M}$ rolling return & -0.2569 & -0.3847 & -0.3988 & -0.1772 & -0.3230 & -0.3826 & -0.7574 & -0.3512 & -0.5736 & -0.3508 \\
\hline \multicolumn{11}{|c|}{ Panel B: Third nearest contract $(m=3)$} \\
\hline Annualized geometric mean & 0.098 & 0.0046 & 0.1903 & 0.0496 & -0.0143 & -0.0276 & -0.0814 & 0.0511 & -0.0337 & 0.0274 \\
\hline Annualized volatility & 0.1955 & 0.1742 & 0.2205 & 0.1417 & 0.1671 & 0.1739 & 0.1896 & 0.1891 & 0.1691 & 0.1946 \\
\hline Annualized downside volatility & 0.1326 & 0.1114 & 0.1318 & 0.0896 & 0.1308 & 0.1166 & 0.1728 & 0.1205 & 0.0911 & 0.1144 \\
\hline Sharpe Ratio & 0.5989 & 0.1117 & 0.9691 & 0.4206 & 0.0018 & -0.0721 & -0.3276 & 0.3629 & -0.1156 & 0.2334 \\
\hline Sortino Ratio & 0.9319 & 0.1763 & 1.7902 & 0.6837 & 0.0022 & -0.1070 & -0.3494 & 0.5876 & -0.2125 & 0.4054 \\
\hline Skewness & -0.2542 & 0.6379 & 0.5856 & -0.0629 & -1.1542 & 0.2026 & -1.6807 & 0.3151 & 0.1314 & 1.3984 \\
\hline Kurtosis & 5.3689 & 8.1748 & 6.9385 & 3.6362 & 11.1395 & 4.7034 & 8.4204 & 6.1396 & 2.8691 & 11.2215 \\
\hline Max monthly gain & 0.2008 & 0.2676 & 0.3409 & 0.1200 & 0.1656 & 0.1989 & 0.0993 & 0.2129 & 0.1622 & 0.3149 \\
\hline Max monthly loss & -0.2362 & -0.1835 & -0.1632 & -0.1039 & -0.2925 & -0.1322 & -0.2678 & -0.1957 & -0.1106 & -0.1629 \\
\hline $99 \%$ VaR(Cornish-Fisher) & 0.1979 & 0.2413 & 0.3008 & 0.1322 & 0.2026 & 0.1810 & 0.1898 & 0.2274 & 0.1512 & 0.3245 \\
\hline$\%$ of positive months & 0.5796 & 0.5478 & 0.6301 & 0.5984 & 0.4872 & 0.4872 & 0.4741 & 0.5086 & 0.5274 & 0.5385 \\
\hline Maximum Drawdown & -0.3455 & -0.5003 & -0.3480 & -0.2340 & -0.5079 & -0.6080 & -0.5535 & -0.3788 & -0.6835 & -0.3495 \\
\hline Drawdown Length (months) & 18 & 19 & 13 & 7 & 59 & 101 & 16 & 56 & 81 & 22 \\
\hline Max Run-up (consecutive) & 0.3705 & 0.2040 & 1.0239 & 0.2596 & 0.1830 & 0.1337 & 0 & 0.3498 & 0.2469 & 0.0549 \\
\hline Runup Length (months) & 2 & 2 & 11 & 3 & 3 & 1 & 0 & 3 & 3 & 1 \\
\hline Max $12 \mathrm{M}$ rolling return & 0.7017 & 0.5357 & 1.0862 & 0.3903 & 0.3537 & 0.2946 & 0.2598 & 0.6594 & 0.4692 & 0.3605 \\
\hline Min $12 \mathrm{M}$ rolling return & -0.3323 & -0.5182 & -0.3937 & -0.2414 & -0.3964 & -0.5407 & -0.4657 & -0.2279 & -0.3155 & -0.2956 \\
\hline
\end{tabular}




\section{Appendix VI Commodity sectors}

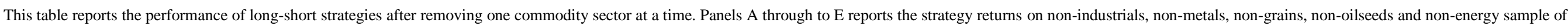

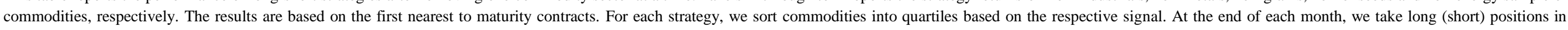

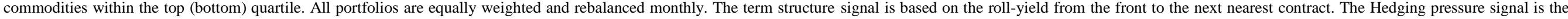

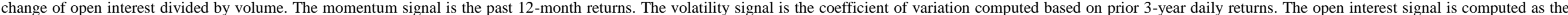

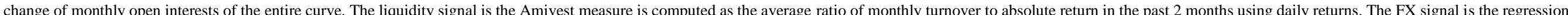

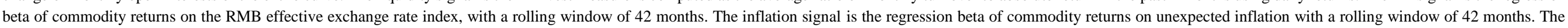

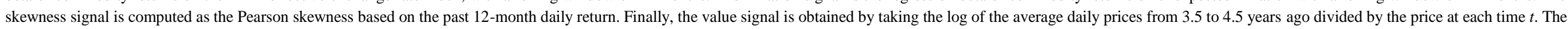
sample period covers February 2004 through to May 2017.

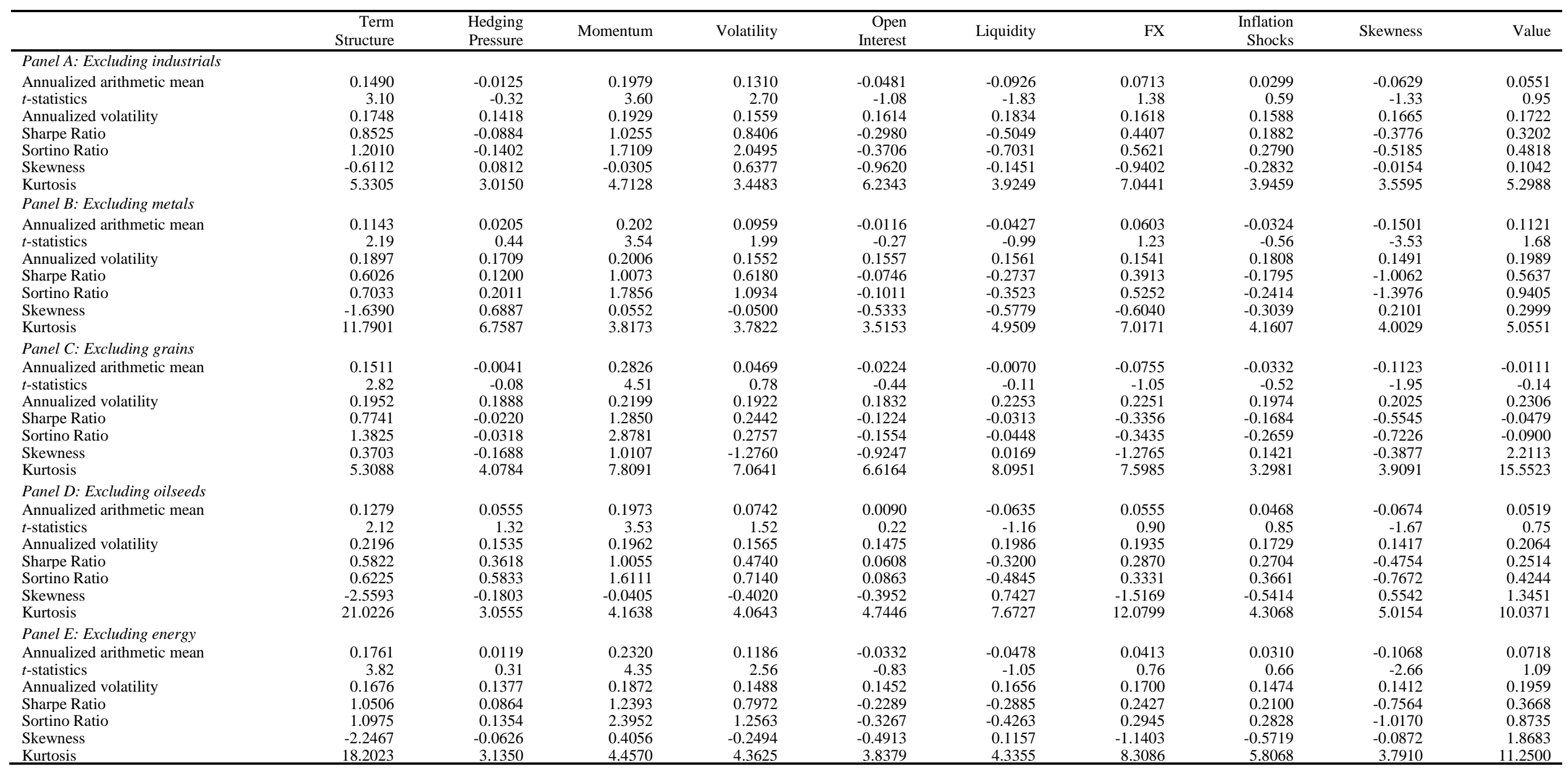




\section{Appendix VII Data-snooping test}

This table reports the Reality Check (White, 2000) and SPA (Hansen, 2005) test. The parameter $q$ is the geometric distribution that determines the block-length in the bootstrap process, where the block-length is computed as 1/q. For each test, the bootstrap is replicated 10,000 times. The stationary and circular bootstraps are based on Politis and Romano (1994) and Politis and Romano (1992) respectively. Only the statistically significant strategies are tested. Panel A reports all strategies as a group against a zero-mean return benchmark. Panel B reports all strategies against the passive long-only benchmark (AVG), an equally weighted portfolio of 30 commodities in the sample. Panels $\mathrm{C}$ through to E report each strategy against the AVG. Significant $p$-values indicate that the strategy outperforms the benchmark.

\begin{tabular}{|c|c|c|c|}
\hline $\begin{array}{l}\text { Bootstrap } \\
\text { dependence }\end{array}$ & $\begin{array}{l}\text { Bootstrap } \\
\text { method }\end{array}$ & $\begin{array}{l}\text { Reality check } \\
\text { Consistent } p \text {-values }\end{array}$ & $\begin{array}{l}\text { SPA test } \\
\text { Consistent } p \text {-values }\end{array}$ \\
\hline \multicolumn{4}{|c|}{ Panel A: All strategies versus zero-mean-return benchmark } \\
\hline \multirow[t]{2}{*}{$q=0.05$} & Stationary & 0.0010 & 0.0020 \\
\hline & Circular & 0.0000 & 0.0000 \\
\hline \multirow{2}{*}{$q=0.1$} & Stationary & 0.0020 & 0.0050 \\
\hline & Circular & 0.0000 & 0.0020 \\
\hline \multirow[t]{2}{*}{$q=0.5$} & Stationary & 0.0020 & 0.0020 \\
\hline & Circular & 0.0000 & 0.0000 \\
\hline \multicolumn{4}{|c|}{ Panel B: All strategies versus AVG } \\
\hline \multirow[t]{2}{*}{$q=0.05$} & Stationary & 0.0010 & 0.0010 \\
\hline & Circular & 0.0020 & 0.0000 \\
\hline \multirow[t]{2}{*}{$q=0.1$} & Stationary & 0.0050 & 0.0000 \\
\hline & Circular & 0.0030 & 0.0010 \\
\hline \multirow[t]{2}{*}{$q=0.5$} & Stationary & 0.0020 & 0.0010 \\
\hline & Circular & 0.0050 & 0.0040 \\
\hline \multicolumn{4}{|c|}{ Panel C: Term structure strategy versus $A V G$} \\
\hline \multirow[t]{2}{*}{$q=0.05$} & Stationary & 0.0000 & 0.0000 \\
\hline & Circular & 0.0000 & 0.0000 \\
\hline \multirow[t]{2}{*}{$q=0.1$} & Stationary & 0.0000 & 0.0000 \\
\hline & Circular & 0.0000 & 0.0000 \\
\hline \multirow[t]{2}{*}{$q=0.5$} & Stationary & 0.0000 & 0.0000 \\
\hline & Circular & 0.0000 & 0.0000 \\
\hline \multicolumn{4}{|c|}{ Panel D: Momentum strategy versus $A V G$} \\
\hline \multirow[t]{2}{*}{$q=0.05$} & Stationary & 0.0000 & 0.0000 \\
\hline & Circular & 0.0000 & 0.0000 \\
\hline \multirow[t]{2}{*}{$q=0.1$} & Stationary & 0.0000 & 0.0000 \\
\hline & Circular & 0.0000 & 0.0000 \\
\hline \multirow[t]{2}{*}{$q=0.5$} & Stationary & 0.0000 & 0.0000 \\
\hline & Circular & 0.0000 & 0.0000 \\
\hline \multicolumn{4}{|c|}{ Panel E: Volatility strategy versus AVG } \\
\hline \multirow[t]{2}{*}{$q=0.05$} & Stationary & 0.0000 & 0.0000 \\
\hline & Circular & 0.0000 & 0.0000 \\
\hline \multirow{2}{*}{$q=0.1$} & Stationary & 0.0000 & 0.0000 \\
\hline & Circular & 0.0010 & 0.0010 \\
\hline \multirow[t]{2}{*}{$q=0.5$} & Stationary & 0.0020 & 0.0000 \\
\hline & Circular & 0.0010 & 0.0020 \\
\hline
\end{tabular}

